\title{
IUCN
}

\section{The marine plastic footprint}

Towards a science-based metric for measuring marine plastic leakage and increasing the materiality and circularity of plastic

Julien Boucher, Guillaume Billard, Eleonora Simeone and Joao Sousa
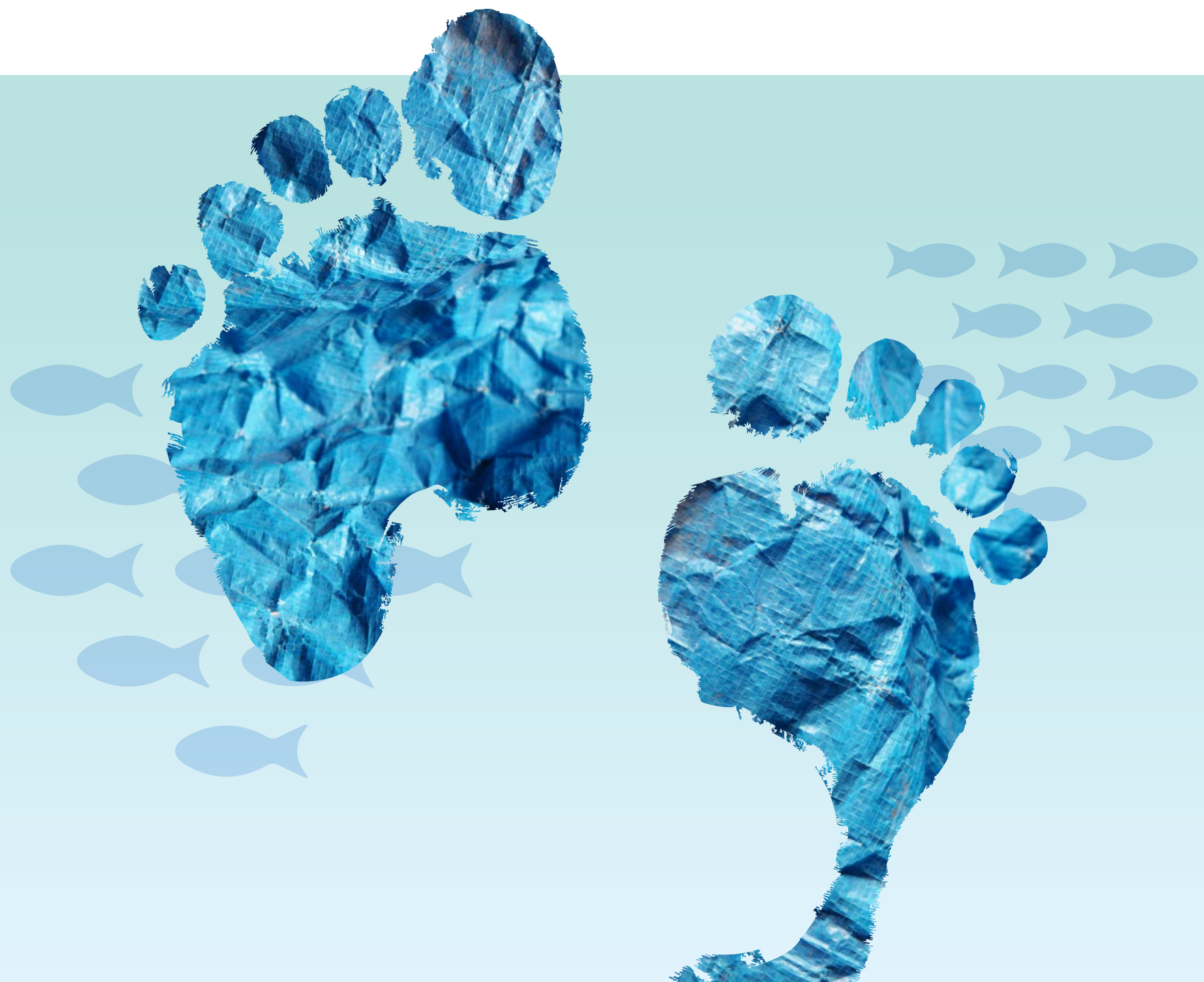



\section{The marine plastic footprint}

Towards a science-based metric for measuring marine plastic leakage and increasing the materiality and circularity of plastic

Julien Boucher, Guillaume Billard,

Eleonora Simeone and Joao Sousa 
The designation of geographical entities in this book, and the presentation of the material, do not imply the expression of any opinion whatsoever on the part of IUCN or other participating organisations concerning the legal status of any country, territory, or area, or of its authorities, or concerning the delimitation of its frontiers or boundaries.

The views expressed in this publication do not necessarily reflect those of IUCN or other participating organisations.

This publication has been made possible in part by funding from the Swedish Postcode Foundation.

Published by:

Copyright:

Citation:

ISBN:

DOl:

Authors

Editor

External reviewers

Cover graphic:

Layout by:

Printed by:

Available from:
IUCN, Gland, Switzerland

(C) 2020 IUCN, International Union for Conservation of Nature and Natural Resources

Reproduction of this publication for educational or other non-commercial purposes is authorized without prior written permission from the copyright holder provided the source is fully acknowledged.

Reproduction of this publication for resale or other commercial purposes is prohibited without prior written permission of the copyright holder.

Boucher, J., Billard, G., Simeone, E. and Sousa, J. (2020). The marine plastic footprint. Gland, Switzerland: IUCN. viii+69 pp.

978-2-8317-2028-9 (PDF)

978-2-8317-2029-6 (print)

https://doi.org/10.2305/IUCN.CH.2020.01.en

Julien Boucher, Ph.D. (julien.boucher@shaping-ea.com), EA - Shaping Environmental Action; University of Applied Sciences and Arts Western Switzerland // HES-SO, HEIG-VD, Yverdon-les-Bains, Switzerland Guillaume Billard (guillaume.billard@shaping-ea.com), EA - Shaping Environmental Action Eleonora Simeone (Eleonora.simeone@shaping-ea.com), EA - Shaping Environmental Action Joao Sousa (joao.sousa@iucn.org), IUCN, Global Marine and Polar Programme, Senior Project Manager, Gland, Switzerland

Amy Sweeting

Dr Anna Kounina (Quantis)

Julia Koskella (SYSTEMIQ)

Dr Emilia Jankowska (Institute of Oceanology - Polish Academy of Science)

Imre Sebestyén

Imre Sebestyén, Unit Graphics, Serbia

BSR Imprimeurs SA, Gland, Switzerland

IUCN (International Union for Conservation of Nature)

Global Marine and Polar Programme (GMPP)

Rue Mauverney 28

1196 Gland

Switzerland

Tel +41229990000

Fax +41229990002

marine@iucn.org

www.iucn.org/resources/publications

The text of this book is printed on paper made from wood fibre from well-managed forests certified in accordance with the rules of the Forest Stewardship Council (FSC). 


\section{Table of contents}

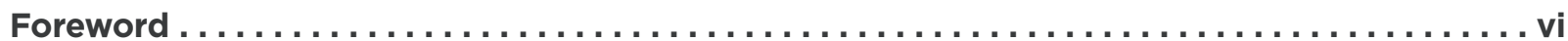

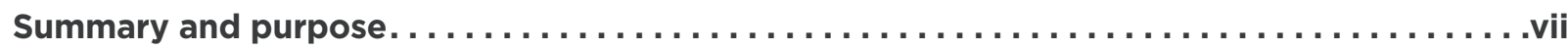

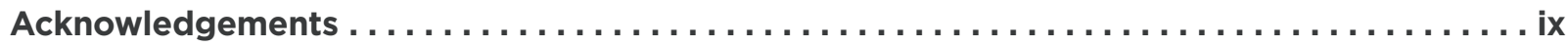

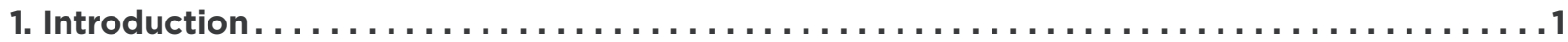

1.1. Marine plastic leakage. ........................................ 1

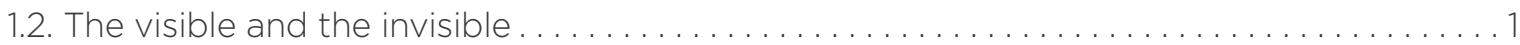

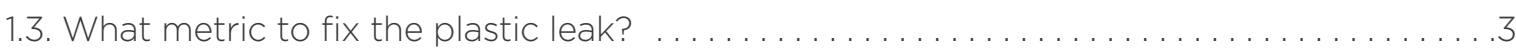

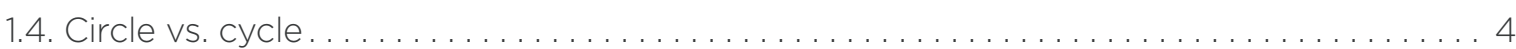

1.5. The materiality of plastic. . . . . . . . . . . . . . . . . . . . . . . . . . . . . . . 7

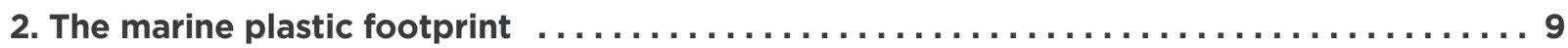

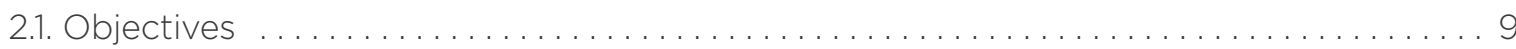

2.2. Methodology...................................................... 10

3. Modelling marine leakage from plastic waste (macroplastics) $\ldots \ldots \ldots \ldots \ldots \ldots \ldots \ldots 14$

3.1. Calculation of the mismanaged waste fraction (the "loss") . . . . . . . . . . . . . . . . . . 14

3.2. Calculation of the release into oceans and waterways (the "release") ............... 16

3.3. Calculating the leakage from macro-plastic waste. . . . . . . . . . . . . . . . . . . 20

4. Modelling marine leakage from primary microplastics $\ldots \ldots \ldots \ldots \ldots \ldots \ldots \ldots \ldots \ldots 21$

4.1. Generic loss rates and release rates of microplastics . . . . . . . . . . . . . . . . . 21

4.2. Calculation route for textile leakage ................................. 22

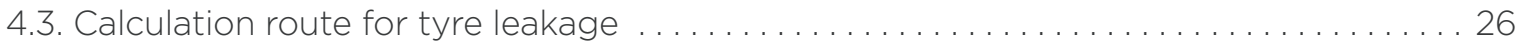

4.4. Calculating the total leakage from microplastics ......................... 28

5. Modelling marine plastic leakage from fishing devices and other maritime sources $\ldots \ldots 29$

6. Modelling the fate of plastics to move from marine leakage calculation to footprint. . . 30

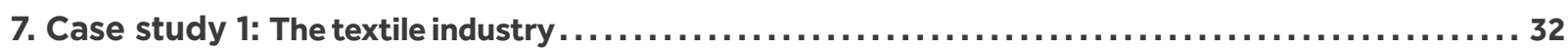

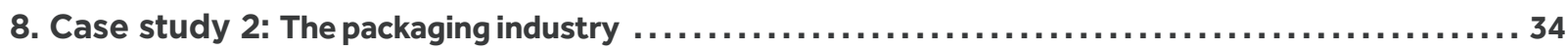

The footprint of a glass bottle vs. a plastic bottle ........................... 34

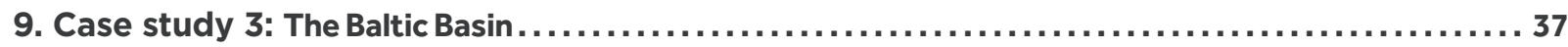

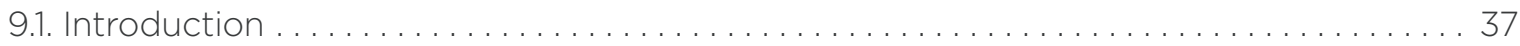

9.2. Objective and methodology ........................................ 37

9.3. Outputs and interpretation.......................................... 38

9.4. Estimating the fate of the leaked plastic: how much is floating? . . . . . . . . . . . . 44

9.5. Limitations and conclusions ........................................ 44

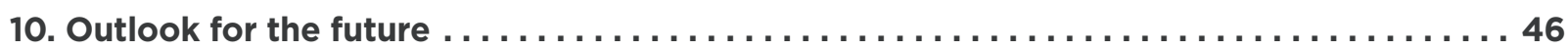

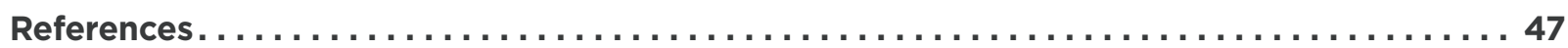

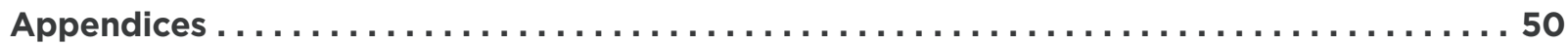

Appendix 1. Textile loss rates .......................................... 50

Appendix 2. Tyre dust loss rates . . . . . . . . . . . . . . . . . . . . . . . . . . . . 50

Appendix 3. Wastewater pathway release rate . . . . . . . . . . . . . . . . . . . . . . . 51

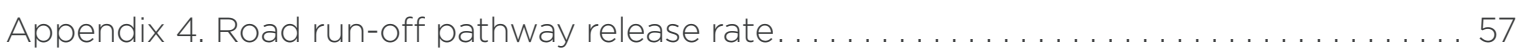

Appendix 5. Data for Case Study 1: The textile industry . . . . . . . . . . . . . . . . . . 58

Appendix 6. Data for Case Study 2: the packaging industry . . . . . . . . . . . . . . . . 59

Appendix 7. Data for Case Study 3: The Baltic Basin ......................... 60 


\section{List of figures and tables}

Figure 1: General framework of the Marine Plastic Footprint, adopting a life-cycle perspective in inventorying marine plastic leakage while also considering the circularity and materiality of plastic. $\ldots \ldots \ldots \ldots \ldots \ldots \ldots \ldots \ldots \ldots \ldots \ldots \ldots \ldots$

Figure 2: Plastic production and marine plastic leakage by source: Current best guesses at the global scale (Mt for million

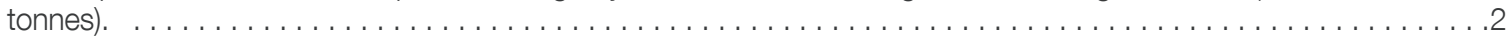

Figure 3: Classification of different categories of single-use/durable plastics, and their fate as microplastics (primary and secondary). The four categories of leakage include: A) mismanaged macroplastic waste, B) discarded or lost macroplastic objects, C) intentionally released out microplastics, and D) unintentionally dispersed microplastics.. . . . .4

Figure 4: Circle versus Cycle. Adopting circularity principles may lead to inappropriate solutions without any means to measure the marine plastic leakage (and other environmental impacts) by adopting a life-cycle perspective. . . . . . .5

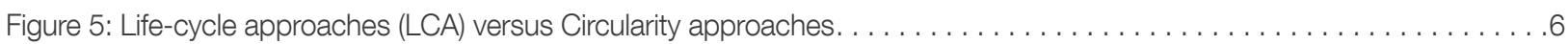

Figure 6: Ecodesign is about balancing the environmental impacts of products (marine plastic leakage in this report) with the

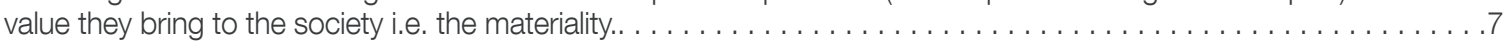

Figure 7: Materiality analysis for plastic as a tool to shape science-based decisions on when to use and when not to use

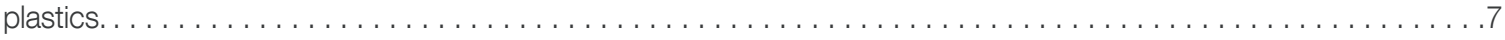

Figure 8: General framework of the Marine Plastic Footprint and relation with the LCA framework, as described in the

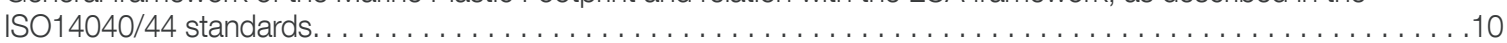

Figure 9: Generic system map and calculation methods for the Marine Plastic Footprint . . . . . . . . . . . . . . . . 11

Figure 10: Loss rates and release rates are, respectively, a measure of the inherent contributions of the product and

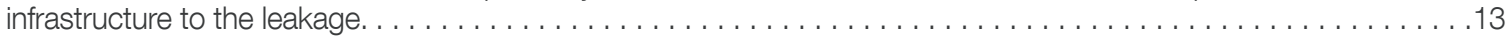

Figure 11: Pathways from plastic waste generation to transfer to the ocean $\ldots \ldots \ldots \ldots \ldots \ldots \ldots \ldots \ldots \ldots \ldots$

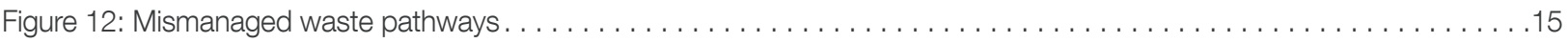

Figure 13: Release rates matrix for country assessment. Distance classes are $10 \mathrm{~km}$ (low), between 10 and $50 \mathrm{~km}$ (mean), and above $50 \mathrm{~km}$ (high). Run-off categories are $<0.4 \mathrm{~mm} /$ day $^{-1} \mathrm{~km}$ (low), between 0.4 and $0.8 \mathrm{~mm}$. day ${ }^{-1}$ (mean),

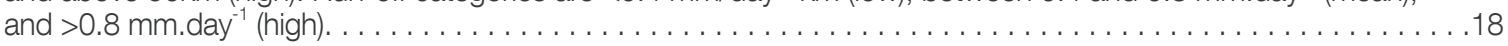

Figure 14: Key parameters potentially influencing the loss rate of textile fibres. $\ldots \ldots \ldots \ldots \ldots \ldots \ldots \ldots \ldots \ldots$

Figure 15: Loss rates reported in the literature for textiles, grouped according to different criteria (washing with/without detergent, fleece versus non-fleece, new versus used garments). All numerical values and references are reported in Table 6 and Appendix 1. The horizontal line in the middle of the box represents the median (central value), the upper vertical line represents the $95^{\text {th }}$ percentile, and the lower vertical line the $5^{\text {th }}$ percentile. The box itself shows the interquartile range, the upper horizontal line the $75^{\text {th }}$ percentile (high value) and the lower line the $25^{\text {th }}$ percentile (low value). Blue stars are the outliers, the highest values reported. $\ldots \ldots \ldots \ldots \ldots \ldots \ldots .24$

Figure 16: System map for estimating the marineplastic leakage from textiles $\ldots \ldots \ldots \ldots \ldots \ldots \ldots \ldots \ldots \ldots \ldots$

Figure 17: Loss rate reported in literature for tyres from different vehicle types. All numerical values and references are reported in Table 6 and in Appendix 2. The horizontal line in the middle of the box represents the median (central value), the upper vertical line represents the $95^{\text {th }}$ percentile, and the lower vertical line the $5^{\text {th }}$ percentile. The box itself shows the interquartile range, the upper horizontal line the $75^{\text {th }}$ percentile (high value) and the lower line the $25^{\text {th }}$ percentile (low value). Blue stars are the outliers, the highest values reported $\ldots \ldots \ldots \ldots \ldots \ldots \ldots \ldots .27$

Figure 18: System map for estimating the marine plastic leakage from tyres $\ldots \ldots \ldots \ldots \ldots \ldots \ldots \ldots \ldots \ldots \ldots \ldots$

Figure 19: Differences in leakage of plastics throughout the life cycle. The main losses appear to occur during the use

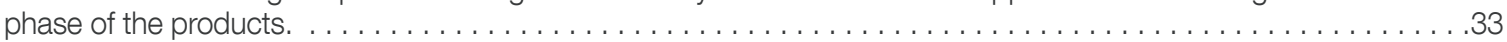

Figure 20: Spatial and temporal differences in loss rates of products of the textile industry. $\ldots \ldots \ldots \ldots \ldots \ldots$

Figure 21: Spatial and temporal differences in loss rates of products in the packaging industry. $\ldots \ldots \ldots \ldots \ldots$

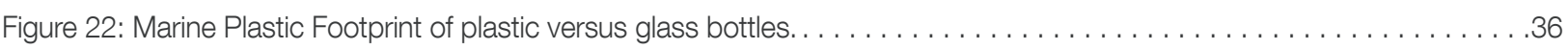

Figure 23: Contribution of different plastic sources to the overall marine plastic leakage in the Baltic Basin . . . . . . . . 37

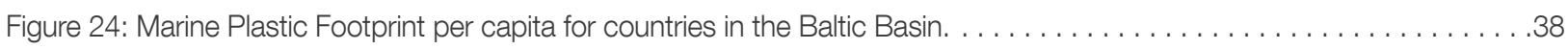

Figure 25: Regional differences in the Marine Plastic Footprint leakage of the Baltic Basin states considered in this study. . . . .39

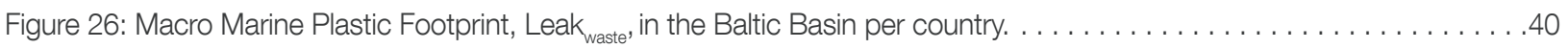

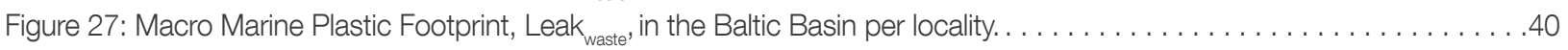

Figure 28: Macro Marine Plastic Footprint, Leak ${ }_{\text {waste, }}$ in the Baltic Basin per watershed. Due to model limitations, no watershed data is available above 60 degrees north latitude (except for the Neva watershed). . . . . . . . . . . . .41

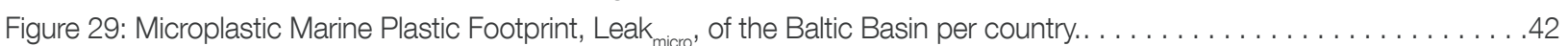


Figure 30: Microplastic Marine Plastic Footprint, Leak micro , of the Baltic Basin per population points. . . . . . . . . . . . 42

Figure 31: Microplastic Marine Plastic Footprint, Leak ${ }_{\text {micro }}$, of the Baltic Basin per watershed. Due to model limitations, no watershed data is available above 60 degrees north latitude, except for the Neva watershed. . . . . . . . . . . . 44

Figure 32: Behaviour of plastic debris in the water column; probable water column loading of the Baltic Sea. . . . . . . . 45

Figure 33: Summary of the different textile loss rates reported in the literature. A central loss value of $124 \mathrm{mg} / \mathrm{kg}$ was

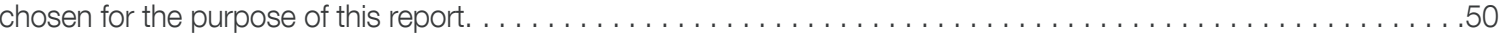

Figure 34: Summary of the different loss rates of tyres reported in the literature. A central loss value of $102 \mathrm{mg} / \mathrm{km}$ was

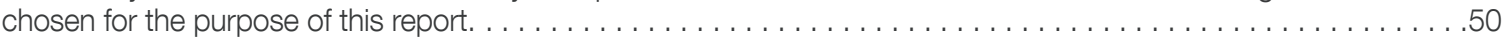

Figure 35: Efficiency of wastewater treatment plants in the removal of microplastics (including microfibres). . . . . . . . .51

Figure 36: Example of a company Marine Plastic Footprint calculator for the textiles sector. . . . . . . . . . . . . . 58

Figure 37: Example of a company Marine Plastic Footprint calculator for the packaging sector. . . . . . . . . . . . . . 59

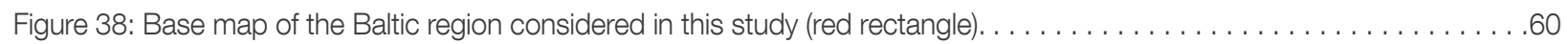

Figure 39: Key information provided in the Gridded Population of the World shapefile. . . . . . . . . . . . . . . 61

Figure 40: Output of the GIS methodology/data matrix; map representing the potential Marine Plastic Footprint of tyre

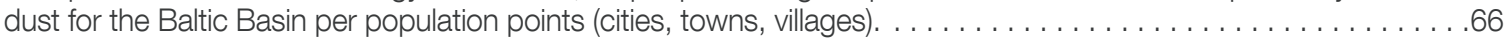

Figure 41: Output of the GIS methodology with the potential Marine Plastic Footprint of textile fibers for the Baltic

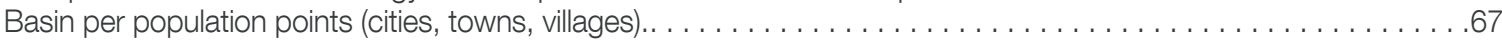

Figure 42: Potential Marine Plastic Footprint of pellets (in $\mathrm{mg}$ to $\mathrm{kg}_{\mathrm{year}}{ }^{-1}$ ) in the Baltic Basin countries per population

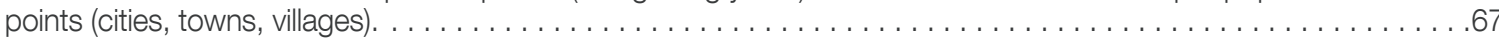

Figure 43: Potential Marine Plastic Footprint of cosmetics in the Baltic Basin countries per population points (cities, towns,

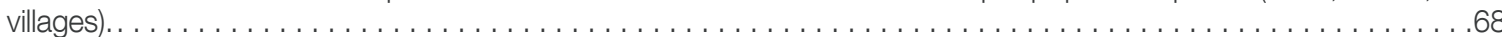

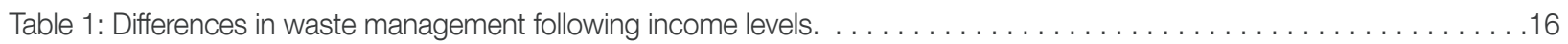

Table 2: List of the different parameters used for the calculation of the leakage $\ldots \ldots \ldots \ldots \ldots \ldots \ldots \ldots \ldots \ldots$

Table 3: Release rates described in the literature (explicit) or extrapolated from the cited study. . . . . . . . . . . . . . 17

Table 4: Description of the different release rates used throughout the report. $\ldots \ldots \ldots \ldots \ldots \ldots \ldots \ldots \ldots$

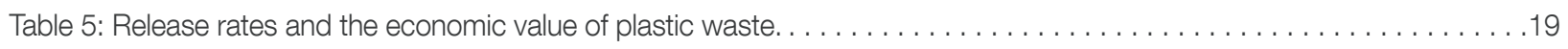

Table 6: Generic Loss Rates (LR) for seven main plastic sources $\ldots \ldots \ldots \ldots \ldots \ldots \ldots \ldots \ldots \ldots \ldots \ldots \ldots \ldots \ldots \ldots \ldots$

Table 7: Generic Release Rates (RR) for three main marine leakage pathways. $\ldots \ldots \ldots \ldots \ldots \ldots \ldots \ldots \ldots \ldots \ldots \ldots$

Table 8: Take-home message of the main factors favoring the release of textile fibers. $\ldots \ldots \ldots \ldots \ldots \ldots \ldots \ldots 22$

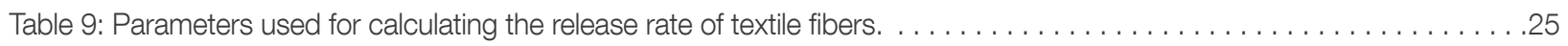

Table 10: Take-home message of the main factors favoring the release of tyre dust. $\ldots \ldots \ldots \ldots \ldots \ldots \ldots$

Table 11: A description of the loss and release rates of tyre dust and main parameters influencing these rates. $\ldots \ldots \ldots 28$

Table 12: Conventional degradation rates of different categories of plastic and plastic applications. Sources: (1) MOTE Marine Laboratory Marine Debris Biodegradation time line, 1993. (2) BIOTEC Environmental, 2019. . . . . . . . . . 30

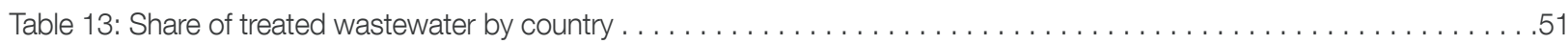

Table 14: Differences in the release rates published in the literature. Based on these numbers it was chosen a 2/12/22\%

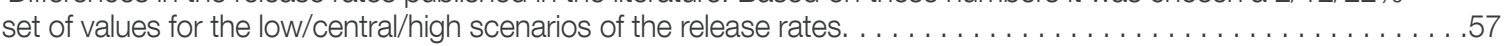

Table 15: Description of the steps followed in the implementation of the GIS methodology and the sources of data. . . . . . .61

Table 16: Example of the information used for the creation of the data matrix $\ldots \ldots \ldots \ldots \ldots \ldots \ldots \ldots \ldots \ldots \ldots \ldots$

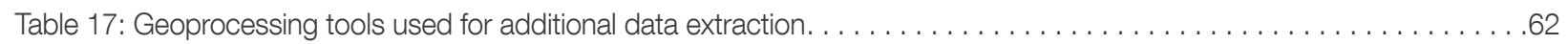

Table 18: Detailed results for the central values of the plastic footprint of the Baltic Basin states considered in this study.. . . .63

Table 19: Updated waste management data for the Baltic Basin states considered in this study. . . . . . . . . . . . 63

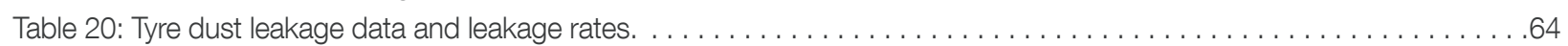

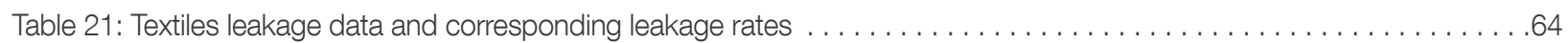

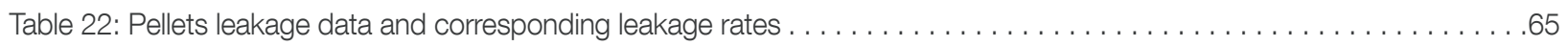

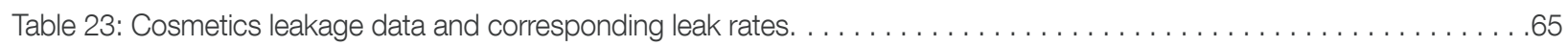

Table 24: Summary table of Leakwaste and Leakmicro for each Baltic Basin country . . . . . . . . . . . . . . 66

Table 25: Parameters used in the sensitivity analysis. Several scenarios were tested using low, central, and high values,

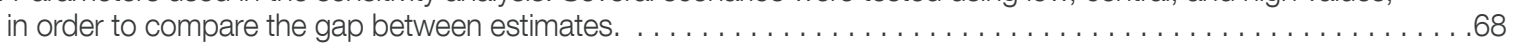

Table 26: Raw data of low values for both micro- and macroplastic leakage per country (data in tonnes/year ${ }^{-1}$ ). . . . . . . . 69

Table 27: Raw data of high values for both micro- and macroplastic leakage per country (data in tonnes/year ${ }^{-1}$ ). . . . . . . 69 


\section{Foreword}

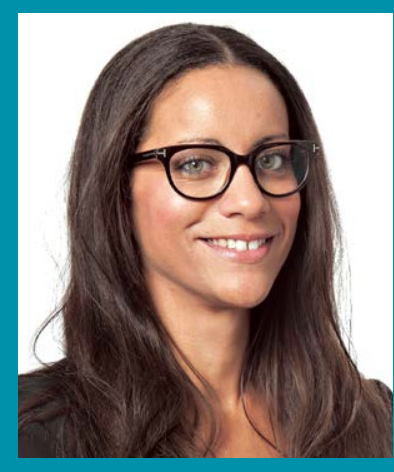

Plastic is an integral part of modern life that has transformed the way we live. The Plastic Revolution in the 50's and 60's spawned by convenience turned into an economic plastic dictatorship where plastic is everywhere and rules everything.

A transition into a plastic Democracy will not be easy but it must be done.

This revolutionary versatile light material has become a fundamental material in an array of industries and has rendered our societies plastic dependent, and it is part of our daily life. But the lack of responsibility of not only managing plastic waste but to re-use and repurpose, to date is terrifying. Cost savings in transport, energy, clothing, shelf life of food are now being outweighed by the impacts on the environment and human health.

Discussion around plastic litter in the oceans and proposed solutions have come a long way in recent years. However, it is a complex problem with a multitude of identified sources. Tackling the multitude of sources of marine plastics needs a holistic approach. To solve a problem one must understand its origin; so identification of plastic sources and pathways are vital.

Quantifying and qualifying the problem is of crucial importance in identifying the pollution sources. However, current knowledge should already be sufficient to shape action, such as new engineered materials, smart design, new solid-liquid separation technologies, supporting legislation and on-the-ground policies that could inspire real change, to mention some.

This new report provides a novel method to estimate and map sources and quantities of plastic leakage (macro and microplastics). To demonstrate the value of the methodology the report presents three case studies that were applied spatially to produce a regional case study focusing on marine plastic leakage into the Baltic Sea, using Geographic Information Systems and two sector specific studies on plastic leakage in the packaging and textile industries. The document serves to inform key stakeholders and shape actions towards closing the plastic tap. It seeks to offers decision-makers a sound basis for taking measured actions distilled from recent undertakings: The Marine Plastic Footprint, an ambitious effort to develop science-based metrics that measure plastic leakage in order to increase both the materiality and circularity of plastic.

From laboratory research to industrial production to retail consumption, private sector decisionmakers hold the power to slow, stop or reverse the flow of plastic to the sea. Marine plastic pollution management often boils down to people management, and one of the most effective ways to change course is through self-imposed measures driven by the need to reduce exposure to brand, finance, or regulatory risk.

By anchoring the roots of polymer pathways, defining the nature and extent of the problem, we gain a better understanding of what is happening, what to anticipate, and which responses are most plausible and effective among voluntary industry approaches and mandatory government policies.

Denise Hardesty once said "in a way we are all Plastic Experts, we buy them, use them and dispose them", so, a big challenge lies ahead of us, but through collective action, we can reverse the exponential forecasts of plastic production and pollution for a healthy and thriving ocean. Knowing what is out there is the first step to a healthy and thriving ocean.

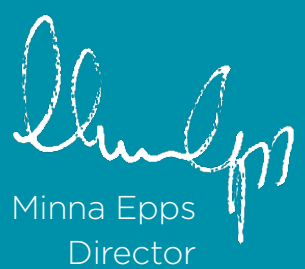

IUCN Global Marine and Polar Programme 


\section{Summary and purpose}

Not only our feet leave footprints on sandy beaches - our global reliance on artificial polymers is leading to a visible and pervasive Plastic Footprint in the marine environment. This report estimates that 12 million tonnes of plastic are leaking into the global ocean every year, causing an unprecedented environmental crisis.

Plastic pollution originates from various sources. While many industries are taking steps to reduce their dependence on plastic, there is currently no reliable methodology to forecast specifically the extent of the marine plastic leakage from an industry or a country and map potential leakage hotspots throughout the value chain.

This report offers, for the first time, a comprehensive framework (see Figure 1) to measure the inventory of marine plastic leakage, step-by-step and using a life-cycle perspective. It also offers generic data that can be used to calculate marine plastic leakage for a defined list of identified sources, including plastic waste, textile fibres, tyre dust, micro beads in cosmetics, and fishing nets.

The report also aims to clarify the key concepts and definitions related to the Marine Plastic Footprint, which will help generate better data for making the methodology more fully applicable and actionable.

The approach discussed in this report focuses on inventorying plastic flows into the marine environment only. It does not look at plastic releases into the terrestrial environment, or any ecosystem or human health impacts that may result from marine plastic leakage. These topics are covered in other ongoing projects such as the Plastic Leak Project (also supported by IUCN) for extending the leakage inventory to other environmental compartments, and the MariLCA

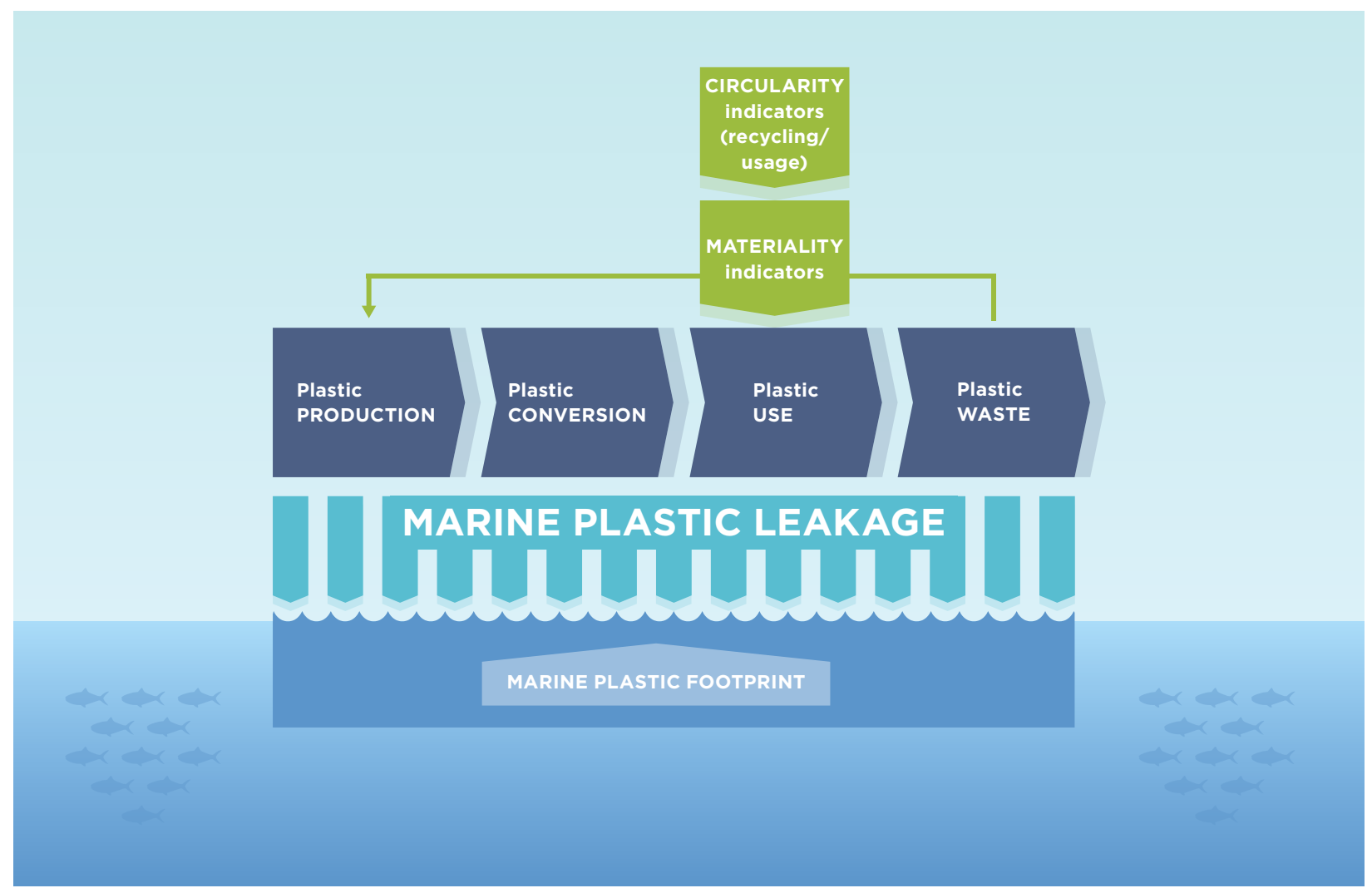

Figure 1: General framework of the Marine Plastic Footprint, adopting a life-cycle perspective in inventorying marine plastic leakage while also considering the circularity and materiality of plastic. 
project for developing a Life Cycle Impact Assessment framework and methodology for marine plastic leakage.

By providing a framework for the assessment of marine plastic leakage, which is called the Marine Plastic Footprint, this reports hopes to support companies that are working towards setting sound priorities for action on the circularity and materiality of plastic. Forecasting metrics are needed to efficiently close the "plastic tap", i.e., stop the flow of plastic into the environment.

Key information in this report includes:

- A full set of calculation methods for estimating the Marine Plastic Footprint of products, companies, or countries. These calculations apply to both macroplastics leaking from mismanaged waste and microplastics from four main sources (textile fibres, tyre dust, cosmetics, and production pellets)

- A generic data set of factors (loss rates and release rates) to be used for calculating the Marine Plastic Footprint.

- A case study of the textile industry that demonstrates how the Marine Plastic Footprint methodology can allow companies to set priorities by focusing on specific markets, life-cycle stages, or plastic sources. Such a tool will allow industries to more efficiently focus investments to yield improvements.

- A case study of the packaging industry that demonstrates that such a methodology can be used to effectively capture the efficiency of recycling and re-use. This shows that the proposed methodology is suited not only as a diagnostic tool, but also as a way to measure and monitor progress.

- A regional case study focusing on marine plastic leakage into the Baltic Sea, using Geographic Information Systems (GIS). The regional Marine Plastic Footprint of the Baltic Basin is estimated at approximatively
27,000 tonnes year $^{-1}$, with a dominance of macroplastics in the leakage $(22,120$ tonnes year ${ }^{-1}$ ), followed by 5,452 tonnes of microplastics. Datafiles and shapefiles in $x / s x$ and .shp formats are provided in the appendix, allowing for each country that borders the Baltic basin to further analyse the data and develop local solutions.

The methodology reconciles the life-cycle perspective with circularity principles by linking the probability of leakage with the residual economic value of the waste. This report aims to provide clarity on marine plastic leakage modelling and offer a first comprehensive set of equations and data to make the methodology applicable. Finally, the report does not pretend to replace field data evidence, but instead stresses current knowledge gaps and areas where further research is needed to make the Marine Plastic Footprint methodology fully actionable, and contribute to stopping the flow of plastic into the marine environment. 


\section{Acknowledgements}

The authors wish to express their sincere thanks to everyone who contributed, directly or indirectly, to the development of this report. In particular, our thanks go to colleagues, country representatives, and partner organisations who actively participated and shared their views and expertise in the various side events and workshops that IUCN co-organised, together with other partners, on this important topic between 2017 and 2019.

This report was made possible through the generous contribution of our donor, the Swedish Postcode Foundation.

We also thank colleagues from Systemiq and Quantis: Julia Koskella, Emilia Jankowska and Anna Kounina who openly reviewed this report in light of other ongoing plastic related projects, such as the Plastic Leak Project and the Global Roadmap to achieve near-zero ocean plastic leakage by 2040, providing very valuable feedback to improve the report. Finally special thanks to Amy Sweeting for editing the report and Imre Sebestyén for the many back and forth discussions during the design process. 


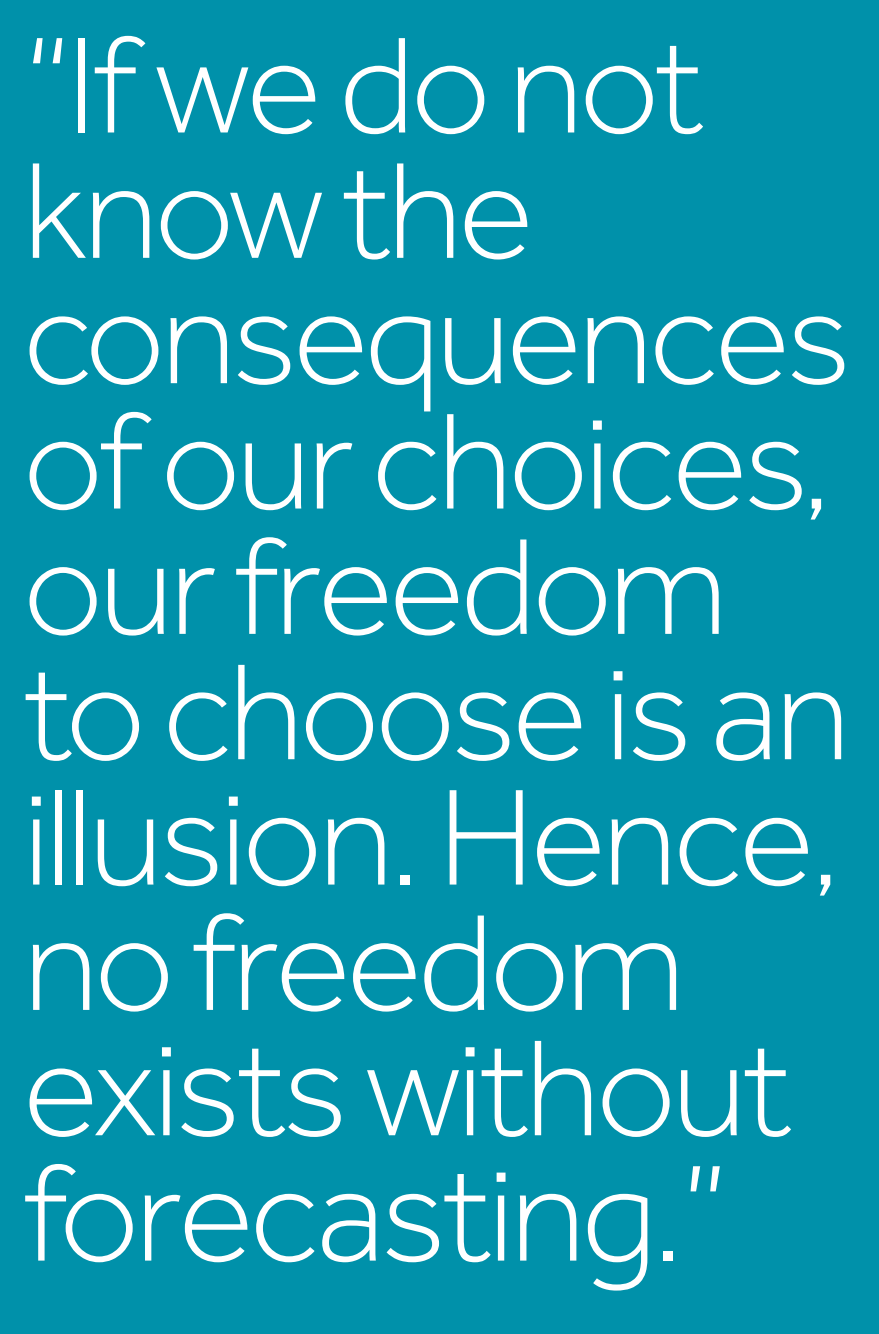

Bertrand de Jouvenel 


\section{Introduction}

\subsection{Marine plastic leakage}

Plastics are a part of everyday life around the globe. Production of plastic has been steadily increasing since the 1950s (Geyer et al., 2017), reaching 335 million tonnes in 2016 (PlasticsEurope, 2017). Because of plastic's pervasive use, unrivalled properties, and low production costs, production is expected to double in the next two decades (Ryan, 2015). Over 90 percent of plastics produced are derived from fossil fuels, accounting for almost 20 percent of total oil consumption. Production of plastics is furthermore expected to account for 15 percent of the global annual carbon budget by 2050 (CIEL, 2017; WEF, 2016).

Of all the plastic produced and put on the market since 1950, only seven percent has so far been recycled (Geyer et al., 2017). Although recycling rates have been increasing in recent years in many countries (reaching 31 percent in Europe in 2016) (PlasticsEurope, 2017), the plastic economy is far from circular. The vast majority of plastic is still being discarded, sometimes in an inappropriate manner.

The rising production of plastic and the low circularity of its economy is increasing the amount leaking into the marine environment each year. The quantity of plastic flowing into waterways and, ultimately, into the oceans is called marine plastic leakage. Several studies have inventoried and quantified different sources of marine plastic leakage, either at the country level or globally (Lassen et al., 2015; Essel et al., 2015; Magnusson et al., 2016). Global estimates fluctuate between studies, however all are in the same order of magnitude:

- $4.8 \mathrm{Mt} /$ year $^{-1}$ to $12.7 \mathrm{Mt} /$ year $^{-1}$ (Jambeck et al., 2015);

- $\quad 8.28 \mathrm{Mt} /$ year $^{-1}$ (UN Environment, 2018);

- $10 \mathrm{Mt} /$ year $^{-1}$ (Boucher and Friot, 2017);

- $12.2 \mathrm{Mt} /$ year $^{-1}$ (EUNOMIA, 2016).
Presented in Box 1 are the results of several studies put together which highlight a global leakage estimate of 12 million tonnes year-1.

The rise in global plastic consumption is not unreasonable - plastics provide many benefits to society through their versatility, durability, malleability, and light weight. For many applications, plastics can even offer a lower carbon footprint alternative to comparable materials. Yet, because the adoption of plastic has been pervasive, the problem is now pervasive. The ever-increasing pollution of the oceans and other aquatic bodies by plastics and microplastics is becoming a major concern, due to potential ecosystem and human health impacts caused by entanglement, plastic absorption, and chemical contaminants adsorption on debris.

\section{Three percent of all plastic we produce leaks into the ocean every year.}

These environmental concerns are not directly related to the use of plastic, but rather to the leakage of plastic and/or potentially toxic chemical additives into the environment during production, transport, use, and end-of-life management. Based on 2016 data (see Figure 2), an estimated three percent of all plastic produced is leaking into the environment. Box 1 discusses in more detail the marine plastic leakage from four main sources and estimates the quantities of plastic flowing into the marine environment.

\subsection{The visible and the invisible}

Plastic is a single word for a multi-faceted reality, encompassing a wide variety of polymers and additives with very different chemical and physical properties. These plastics are used for many different applications, including plastic objects, packaging, infrastructure, vehicles, paints, and textiles. 


\section{Box 1: Plastic production and leakage, by source}

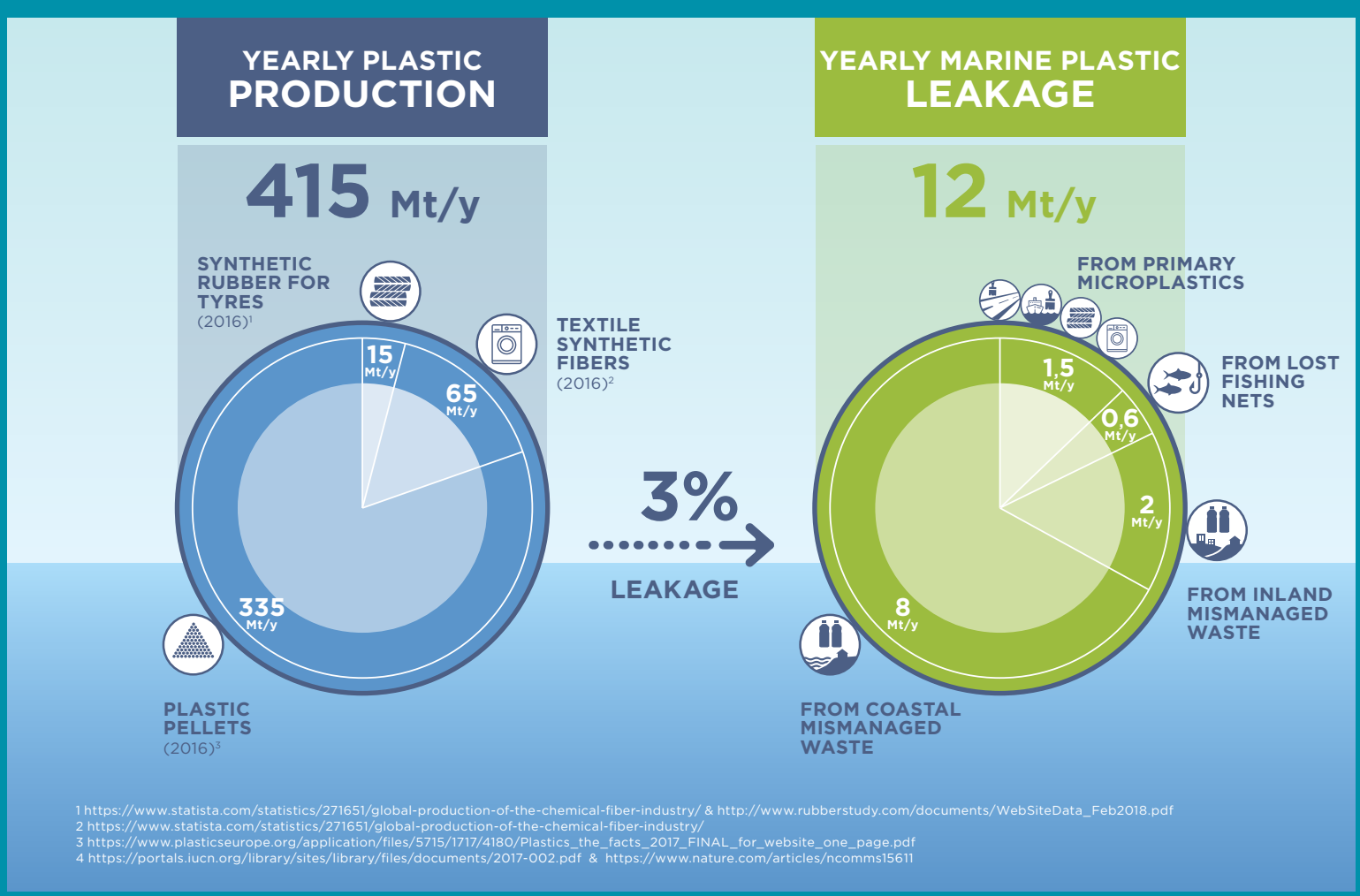

Figure 2: Plastic production and marine plastic leakage by source: Current best guesses at the global scale (Mt for million tonnes).

i. $\quad$ Coastal mismanaged plastic waste (MPW): $8 \mathrm{Mt} / \mathrm{year}^{-1}$

The most commonly cited orders of magnitude for mismanaged plastic waste have been published by Jambeck et al. (2015). This research focused on the amount of mismanaged plastic waste likely to be generated by the coastal populations of 192 countries, living within $50 \mathrm{~km}$ of the shore. Calculations were based on the mass of waste generated per capita annually, the percentage of plastic materials in the waste, and the percentage of mismanaged plastic waste likely to enter the oceans as debris (which is based on the share of inadequately managed waste per country and a default global littering rate of two percent). This research concluded that annual leakages of MPW into the marine environment range from 4.8 to $12.7 \mathrm{Mt} /$ year ${ }^{-1}$. Additionally, other MPW estimations have been published, varying from $3.87 \mathrm{Mt} /$ year $^{-1}$ of a total global marine plastic leakage of $8.28 \mathrm{Mt} /$ year $^{-1}$ (UN Environment, 2018 ) to $9 \mathrm{Mt} /$ year ${ }^{-1}$ of a total global marine plastic leakage of $12.2 \mathrm{Mt} /$ year $^{-1}$ (EUNOMIA, 2016).

ii. Inland MPW: $2 \mathrm{Mt} /$ year

Contributions of rivers to the global marine plastic leakage fluctuate based on seasonality and geographic location. Globally, rivers are estimated to be responsible for a plastic waste input ranging from $1.15 \mathrm{Mt} / \mathrm{year}^{-1}$ to $2.41 \mathrm{Mt}^{\text {year }}{ }^{-1}$, with 67 percent of these emissions originating from Asia alone (Lebreton et al., 2017). Interestingly, the above-mentioned study is supported by field measurements showing good correlation between population densities, waste management data, and results from observational river studies. In addition, another study estimated riverine inputs to range between $0.41 \mathrm{Mt}^{\text {year }} \mathrm{y}^{-1}$ and $4 \mathrm{Mt} / \mathrm{year}^{-1}$ (Schmidt, Krauth, and Wagner, 2017). Discrepancies between the two studies rely on different parameters, such as the number of coastal countries considered, for example.

iif. Lost fishing gear: $0.6 \mathrm{Mt} /$ year

The fishing and aquaculture sectors emit large quantities of litter (e.g. derelict gear), including an estimated 0.6 Mt of microplastics per year (Boucher and Friot, 2017). Other orders of magnitude have been published with, for example, a loss of derelict fishing gear of $1.15 \mathrm{Mt} /$ year $^{-1}$ (EUNOMIA, 2016). The sources here are very scarce, and the precise contribution is highly unreliable. But field studies report a prevalence of blue fibres (nylon) specific to fishing devices. In addition, shipping litter illegally thrown overboard also contributes to the overall plastic pollution, with estimates of 600 kiloton-kt/ year ${ }^{-1}$ (EUNOMIA, 2016).

iv. Primary microplastics: $1.5 \mathrm{Mt} /$ year

In this study, it is considered that marine plastic leakage of $1.5 \mathrm{Mt} /$ year $^{-1}$ enters the marine environment in the form of primary microplastics, i.e. plastic entering the ocean already in a micro-format, due to the alteration of 
its chemical composition (marine paint, tyre abrasion) or intentionally manufactured in a sub-millimetre format (microbeads, pellets). However, many sources differ on the contribution of primary microplastics to the overall plastic loss. Primary microplastics have been estimated at:

3.01 Mt of a total plastic loss of 8.28 Mt/ year-1 (UN Environment, 2018)

$0.95 \mathrm{Mt}$ of a total plastic loss of $12.2 \mathrm{Mt} /$ year $^{-1}$ (EUNOMIA, 2016).

In percentage share, this equates to approximatively 36 percent, 15 percent, and 8 percent of total global marine plastic leakage estimates (UN Environment, 2018; Boucher and Friot, 2017; EUNOMIA, 2016). In detail, leakages due to tyre abrasion would equate to 1,400/420/270 kt/ year ${ }^{-1}$ (UN Environment, 2018; Boucher and Friot, 2017; EUNOMIA, 2016). According to the same sources, road marking leakages account for 590/105/80 kt/ year ${ }^{-1}$, and washed-out microfibres are estimated at 260/525/190 kt/ year-1.

All of this plastic enters oceans and soils from various sources and pathways, but mainly from two different streams: (1) the visible macroplastics resulting from mismanaged waste (Jenna $\mathrm{R}$. Jambeck et al., 2015) or discarded/lost plastic objects (e.g., fishing nets), and (2) the mostly invisible microplastics released from different sources, either intentionally (microbeads from cosmetics) or resulting from the unintentional abrasion of plastic objects throughout their life cycle (e.g. fibre shedding from textile garments or abrasion of tyres) (Boucher and Friot, 2017) (see Figure 3). Microplastics, in contrast with macroplastics, are plastics that measure less than $5 \mathrm{~mm}$. There is a need to distinguish between primary microplastics, which are plastic fragments entering the ocean already in micro format, and secondary microplastics, which result from the fragmentation of bigger plastic objects/waste once they are exposed to the environment (Boucher and Friot, 2017; Sundt et al., 2014).

The amount of leakage from these different types of plastic is dependent on the geographical context: leakage of macroplastics from mismanaged waste is dominant in costal countries, especially countries with less-advanced waste management. However, microplastics are much more pervasive than macroplastics and have more subtle routes to marine environments. Released through household wastewater or road run-off, microplastics can pass through treatment systems and end up in rivers and oceans. Primary microplastics account for 15 percent of global marine plastic leakage (Boucher and Friot, 2017). Finally, in countries with advanced waste management facilities, the relative contribution of microplastics versus mismanaged waste can be much higher.

Macro- and microplastic from

many sources contribute to the

marine plastic leakage over the

Iife cycle of plastic products and packaging.

\subsection{What metric to fix the plastic leak?}

Although the impacts of plastics in the environment are still being determined, the first steps to reduce the amount of plastic in the environment have been taken in recent years. Such measures include beach clean-up campaigns or plastic waste collection at sea. This is a first step towards local action and awareness raising, but it is not a solution to the root cause of the problem. It is key to first close the plastic tap, i.e. stop the flow of plastic into the environment (the leakage).

Closing the plastic tap does not necessarily mean stopping the use of plastics, but rather stopping plastic leaking into the environment and the ocean.

To act, companies have three options:

- Eco-designing a product to reduce the leakage: an initiative usually taken by a company that has direct control on the production line, e.g. supress tear-off parts of packaging or add a coating layer on a textile to reduce the shedding of microfibers. 


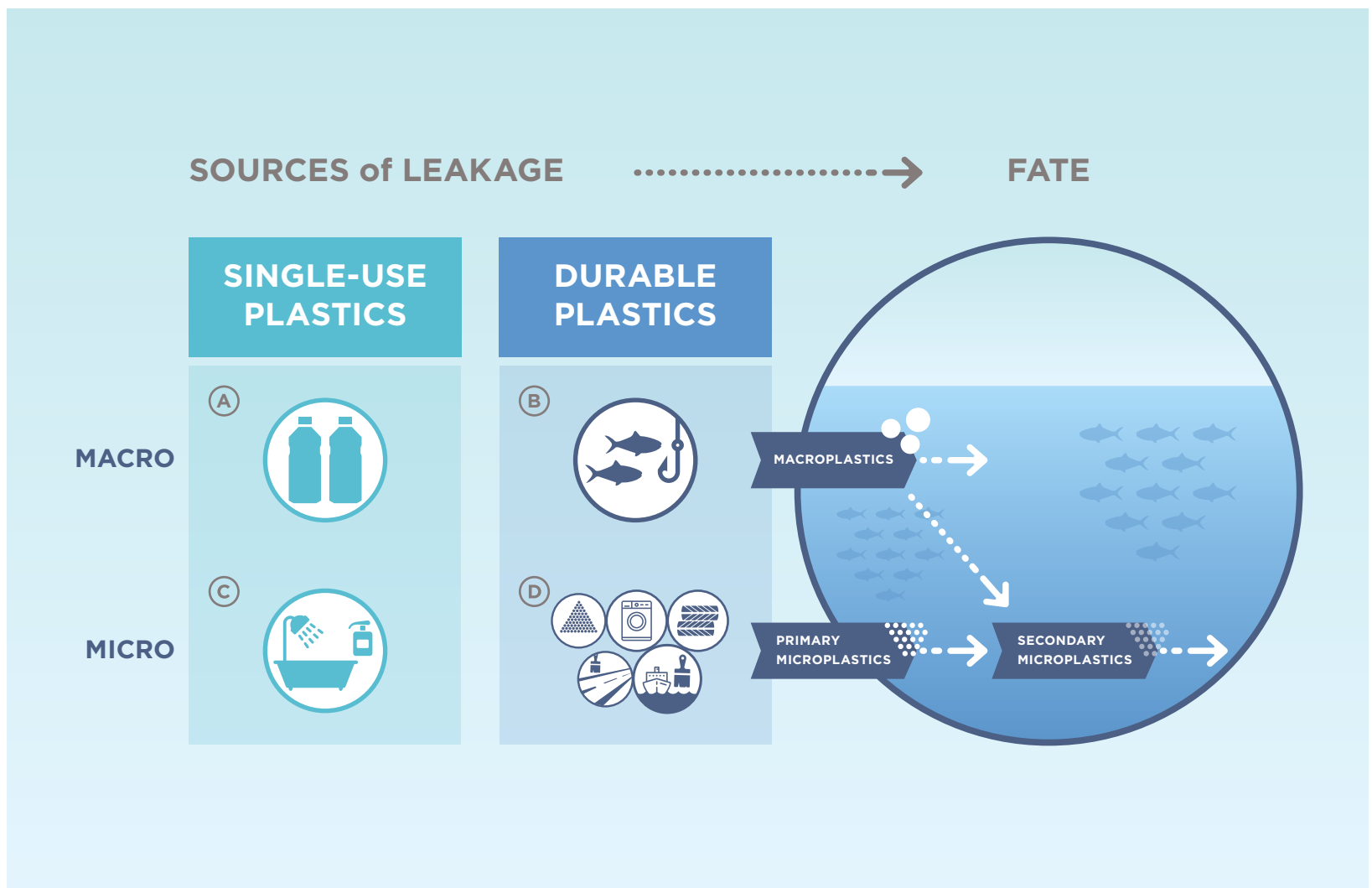

Figure 3: Classification of different categories of single-use/durable plastics, and their fate as microplastics (primary and secondary). The four categories of leakage include:A) mismanaged macroplastic waste, B) discarded or lost macroplastic objects, C) intentionally released out microplastics, and D) unintentionally dispersed microplastics.

- Developing plastic stewardship: is generally carried by a company that has influence over the context where a product is used and/or disposed. For example, supporting the creation and implementation of waste management facilities in key markets.

- Changing a business model: If a company can neither eco-design nor change the context, the company should consider stopping putting the product on the market and change the business model.

These measures represent a challenging endeavour, requiring a life-cycle and a regionalised perspective as well as a personal commitment. Fixing marine plastic leakage requires identifying where to prioritise this action: "We can't manage what we can't measure". Good recapitulation of potential action can be found in the report from Ocean Concervancy (2015) "Stemming the tide - Landbased strategies for a plastic-free ocean".
A life-cycle approach is needed to assess the marine plastic leakage into the marine environment.

The need to provide the private and public sectors with better tools and metrics to assess and monitor marine plastics has been recently stressed by UNEP and Medellin Declarations (UNEP, 2016; Medellin Declaration, 2016). There is a need to act now to build on existing methods to adequately prioritise when to use or avoid plastics.

\subsection{Circle vs. cycle}

The plastic crisis has spurred the existing debate between life-cycle assessment ("cycle") and circularity ("circle") (see Figure 5). While LCA is criticised by some for not having anticipated the plastic crisis, circularity is seen by others as a solution to this crisis. 


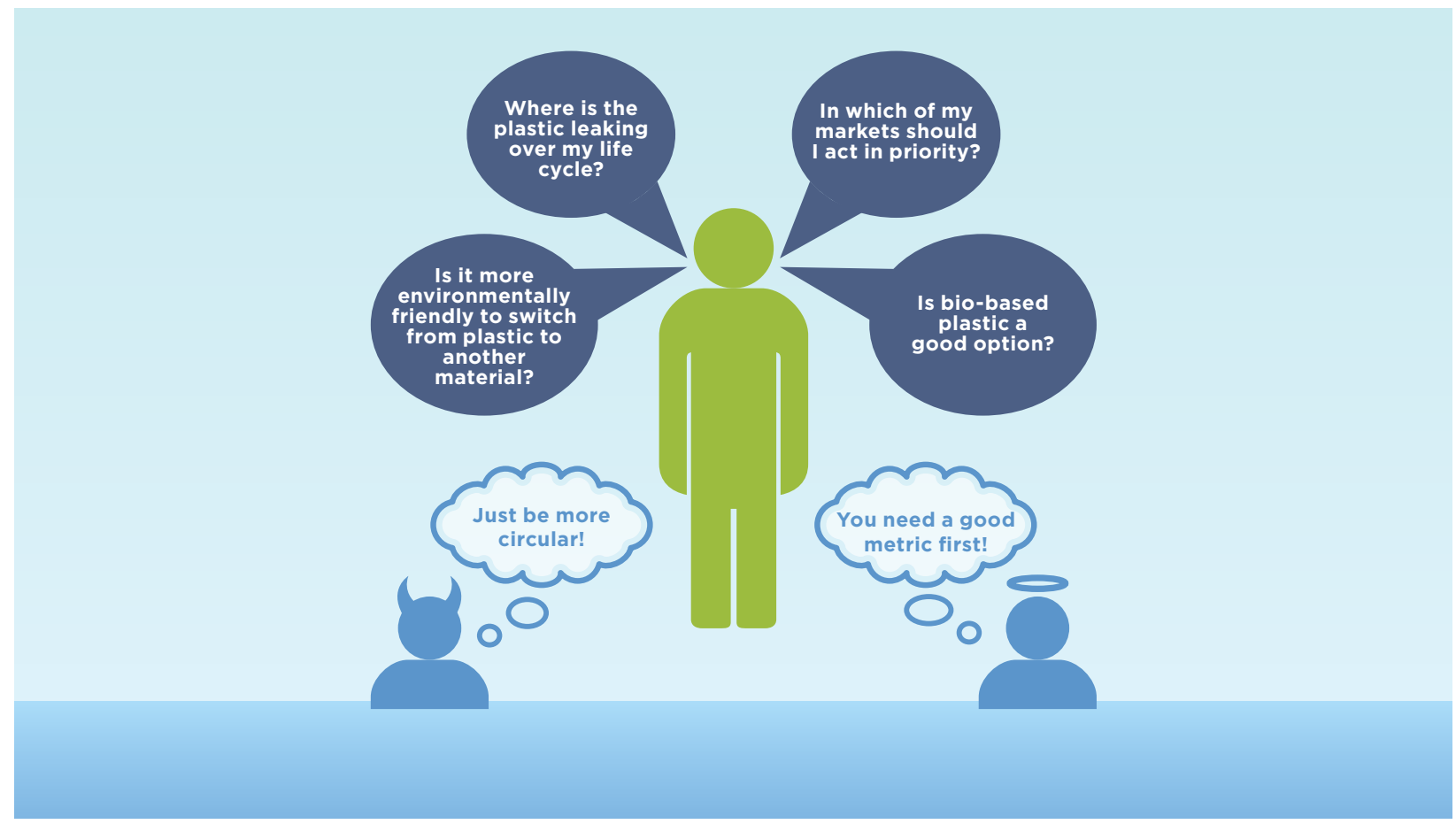

Figure 4: Circle versus Cycle. Adopting circularity principles may lead to inappropriate solutions without any means to measure the marine plastic leakage (and other environmental impacts) by adopting a life-cycle perspective.

Circularity and LCA must not be seen as conflicting; rather, they should be used synergistically to optimise plastic production, use, and end-of-life management.

\section{Life cycle assessment (LCA) is an} environmental assessment method, used by companies to tackle issues related to resource use that is based on the inventory of potential flows of pollutants entering different areas of the environment (e.g., air, water, soil) and the assessment of associated environmental impacts (ISO, 2006). However, a challenge with LCA methodologies is that they do not account for plastic as a pollutant, but rather only for the indirect effects of plastic use, e.g. depletion of resources, energy consumption, or emission of chemical contaminants. LCA methodologies neither provide an inventory of the marine plastic leakage nor characterise factors to assess the impacts of plastics on ecosystems or human health. This lack of appropriate accounting of plastic leakage has encouraged companies to massively favour plastic packaging in many situations, due to its lightweight nature and low carbon requirements. Yet, although it is true that current LCA methodologies are lacking a proper accounting of plastic leakage and associated impacts (Woods et al., 2016), LCA is a unique holistic environmental assessment framework, enabling the assessment of various environmental impacts in a coherent manner, and thus avoiding trade-offs between competing environmental issues.

Circularity is part of the concept of a circular economy. While the circular economy is a global economic model that aims to decouple economic growth and development from the consumption of finite resources (EMF, 2015), circularity is a concept that has emerged to describe how restorative the material flows of a product or company are (EMF, 2015). However, there have been only a few attempts to develop applicable metrics to measure this circularity (Aoustin et al., 2015; EMF, 2015; Linder et al., 2017; Otero and Pizarro, 2017; Saidani et al., 2017). Some approaches are based on the use 


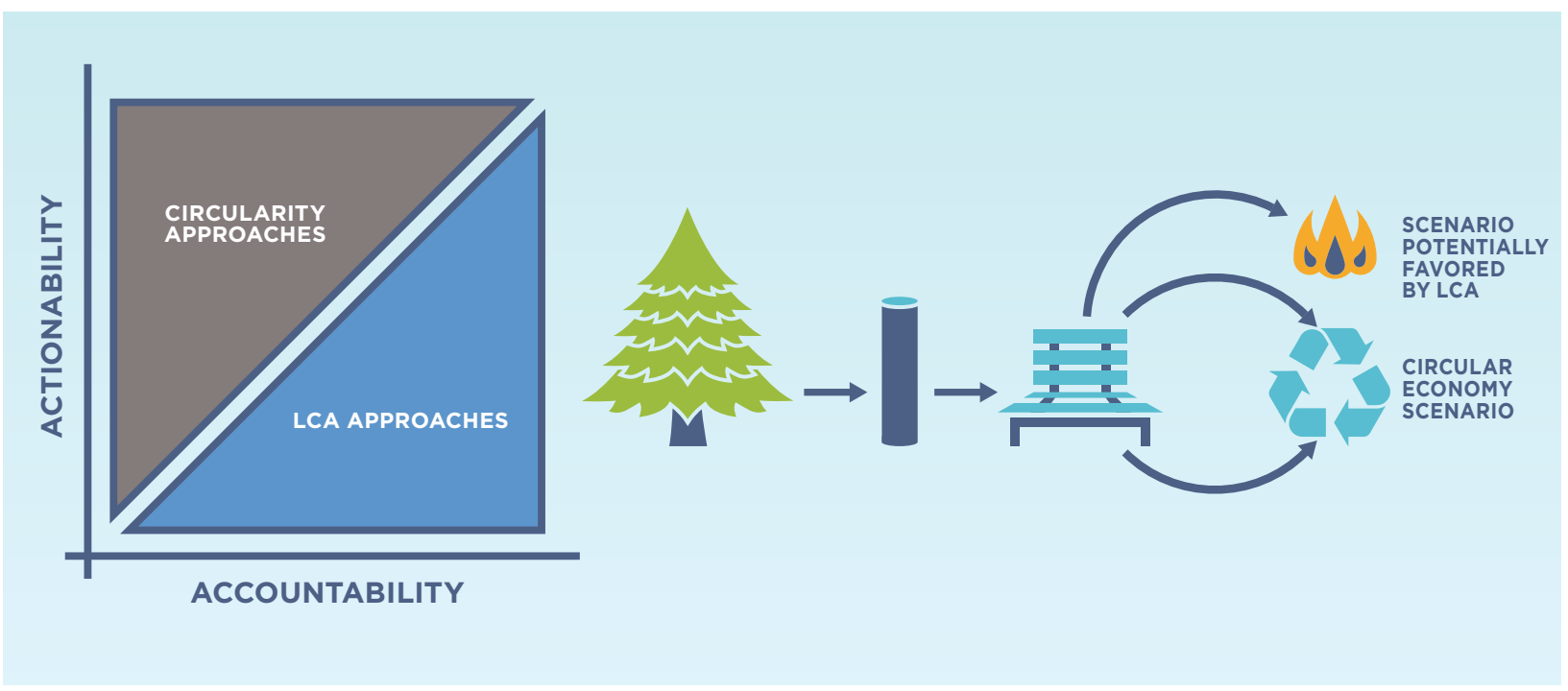

Figure 5: Life-cycle approaches (LCA) versus Circularity approaches

of economic value as a basis for measuring product circularity, using the ratio of recirculated economic value to total product value as a circularity metric (Linder et al., 2017). Other approaches base the metrics on an analysis of material flows and recycling rates (EMF, 2015). There is an urgent need to carefully review the available options for measuring circularity at the product level, and to find solutions to the varying weaknesses inherent in each of these options, in order to create a robust and valid circularity metric. In practice, for companies the measure of circularity is often limited to measuring recycling rates.

The material circularity index (EMF, 2015) is particularly interesting, because it accounts for both the recycled material embedded in the product and the recycled material at the end of life, while the accounting rules in LCA only allocate the benefits to one or the other, in order to avoid double counting. The method also assesses the intensity of use of the material per functional unit, which creates a close link with LCA methods and introduces a driver for reducing quantities of plastic use.

In a nutshell: LCA is an accounting method; it is required to assess the result and measure the trade-off between different environmental aspects. With eco-design, LCA is used to identify actions such as:
- reducing material reliance;

- $\quad$ replacing materials with more environmentally friendly alternatives;

- $\quad$ improving recycling rates or re-using products; and

- $\quad$ increasing product service life, favouring local material and production to cut down on logistics, etc.

These are the exact principles that are also favoured in the circular economy, when seen as a restorative approach. Circularity is a measure of actions. However, in some cases it is not the best option, and the diffuse loss of microplastics will not be solved based on the circularity principle.

As LCA is not a static methodology, it must evolve to integrate plastics and be complemented by the more actionable approach of circularity. Life-cycle thinking and the idea of the circular economy interact and feed off each other. The circular economy can be used for eco-design, while LCA can be used to evaluate circular economy projects. Sometimes, circular economy and life-cycle thinking can have conflicting views, for example, a circular economy encourages recycling (no questions asked), while in LCA energy recovery is sometimes more beneficial. 


\subsection{The materiality of plastic}

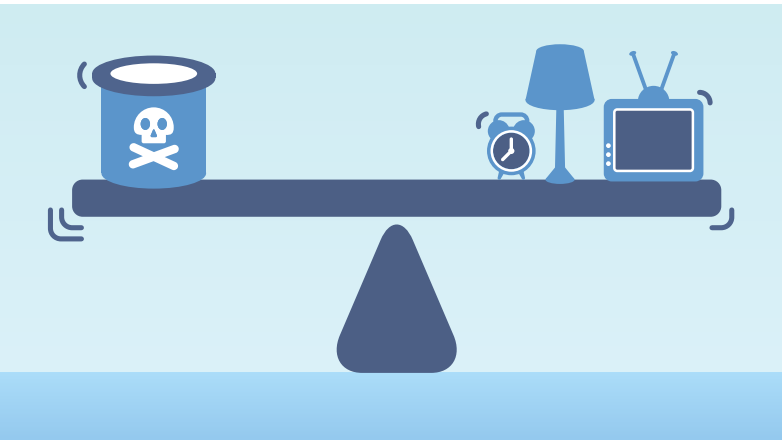

Figure 6: Ecodesign is about balancing the environmental impacts of products (marine plastic leakage in this report) with the value they bring to the society i.e. the materiality.

When designing a new product or packaging, a difficult trade-off lies in the balance between service provided and potential impacts. Is plastic necessary for the product or will it cause more harm than benefit? This is what we call the materiality of plastic, inspired by the materiality assessment commonly performed in CSR (corporate social responsibility) strategy setting and reporting (GRI, 2015).

At present, there is no fully quantitative methodology to assess the materiality of plastic, as the added value is greatly subjective. As with other materiality assessment methods (GRI, 2016), the assessment can be made in a qualitative way.

The materiality of plastic is a function of the magnitude of the added service (the functionality), and the intensity and duration of use from this service (Figure 7).

Accordingly, single-use plastics and overpackaging may be examples of when plastic should be reduced. Even though they may provide some services, their intensity and duration of use are almost null.

\section{Materiality of plastic allows us to determine when plastic is good to use and when it should be substituted.}

Although most of a product's impact could be caused elsewhere, avoided materials represent low-hanging fruits when it comes to impact savings.

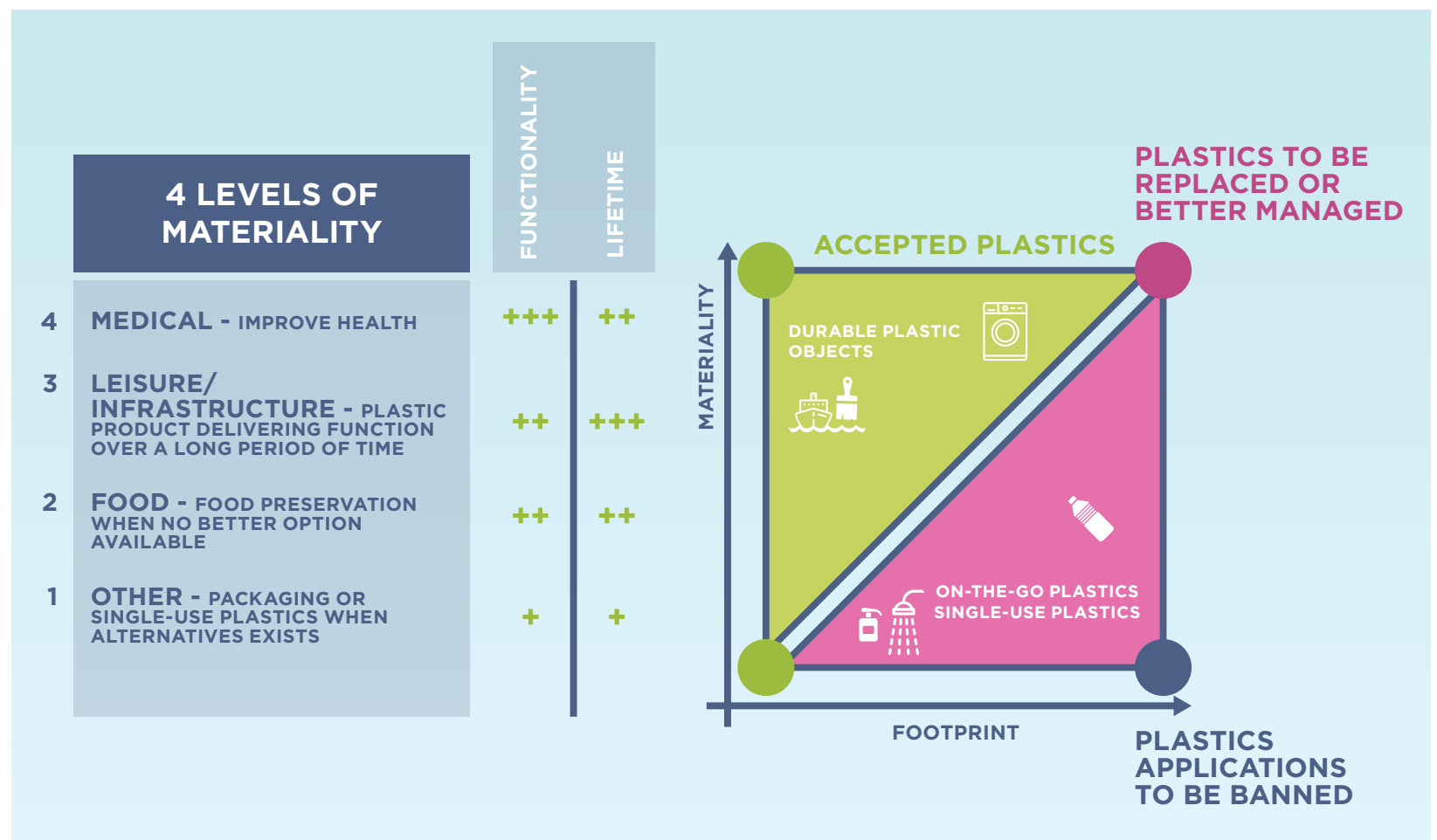

Figure 7: Materiality analysis for plastic as a tool to shape science-based decisions on when to use and when not to use plastics. 
Key contributing elements may be more difficult to reduce without altering the functionality of the product.

In essence, increasing the materiality of plastics means increasing their value and prioritising their usage for restrained applications only. Doing this would offer the double benefit of reducing marine plastic leakage as well as preserving fossil fuel resources.

Debates about plastics often lead to a dead end, usually resulting in plastic being labelled as having harmful negative impacts. However, totally eliminating plastics without sacrificing our living standards is impossible. In addition, the environmental cost of plastic in consumer goods is 3.8 times less than the alternatives materials that would be needed to replace 100 percent of plastic packaging (American Chemistry Council, 2016)

Materiality is thus an important tool to couple with circularity and LCA, in order to fix marine plastic leakage. There is no established way for making such an assessment to date, but a simple four-level qualitative scoring system could be easily deployed in order to map different plastic applications (see Figure 7). 


\section{The marine plastic footprint}

\subsection{Objectives}

The Marine Plastic Footprint is a concept intended to improve the understanding of marine plastic leakage and promote progress towards better integration of plastic leakage within the LCA framework.

\section{An inventory rather than an impact assessment methodology}

LCA methodologies are developed to assess environmental impacts, based on an inventory of different pollutants and emissions released into the environment. However, current knowledge of both macro- and microplastic impacts is still scarce (Woods et al., 2016) and needs to be further developed.

For this reason, the proposed methodology focuses on inventorying the different plastic fluxes leaking into the marine environment along the life cycle. The term Marine Plastic Footprint is derived from the idea of a carbon footprint: The total environmental footprint for a product or company is a measure of the direct (Scope 1) and indirect (Scopes 2 and 3) pollutant emissions associated with all activities in the product or company's life cycle. Products can be both goods and services.

\section{A life-cycle approach}

The Marine Plastic Footprint uses a full life-cycle approach, tackling waste generation during production and after use of the product, as well as other losses, including microplastic emissions during use, maintenance, or transport of the product.

\section{An accounting and actionable approach}

The Marine Plastic Footprint methodology is an accounting method intended to serve as a decision-making tool, as well as a way to standardise communication related to plastic use and leakage in industries. It follows the following objectives:

- Less leakage over the life cycle: It is necessary to consider the entire life cycle of a product or a company, including the leakage of microplastics, rather than focusing only on plastic's end-of-life.

- More materiality: Increasing the materiality of plastic is key to channelling plastic usage towards higher value-added applications, where it delivers all of its functionalities.

- $\quad$ More circularity: Increasing the circularity of the economy requires promoting the recycling of plastic waste and the use of recycled materials in new products to reduce our dependency on non-renewable resources.

\section{Clear objectives:}

- Less leakage

- More materiality

- More circularity

- No trade-offs

- No trade-offs: A marine plastic leakage assessment should fit within a holistic environmental framework, in order to measure all impacts in a coherent manner, avoiding risk, reducing plastic leakage, and considering impacts on other indicators, such as climate change. For example, a recycling rate of 100 percent is not necessarily ideal (e.g., if logistical constraints are too high). In some cases, energy recovery incineration can present a more interesting option in terms of global environmental performance. 


\subsection{Methodology}

The Marine Plastic Footprint methodology is based on the same high-level structure as LCA (ISO14040/44), with the difference that the impact assessment stage is not yet fully developed (see Figure 8).

\subsubsection{Goal and scope of the Marine Plastic Footprint methodology}

This methodology can be applied to products, companies, or countries, using the following key steps:

- Footprinting objective: Defining the study's objective can help determine the level of effort required to collect primary activity data, loss rates, and release rates. The generic approach, intended to compare leakage from different industries or study it at the country level, may rely on general and averaged data (such as that provided within this report). A more specific approach, targeting a specific industry or product and seeking to design solutions within this industry, will require refining the emission factors to encompass the drivers for progress in the output metric. As an illustration, marine plastic to improve the design of textiles should be based on a set of loss rates accounting for different fibres, yarns, wash parameters, etc. The challenge here is that the loss or release rates may not be readily available and may require further research or testing.

- Functional unit (FU) definition: The functional unit is the unit to which reference flows (see below) are accounted and the results expressed. A product's FU should be defined on a case-by-case basis, as in product LCA, with proper understanding of the product function. Refer to conventional LCA textbooks for detailed explanations. In general, company or country footprints are based on a one-year period.

- System boundaries: System boundaries should be chosen in accordance with

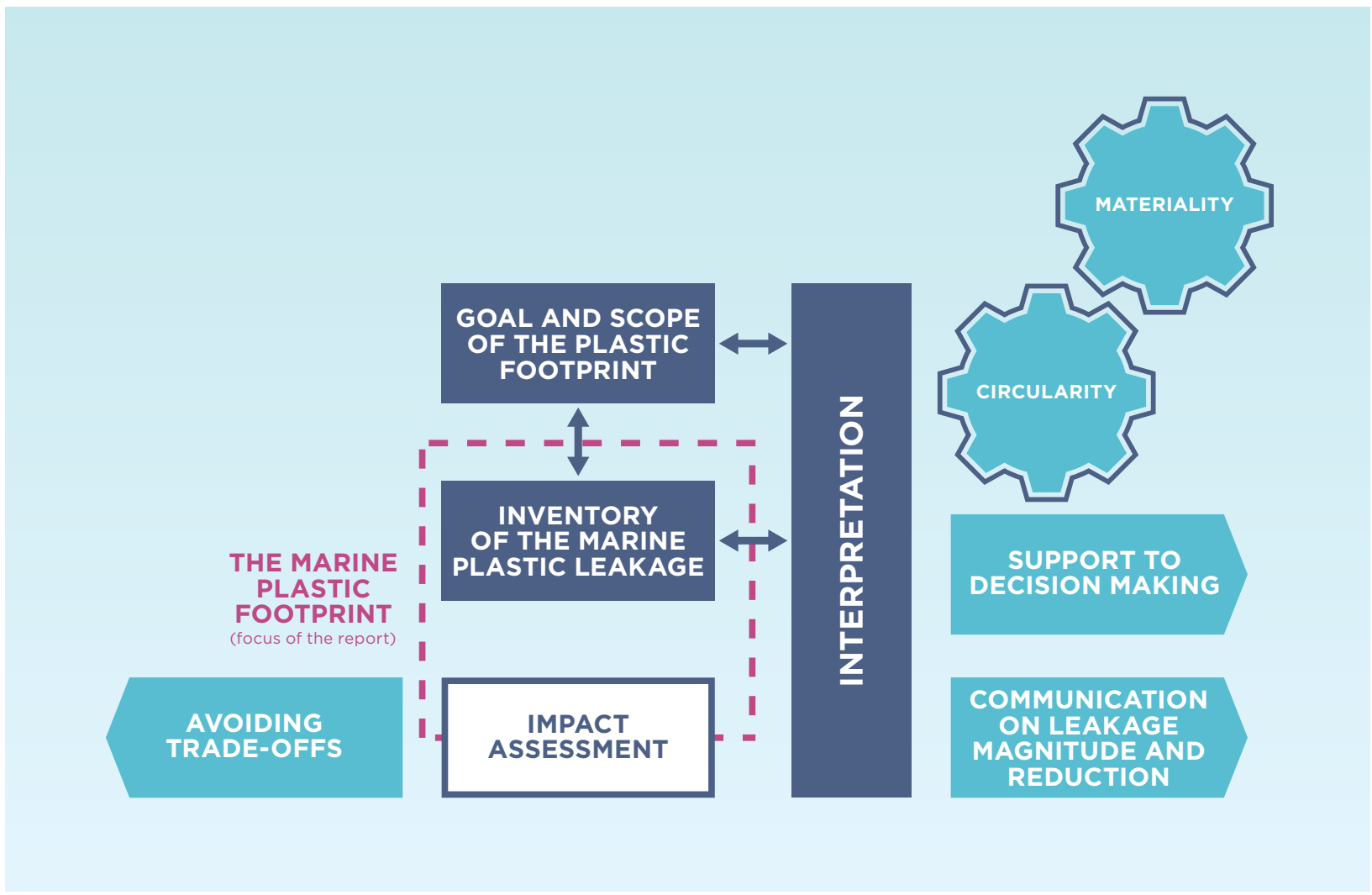

Figure 8: General framework of the Marine Plastic Footprint and relation with the LCA framework, as described in the IS014040/44 standards. 


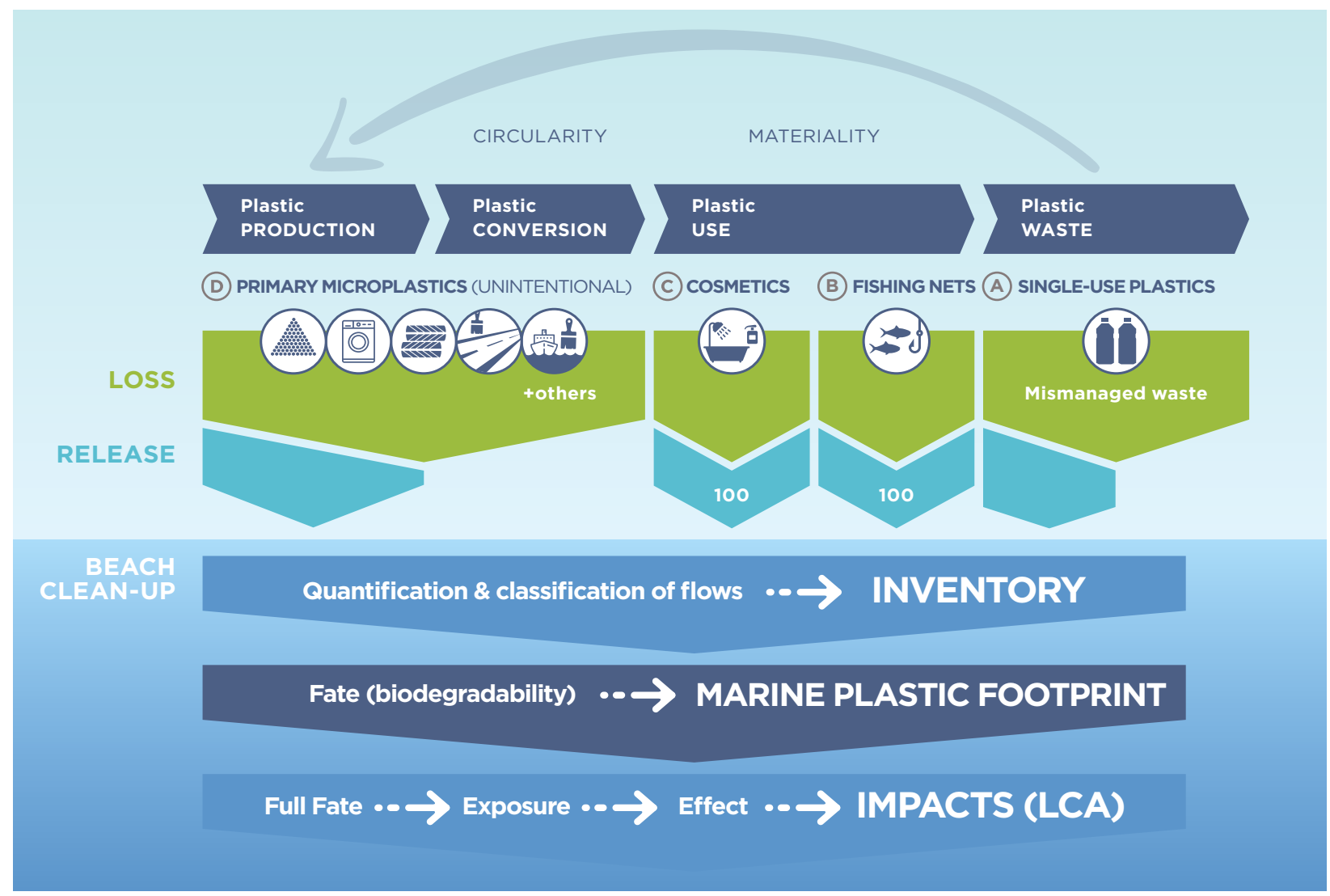

Figure 9: Generic system map and calculation methods for the Marine Plastic Footprint

the objective of the study and carefully documented. In the case of plastics, all sources of leakage are not well-known; thus, this document focuses on known sources, including mismanaged waste, textiles, tyres, cosmetics, and primary production pellets.

- Reference flows: These are the flows of material and energy needed to achieve the functional unit. It refers to the resources needed to make the product function during the different stages of its life cycle, corresponding to what you need to buy to make it work at the different stages of its life cycle.

The added value of this report is to detail the inventory data required to complement LCA with a Marine Plastic Footprint indicator.

\subsubsection{Inventory of the marine plastic leakage}

Figure 9 above summarises the footprinting methodology for the four categories of leakage ( $A, B, C$, and D), as described earlier in Figure 3.

For each of the leakage pathways, there are two main components:

- The loss, translated into a loss rate, is the quantity of plastics that leaves the product system, as the fraction of materials that is detached from the plastic product during manufacturing, use, or transport for microplastics or as mismanaged waste for macroplastics. Losses are specific to various sources and activities (e.g., the processes of losing all types of plastics into the environment through abrasion, weathering, or unintentional spills during production, transport, use, maintenance, or recycling of products containing plastics, littered plastic packaging, etc.). To this loss can be attributed a probability of it being transferred to the ocean, measured through the release rate. 


\section{Box 2: The challenge of estimating littering rates}

Littering rates are inherently difficult to estimate. While municipality cleaning operators' statistics may account for some, they do not include the fraction that "falls through the cracks" (i.e., the leakage). This fraction is, by definition, not measured and very difficult to estimate. A proxy of littering has been brought forward by Jambeck et al. (2015), using a level of two percent for all countries.

Litter studies are typically designed to count plastic items in specific places (Keep Australia Beautiful, 2017) or for defined types of littering, i.e., litter from roadways and interchanges (Cascadia Consulting Group Inc., 2005). Litter can also be inventoried by brand, though overall litter mass is rarely reported. Different littering rates have been brought forward, for example 6.2 percent of subjects in an experiment in the New York Metropolitan Area tended to litter (Krauss et al., 1978), and at rates up to 17 percent in various observation sites across America (Schultz, 2009).

The availability and distance of trash receptacles has been shown to be strongly predictive of littering behaviour (Schultz, 2009). The main sources of litter pollution are pedestrians and motorists (TOBIN Consulting Engineers, 2016). Littering practices are different depending on litter type (cigarette butts are often the most represented, followed by take-away packaging) (Keep Australia Beautiful, 2017). Jambeck et al. (2015) calculated that approximately two percent of national waste generation ends up as litter, based on an estimation of collected litter in the United States compared to overall generated municipal waste. However, this estimation is for all municipal waste and is not specific to plastic. Furthermore, it addresses only collected municipal waste compared to generated waste, and the uncollected part might not be negligible.

Finally, this estimation is based on United States statistics, with no variability from one country to another, while there might be substantial variations related to a country's level of development, education, etc.

For example, a recent study in Switzerland concluded a much smaller estimate for the littering rate: 0.1 percent (Boucher et al., 2019). Indeed, countries where litter studies have been compiled indicate that practices vary among settings (urban/rural), population age, and gender, as well as the availability and distance to trash receptacles.

This can indicate that there could be a very wide variability, depending on a country's level of development, existing waste management infrastructure, and citizens' education/awareness in terms of littering practice. To define littering rates differentiated by country, it is suggested, as a first step, collecting quantitative data through surveys and investigations on the generation of plastic litter mass, in order to have more primary data available to deduce any trend. For example, a sample of countries that differ in size, level of development, and waste management infrastructure could be studied. In a second step, based on the generated data, key driving parameters could be deduced to develop a model to predict the littering rate in all countries, based on a defined rationale. Driving parameters might include the human development index, the level of waste collection infrastructure, the share of urban/rural populations, etc. 
- The release, translated into a release rate, is the fraction of the loss that is ultimately released into the marine compartment. We include releases to waterways and rivers in this compartment, as the plastic may be transported to the estuary (Hurley et al., 2018).

As shown in Figure 9, the Marine Plastic Footprint also accounts for a first level of fate, which is based on the estimated degradation time of plastic in the environment. In other words, the plastic transport occurring from loss to release, as well as the transformation taking place after the release, is called the plastic fate. Similar to how multimedia models cover the impact pathway of chemicals emitted in the environment (e.g., USEtox (Rosenbaum et al. 2008)), fate represents the net result of mass flows across various compartments.

Note that this methodology only focussed on the plastic leakage in marine environment. Although leakage in other environmental compartments (e.g., soil, air) is also an important area of concern, this is beyond the scope of the present report. Other ongoing projects (e.g., the Plastic Leak Project) are in the process of filling this gap.

\subsubsection{Impact assessment}

The MARILCA (Marine Impacts in LCA) international working group was launched at the end of 2018 with the support of UN Environment Life Cycle Initiative, and Forum for Sustainability through Life Cycle Innovation (FSLCl). The objective of the working group is to foster the harmonized development of environmental impact pathways and characterization factors for marine impact assessment in life cycle assessment (LCA), in priority associated with marine litter, and more specifically with plastic.

This project will allow, in the short term, to coordinate and encourage the harmonious development of the user impact assessment methods, and, in the longer term, to integrate the marine impacts in LCA, including those from plastic litter, in a consistent approach that is compatible with the LCA framework. For an additional review of impact analysis methods for plastic, see Boucher et al. (2018).

\subsubsection{Interpretation and actionability}

The objective of the assessment should always be considered when interpreting the Marine Plastic Footprint results. Providing a global picture of a system or a region is different from launching a specific eco-design project. The user should keep in mind that footprinting is an iterative process, starting with a generic approach and refining when necessary. The Marine Plastic Footprint allows to determine whether the plastic leakage is driven by the loss rate, i.e., is product-dependent, or by the release rate, i.e., infrastructure-dependent, or both, and thus guide the solution towards different types of strategies.

The methodology developed in this report splits loss rates and release rates into two distinct stages. Refining the data for one or the other of these stages will depend on the objective of the study.

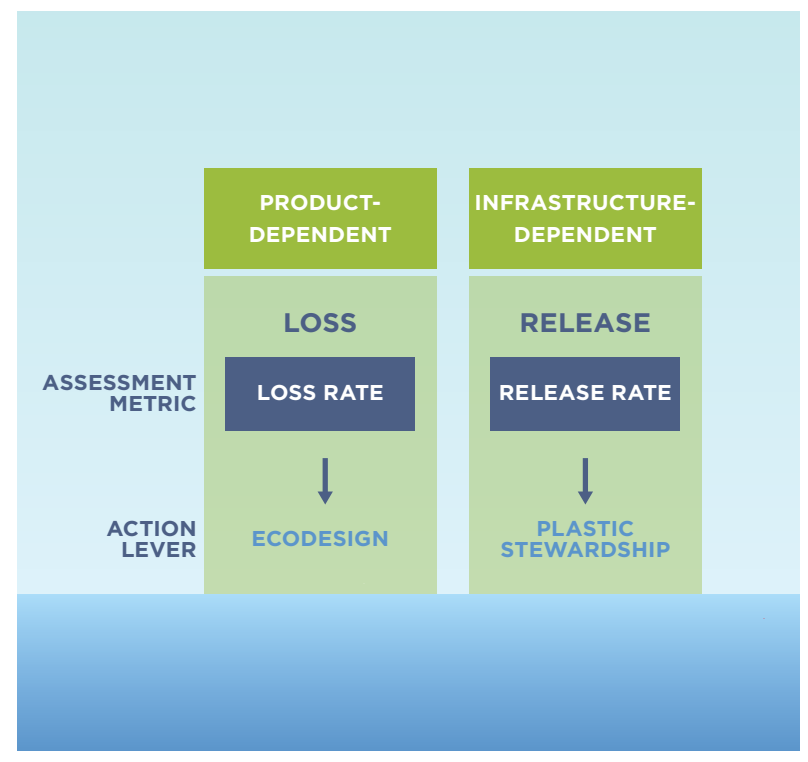

Figure 10: Loss rates and release rates are, respectively, a measure of the inherent contributions of the product and infrastructure to the leakage. 


\section{Modelling marine leakage from plastic waste (macroplastics)}

Modelling the leakage consists of three main steps: (1) estimating the mass of plastic ending up as waste, (2) quantifying the fraction of mismanaged waste, and (3) estimating the release from the mismanaged waste fraction (see Figure 11).

Macroplastic waste mass (step 1) is mainly obtained through data collection and is available through industrial/national statistics. The calculation methods for steps 2 and 3 are detailed in sections 4.1 and 4.2 below.

\subsection{Calculation of the mismanaged waste fraction (the "loss")}

Knowing the amount of mismanaged waste is the first step towards estimating the quantity of plastic that is likely to be lost and eventually released into rivers and, ultimately, the oceans. Jambeck et al. (2015) define mismanaged waste as "material that is either littered or inadequately disposed. Inadequately disposed waste is not formally managed and includes disposal in dumps or open, uncontrolled landfills, where it

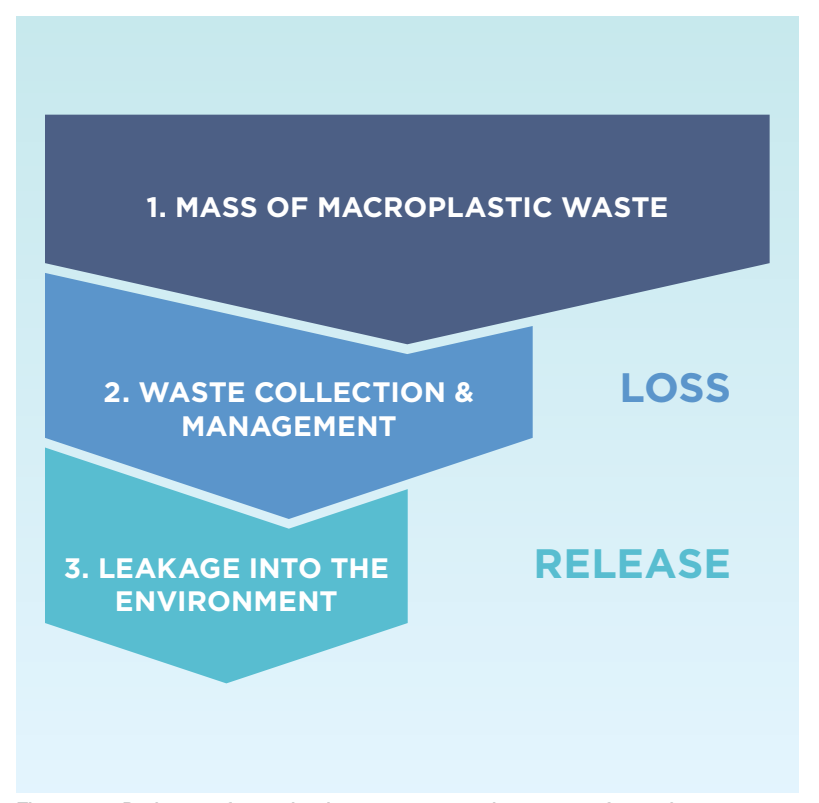

Figure 11: Pathways from plastic waste generation to transfer to the ocean is not fully contained." This definition is extended by also considering waste to be mismanaged when its collection or disposal route creates a chance for it to be lost and potentially released into the environment. This includes waste that is not appropriately transported, collected, or stored.

Figure 12 details the mismanaged waste pathways of macro waste.

- Uncollected (behavioural) waste, from:

- Littering is the incorrect disposal of small, one-off items such as: throwing a cigarette, dropping a crisp packet or a drink cup. These items are likely to end up on the road or sidewalks and may not be collected by municipal street cleaning. It is common in all parts of the world, irrespective of the income level (Velis et al., 2017).

- $\quad$ Fly tipping: In low- and middle-income countries, where waste collection systems may be inadequate, leaving householders no better option than to dispose of their waste by dumping/ tipping it in a location within or close to the community (Velis et al., 2017), fly-tipping is the deliberate disposal of larger quantities of litter in the environment without any specific location. This could be anything from a single bag of rubbish to a large sofa to a broken refrigerator, e.g., accumulating on the road side or remote places.

- Dumping: Dumping is similar to flytipping as it consists of the deliberate disposal of litter, but in a particular area that is not controlled or managed (i.e., not spread throughout the countryside as for fly-tipping). Dumping can be 
the result of the formal and informal collection sector.

- Disposal in the sewage system: When waste is disposed in a sewage system, larger items will normally be captured by wastewater treatment, where such facilities exist. However, materials can bypass systems and enter waterways when rain levels exceed sewage treatment facility handling capacities.

- Burning: Burning waste without proper fume treatment releases potentially toxic emissions and greenhouse gases. Burned waste does not contribute to macroplastic debris that can leak into the environment, although it can induce microplastics formation.

- Collected (structural) waste, from:

- Dumping: Same as for uncollected waste.

- Non-sanitary landfills: In transition countries, landfills planned as controlled engineered sites can end up being mismanaged (e.g., light plastic waste can escape through wind or runoff) (Velis et al., 2017).

- Burning (same as for behavioural waste): Collected waste can be burned, in which case macroplastics do not leak into the environment, but toxins may be released in the air, soil, and/or water.

Increasing the share of well-managed waste (i.e., formally collected waste that is treated in sanitary landfills, incinerators, or recycling facilities) would have an important influence on reducing behavioural and structural mismanaged waste. According to the Ocean Conservancy, improving current waste-management systems to increase collection and plug post-collection leakage could reduce macroplastic leakage by nearly 50 percent (Mckinsey Center and Ocean Conservancy, 2015). Overall, uncollected and collected waste is responsible for 75 percent and 25 percent of the land-based macroplastic leakage, into the marine environment respectively (McKinsey Center and Ocean Conservancy, 2015).

The mismanaged waste index (MWI) is calculated as the percentage of total waste in a country that is mismanaged (total waste $=$ waste produced in a country - exported waste + imported waste).

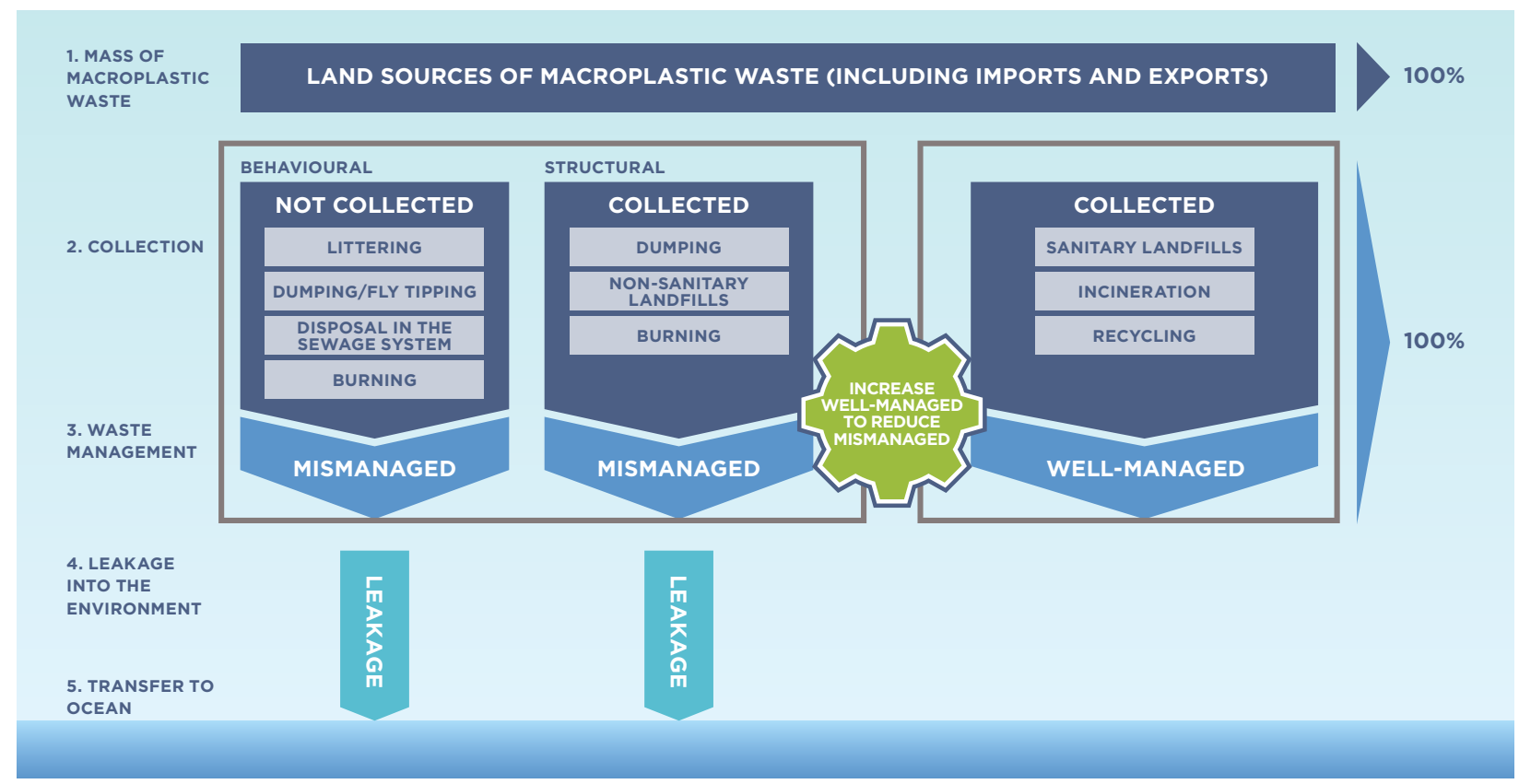

Figure 12: Mismanaged waste pathways 


\section{(1) Calculation of the Mismanaged Waste Index (MWI)}

MWI $=\frac{(\text { Mismanaged waste in the country) }}{\text { (Total waste in the country) }}$

The equation for calculating MWI for packaging and non-packaging waste is proposed below:

$$
\mathrm{MWI}_{\text {pack }}=\mathrm{NonCol}+\text { ColMisM }+ \text { Litt }
$$

$\mathrm{MWI}_{\text {non-pack }}=\mathrm{NonCol}+$ ColMisM

\section{(2) Estimation of the littering rate (Litt)}

The littering rate is difficult to estimate (see Box 2). While no better data is available, it can be estimated that the littering rate is two percent for plastic land sources, based on Jambeck et al. (2015), keeping in mind the limitations mentioned in Box 2.

The littering rate is estimated by a default of two percent for packaging, single-use plastic, or any on-the-go plastic waste (Jambeck et al., 2015), and $O$ percent for other more durable types of plastic waste. More specific values can be used if available.
(3) Calculation of the non-collected fraction (NonCol)

\author{
NonCol $=$ \\ FlyTipping + Dumping \\ + Disposed in the sewage system
}

(4) Calculation of the mismanaged plastic waste
quantities (MPW)

$$
\begin{gathered}
\mathrm{MPW}=\mathrm{TPW}^{*}(\text { NonCol+ColMisM }) \\
+\mathrm{PPW}^{*} \mathrm{Litt}
\end{gathered}
$$

\subsection{Calculation of the release into oceans and waterways (the "release")}

Not all mismanaged waste is leaking into the marine environment; the fraction of mismanaged waste that does eventually reach the ocean is called the release rate.

Release rates are complicated to estimate, as release pathways are poorly understood; therefore, these rates provide indications rather than estimations. The most commonly used release rate estimate to date is 25 percent, published by Jambeck et al. (2015), but here the publication presents three possible values: 15 percent, 25 percent, and 40 percent.

Table 1: Differences in waste management following income levels.

\begin{tabular}{lllll}
\hline & HIC & UMI & LMI & LI \\
\hline Sanitary Landfill & Managed & Managed & Managed & Managed \\
\hline Incineration & Managed & Managed & Managed & Managed \\
\hline Unspecified Landfill & Managed & Mismanaged & Mismanaged & Mismanaged \\
\hline Open Dump & Mismanaged & Mismanaged & Mismanaged & Mismanaged \\
\hline Sanitary Landfill Gas Plant & Managed & Managed & Managed & Managed \\
\hline Discharge in Waterways & Mismanaged & Mismanaged & Mismanaged & Mismanaged \\
\hline Unaccounted For & Mismanaged & Mismanaged & Mismanaged & Mismanaged \\
\hline $\begin{array}{l}\text { Key: HIC: High-Income Country; UMI: Upper-Middle-Income Country; LMI: Low-Middle-Income Country; LI: Low- } \\
\text { Income Country. }\end{array}$ & & & \\
\hline
\end{tabular}


Table 2: List of the different parameters used for the calculation of the leakage.

\begin{tabular}{|c|c|c|c|c|}
\hline & Description & Unit & $\begin{array}{l}\text { Generic value, } \\
\text { if available }\end{array}$ & Reference \\
\hline MWI & Mismanaged Waste Index & $\%$ & & \\
\hline Leak $_{\text {waste }}$ & Total leakage from mismanaged waste & Tonnes or kg & & \\
\hline NonColl & Non-collected fraction & $\begin{array}{l}\text { Tonnes or } \mathrm{kg}(\text { or } \% \\
\text { of total waste) }\end{array}$ & & \\
\hline ShareP & $\begin{array}{l}\text { Percentage of plastic in the waste } \\
\text { stream }\end{array}$ & $\%$ & & \\
\hline ColMisM & $\begin{array}{l}\text { Collected fraction inadequately } \\
\text { managed }\end{array}$ & $\begin{array}{l}\text { Tonnes or } \mathrm{kg}(\text { or } \% \\
\text { of total waste) }\end{array}$ & & \\
\hline Litt & Littering rate & $\%$ & $2 \%$ & (Jambeck et al., 2015) \\
\hline MPW & Mismanaged plastic waste & $\begin{array}{l}\text { Tonnes or } \mathrm{kg}(\text { or } \% \\
\text { of total waste) }\end{array}$ & & \\
\hline TPW & Total plastic waste & Tonnes or kg & & \\
\hline$P P W$ & Plastic packaging waste & Tonnes or kg & & \\
\hline Leak & Leakage & Tonnes or kg & & \\
\hline$R \boldsymbol{R}$ & Release rate & $\%$ & & \\
\hline $\boldsymbol{R}_{\text {high }}$ & Highest value expected for release rate & $\%$ & & \\
\hline Val & $\begin{array}{l}\text { Residual value of the waste on the } \\
\text { market }\end{array}$ & Price per mass & & \\
\hline$V a I_{\max }$ & $\begin{array}{l}\text { Maximum residual value for any plastic } \\
\text { on the market }\end{array}$ & Price per mass & & \\
\hline
\end{tabular}

Factors such as cultural behaviours (e.g., littering habits), climatic conditions (e.g., effect of rain or wind on dispersal of waste from dumpsites), geographic specificities (e.g., distance to shore and waterways), and economic considerations (residual value of the waste) will have a significant influence on these release rates.

Table 3 lists release rates obtained or extrapolated from different literature sources. It shows that release rates are, in most cases, one order of magnitude smaller than the 25 percent default assumption mostly used in current reports.

Field studies and a more in-depth understanding of the release pathways are needed in order to fine tune these numbers. This report proposes a hybrid approach by defining a default range of leakage and then using key parameters to make the chosen release rate vary within this range. The objective here is to develop a method that allows progress on measurement, even if it does not necessarily provide an accurate assessment of the actual leakage.

Two approaches are proposed:

Approach 1: For country assessment (such as the Baltic case study presented later in this report), two parameters to calibrate the release rate are used (see Figure 13):

- The distance to shore: Through GIS analysis, the distance to the nearest coast was obtained for each locality (village/town/ city) of a country located within a watershed communicating with the Baltic Sea. Then, a formula was created to account for the

Table 3: Release rates described in the literature (explicit) or extrapolated from the cited study.

\begin{tabular}{ccccc} 
Release Rates & Scope & Waste Generation Area & Type & Source \\
\hline $15 / 25 / 40 \%$ & Global & Coastal & Explicit & Jambeck et al., 2015 \\
\hline $10 \%$ & Global & Global & Explicit & UN Environment, 2018 \\
\hline $3.2 \%$ & Global & Inland & Extrapolated & Lebreton et al., 2017 \\
\hline $2.9 \%$ & Global & Inland & Extrapolated & Schmidt et al., 2017 \\
\hline
\end{tabular}




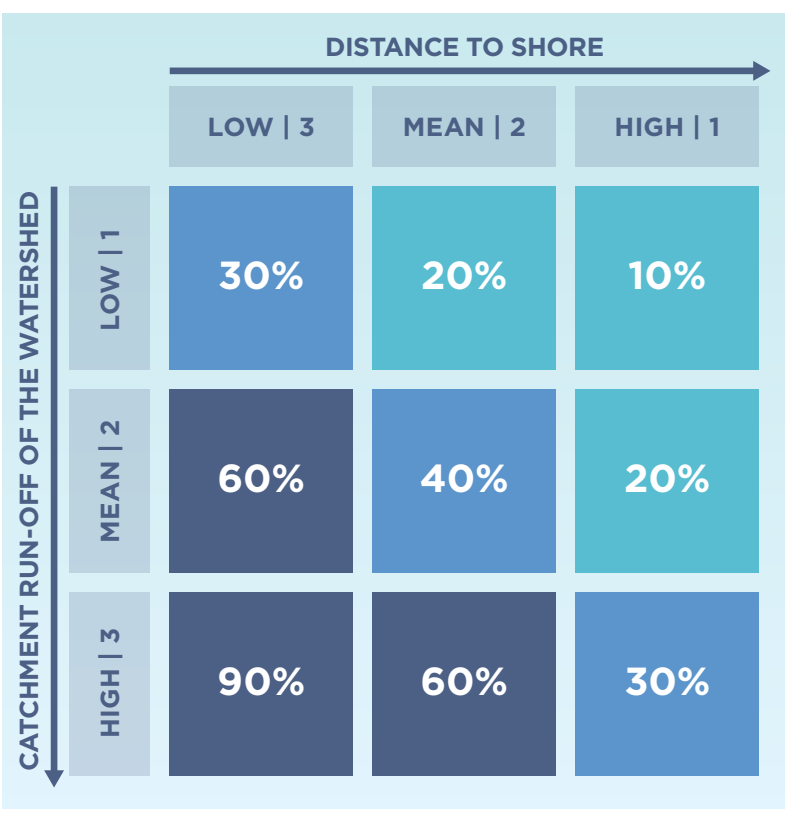

Figure 13: Release rates matrix for country assessment. Distance classes are $10 \mathrm{~km}$ (low), between 10 and $50 \mathrm{~km}$ (mean), and above $50 \mathrm{~km}$ (high). Run-off categories are $<0.4 \mathrm{~mm} / \mathrm{day}^{-1} \mathrm{~km}$ (low), between 0.4 and 0.8 $\mathrm{mm}$ day $^{-1}$ (mean), and $>0.8 \mathrm{~mm}$.day ${ }^{-1}$ (high).

leakage of a settlement living at different distances from the coast. The distance classes chosen in our study are $<10 \mathrm{~km}$ (low), between 10 and $50 \mathrm{~km}$ (mean), and above $50 \mathrm{~km}$ (high).

\section{- The catchment run-off of the watershed:}

WWF's HydroSHEDS model was used to map watersheds. Additionally, open-source run-off data was obtained through Lebreton et al.'s (2017) article "River plastic emissions to the world's oceans," which includes run-off data for each basin. The run-off categories chosen for our study are $<0.4$ mm.day ${ }^{-1} \mathrm{~km}$ (low), between 0.4 and 0.8 mm.day ${ }^{-1}$ (mean), and $>0.8$ mm.day $^{-1}$ (high)
The following equation can be used to calculate the release rate in a country:

$$
\mathrm{RR}=\mathrm{RR}_{\text {factor1 }} * \mathrm{RR}_{\text {high }}
$$

Approach 2: For industry or product assessment, one parameter is used, the residual value of the plastic waste, to fine tune the release rate, thus creating a link between the footprinting approach and the circular economy concepts.

Leakage to the environment depends highly on the plastic's residual value and the probability of it being collected through the informal waste collection system, even if it has not been properly collected or treated through the formal waste collection and treatment pathway.

\section{Definition:}

The residual value of a product or polymer can be assumed to be equal to the market price, or it can be calculated as a function of product homogeneity, time to collect, and resale price.

- The amount of mismanaged macroplastic waste depends on the country and the type of waste considered. The Ocean Conservancy (2015) classifies plastic waste by its value and relates this to the likelihood that it will be picked up by a waste picker. Indeed, among all the land-based inadequately managed macroplastic waste, an informal system of waste picking of high residual value plastic waste does exist. About

Table 4: Description of the different release rates used throughout the report.

\begin{tabular}{llccc} 
& Description & Unit & Generic value, if available & Reference \\
\hline $\mathbf{R} R$ & Release rate & $\%$ & $15 / 25 / 40 \%$ & Jambeck et al., 2015 \\
\hline $\mathbf{R}_{\text {factor }}$ & $\begin{array}{l}\text { Release rate factor obtained from } \\
\text { the release rate matrix Figure } 13\end{array}$ & $\%$ & $25 \%$ & This report \\
\hline $\mathbf{R} \mathbf{R}_{\text {high }}$ & Highest value of release rate chosen & $\%$ & $25 \%$ & Jambeck et al., 2015 \\
\hline
\end{tabular}


20 percent of the municipal plastic waste stream has enough value to incentivise waste pickers to collect it (McKinsey Center and Ocean Conservancy, 2015).

- The generic approach evaluates which share of each mismanaged waste pathway (waste disposed in dumps, landfills in lowincome and lower-middle-income countries, littered waste, and waste thrown into the sewage system) leaks into the environment, depending on the polymer's residual value. It is estimated that 80 percent of waste dumped or disposed in landfills has low residual value (e.g., thin films), and 20 percent has a high residual value (e.g., PET, HDPE) (McKinsey Center and Ocean Conservancy, 2015). For low residual value plastics, it is estimated that 100 percent of the waste dumped or disposed in poorquality landfills leaks into the environment, while only 10 percent of high residual value plastic does (90 percent is assumed to be collected by waste pickers). For littered waste, it is assumed that 100 percent leaks into the environment, but only 10 percent of waste disposed in the sewage system leaks (90 percent is assumed to be removed during the wastewater treatment system). All these expert judgements can be refined if higher-quality specific data is available.
The following equations can be used to calculate the release rate for an industry or product:

\section{Generic approach:}

$$
\mathrm{RR}=\mathrm{RR}_{\text {factor2 }} * \mathrm{RR}_{\text {high }}
$$

With $R_{\text {factor2 }}$ as a function of the residual value of plastic as defined in Table 5, considering two categories of plastic (low and high value plastics).

\section{Specific approach:}

A specific approach is also possible when the economic values of different plastic wastes considered are available for a given market or country where the Marine Plastic Footprint is being calculated.

$$
\mathrm{RR}=\mathrm{RR}_{\text {high }} *\left(1-\mathrm{Val} / \mathrm{Val}_{\text {max }}\right)
$$

\begin{tabular}{|c|c|c|c|c|}
\hline & Description & Unit & Generic value, if available & Reference \\
\hline$R R$ & Release rate & $\%$ & & \\
\hline $\boldsymbol{R} \boldsymbol{R}_{\text {factor2 }}$ & $\begin{array}{l}\text { Release rate correction } \\
\text { for high/low-value } \\
\text { plastics }\end{array}$ & $\%$ & $\begin{array}{l}\text { Low-value plastics (e.g., non-recyclable, } \\
\text { thin films) } \\
80 \% \\
\text { High-value plastics (e.g., recyclable, } \\
\text { PET, HDPE) } \\
20 \%\end{array}$ & $\begin{array}{l}\text { Mckinsey Center and } \\
\text { Ocean Conservancy, } 2015\end{array}$ \\
\hline $\boldsymbol{R}_{\text {high }}$ & $\begin{array}{l}\text { Highest value of release } \\
\text { rate chosen }\end{array}$ & $\%$ & $25 \%$ & Jambeck et al., 2015 \\
\hline Val & $\begin{array}{l}\text { Economic value of the } \\
\text { plastic waste in the } \\
\text { market (defined in the } \\
\text { system boundaries) }\end{array}$ & $\begin{array}{l}\text { Monetary } \\
\text { value }\end{array}$ & & \\
\hline $\mathrm{Val}_{\max }$ & $\begin{array}{l}\text { Maximum value } \\
\text { achieved by a category } \\
\text { of plastic waste in the } \\
\text { market (defined in the } \\
\text { system boundaries) }\end{array}$ & $\begin{array}{l}\text { Monetary } \\
\text { value }\end{array}$ & & \\
\hline
\end{tabular}

Table 5: Release rates and the economic value of plastic waste. 


\subsection{Calculating the leakage from macro-plastic waste}

The mass of ocean macroplastics, i.e., plastics transferred to the ocean, depends on the mass of macroplastic waste, generated at the defined geographical level which is then multiplied by the defined release rate $R R$, leading to a total leakage Leakwaste.

\section{(5) Calculation of the leakage (Leak)}

$$
\text { Leak }_{\text {waste }}=\mathrm{MPW}^{*} \mathrm{RR}
$$

Once the above equations are calculated using best available data and inputted to a GIS environment, it is possible to visually represent the possible Marine Plastic Footprint of a given area on a digital map. 


\section{Modelling marine leakage from primary microplastics}

\subsection{Generic loss rates and release rates of microplastics}

The leakage rate of microplastics (quantity of plastic involved ${ }^{*}$ loss rate ${ }^{*}$ release rate) is based on a compilation of current literature; the intention is to provide a mean value and lowerhigher bounds, as synthetized in Table 6. Many parameters could influence these leakage rates. These parameters are listed in Table 6 below, but without linking to the effect on the loss rates. For each of the sources, a specific sub-FU is defined.

Data provided in Table 6 constitute a key output of this report, as it provides generic loss and release rates that can be used to calculate a Marine Plastic Footprint, at country, company or product level. A generic per-capita loss is also reported, as an illustration of the importance of the different sources. The eight sources listed in the table correspond to the most frequently cited and/or most contributive sources of microplastics, as decribed in current literature (Boucher and Friot, 2017).

\subsubsection{Generic loss rates for seven main sources}

Loss rates from textile shedding and tyre dust have been specifically computed for this study based on the compilation of multiple studies (Appendix 1 and 2).

For other sources, presumably less contributive and/or supported by less datapoints, references were directly extracted from the literature and reported in the right column of Table 6 .

\subsubsection{Generic release rates for three main pathways}

Sections 5.2 and 5.3 provide details on calculations for the two main sources of marine microplastic leakage: textiles and tyres. The three pathways considered leading from the loss to the release in water are wastewater treatment plants (WWTP), road run-off (i.e., when roads are washed by water during rain events) and direct release (when plastic is directly discarded in water)

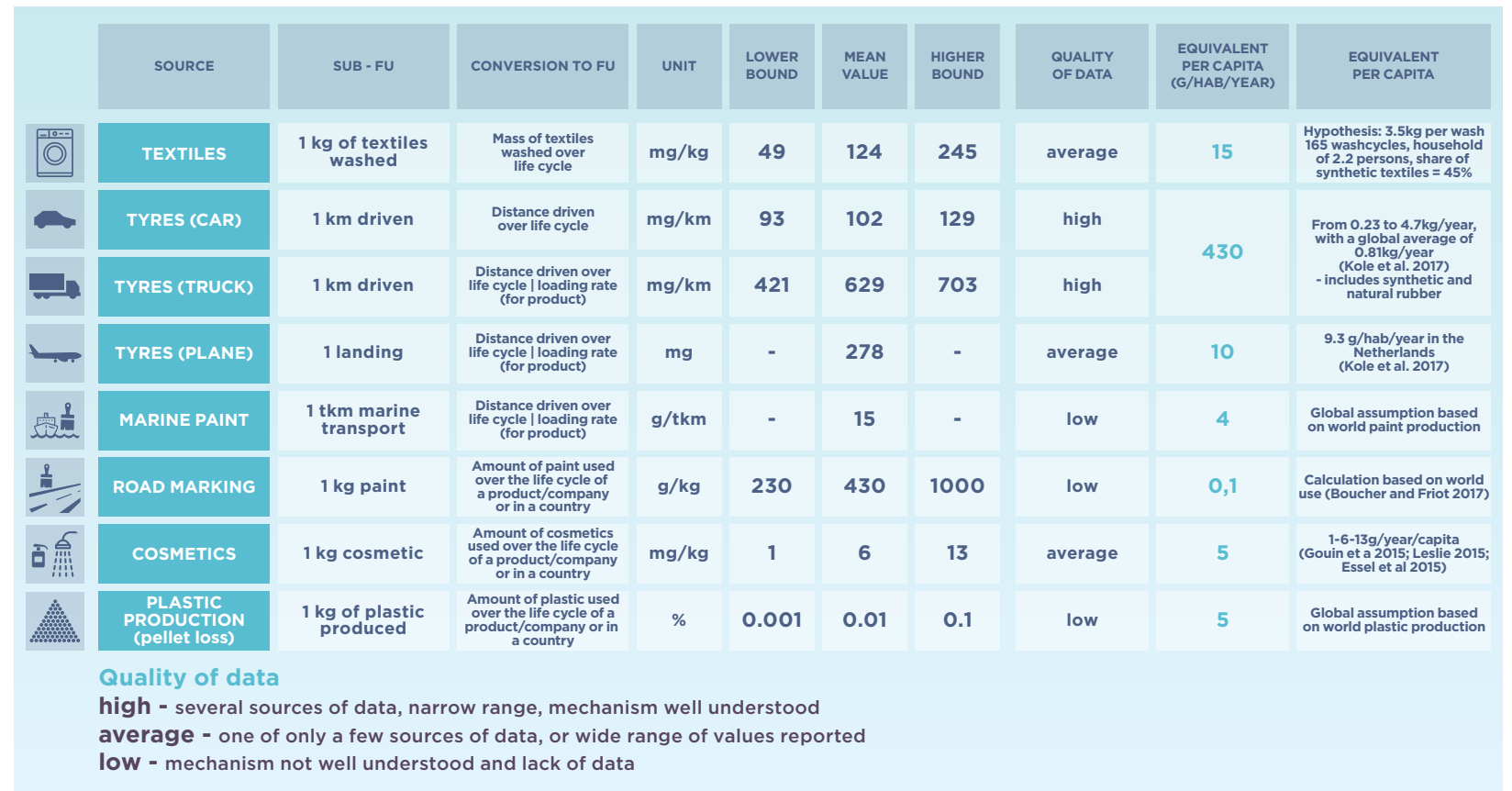

Table 6: Generic Loss Rates (LR) for seven main plastic sources 


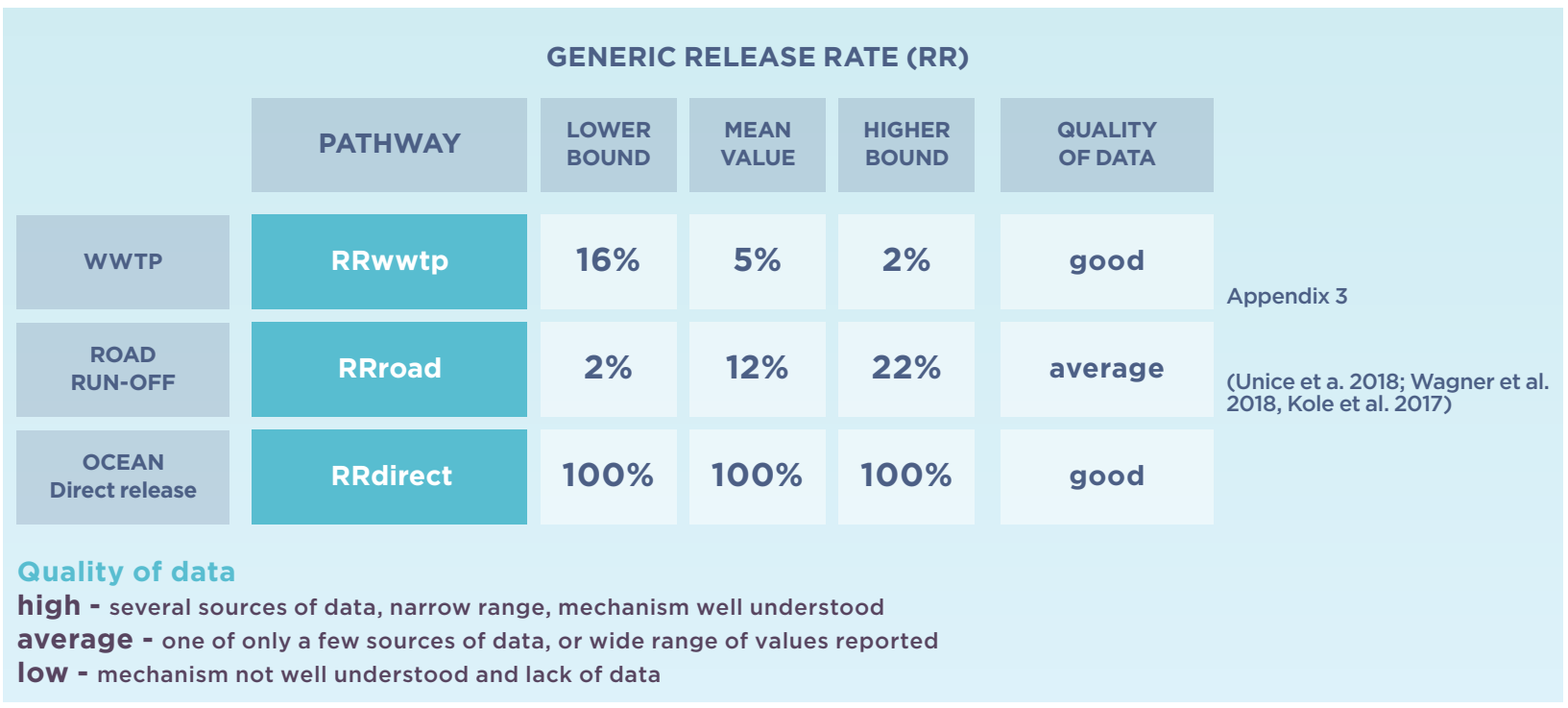

Table 7: Generic Release Rates (RR) for three main marine leakage pathways.

\subsection{Calculation route for textile leakage}

Synthetic microfibres, widely used in the textile and fishing industries, have been identified as one of the main sources of microplastic pollution in the marine environment (Carr, 2017). Textile fibres can be released into the environment via household laundering in washing machines, an can flow into sewage systems and ultimately into the oceans (Boucher and Friot, 2017; EUNOMIA, 2016).

\subsubsection{Relevance of the source}

Many studies have identified microfibres as the dominant fraction among microplastics in samples collected around the world, including in surface and subsurface seawater, beach sediments, estuarine sediments, coastal sediments, and deep-sea sediments (Salvador Cesa et al., 2017). These findings confirm the existence of clear pathways that allow primary microplastics to reach the oceans and seas.

Table 8: Take-home message of the main factors favoring the release of textile fibers.

\begin{tabular}{|c|c|c|}
\hline Type of Fabric & O & $\begin{array}{l}\text { Microfibre polymers with the highest loss rate are polyester, acrylic, and polypropylene. } \\
\text { Garments that are made of } 100 \text { percent of these synthetic materials have a higher loss rate } \\
\text { than cotton-synthetics blends (Napper and Thompson, 2016). } \\
\text { The influence of knitting techniques on fibre release is still unclear. For some authors there } \\
\text { is no statistical difference between different knitting techniques on the release of fibres } \\
\text { from polyester (Hernandez et al., 2017) especially in urban areas. There is good reason to } \\
\text { consider synthetic textiles a major source of microplastic fibers, and it will not diminish } \\
\text { since the use of synthetic fabrics, especially polyester, continues to increase. In this study } \\
\text { we provide quantitative data regarding the size and mass of microplastic fibers released } \\
\text { from synthetic polyester, other studies have observed that woven polyester releases the } \\
\text { most fibres, compared to knit polyester (De Falco et al., 2018). }\end{array}$ \\
\hline Age of Fabric & o & $\begin{array}{l}\text { Fibre shedding changes over time. Older garments release about 20-25 percent fewer fibres } \\
\text { than new ones (Hartline et al., n.d.; Pirc et al., 2016), and after five to } 10 \text { washes, the loss rate } \\
\text { can be considered stabilised (Browne et al., 2011; Pirc et al., 2016). }\end{array}$ \\
\hline $\begin{array}{l}\text { Washing w/o } \\
\text { Detergent }\end{array}$ & O & $\begin{array}{l}\text { The use of detergent (liquid or powder) causes a higher release of fibres compared to } \\
\text { washing without detergent (De Falco et al., 2018; Hernandez et al., 2017), while addition of a } \\
\text { softener (conditioner) may have a mitigating effect and reduce fibre loss by } 35 \text { percent (De } \\
\text { Falco et al., 2018). Mechanical stress must also be considered. }\end{array}$ \\
\hline $\begin{array}{l}\text { Washing Machine } \\
\text { Settings }\end{array}$ & O & $\begin{array}{l}\text { Top-loading machines produce } 5-7 \text { times more shedding than front-loading machines } \\
\text { (Hartline et al., n.d.; Napper and Thompson, 2016). } \\
\text { Temperature is not considered as a variable, assuming that all washing is done at } 30-40^{\circ} \mathrm{C} \text {, } \\
\text { which is usually recommended for synthetic fabrics, and taking into consideration that } \\
\text { nowadays higher temperatures are generally avoided thanks to a stronger "eco-awareness" } \\
\text { and more effective detergents. } \\
\text { Tumble drying also influences fibre loss rates, which can be } 3.5 \text { times higher than during } \\
\text { washing (Pirc et al., 2016). }\end{array}$ \\
\hline
\end{tabular}




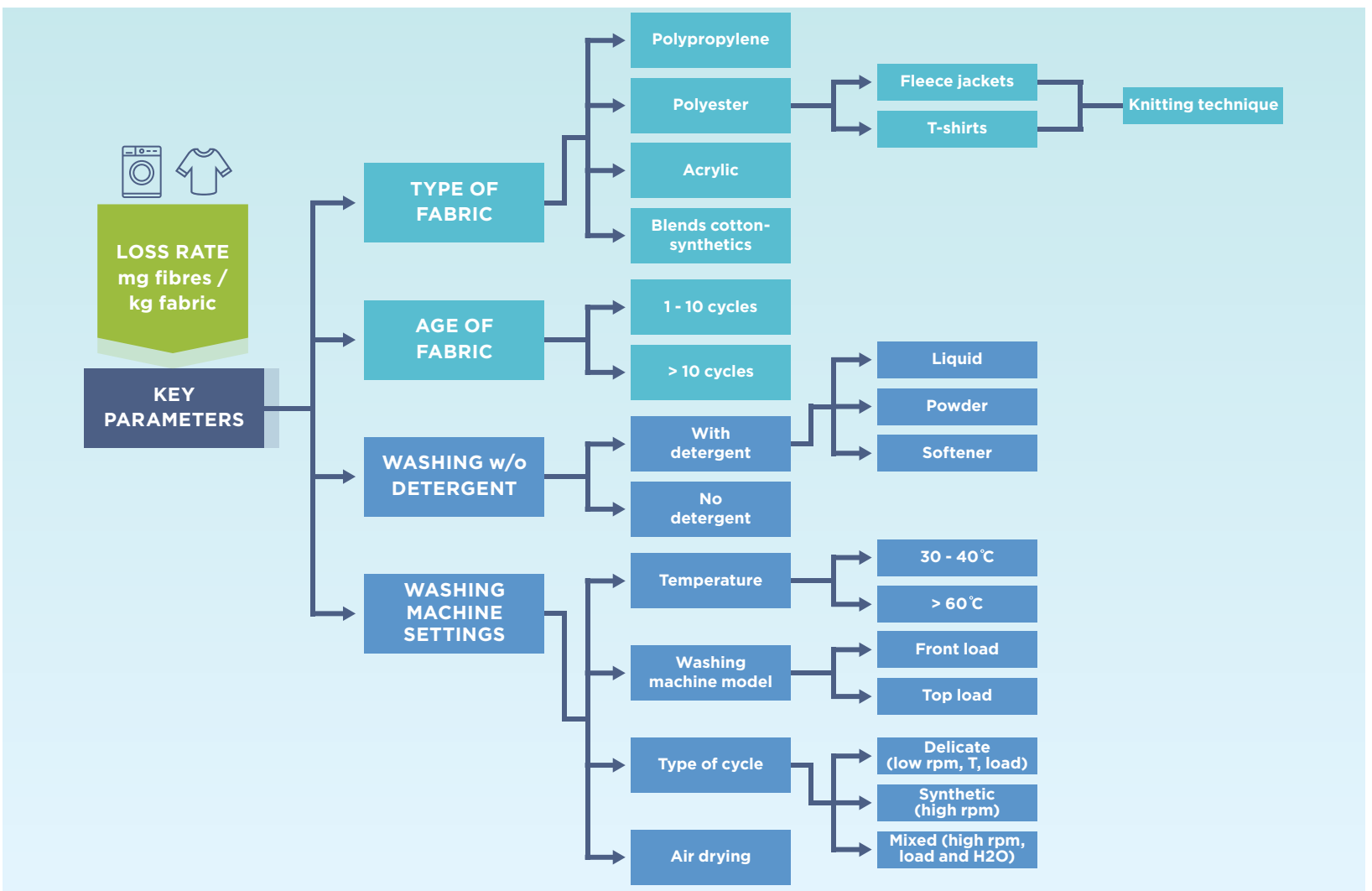

Figure 14: Key parameters potentially influencing the loss rate of textile fibres.

\subsubsection{Release pathway}

Most studies have identified common key parameters that influence the loss of microfibres (mg fibres/g fabric) during washing. These parameters, related to either garment or washing conditions, are summarised in Figure 14.

The main conclusions obtained so far for each key parameter are given in Table 8.

\subsubsection{Generic loss rate to be used for calculation of a Marine Plastic Footprint}

With the increasing interest shown in shedding of microfibres from fabrics during washing stage and the many studies done on this topic, a wide range of values have been reported in the literature (see Figure 15). This is probably due to both the lack of a standardised methodology to measure fibre release during laundering, and also very different loss rates for the different key parameters described above.

All reported values used for the statistical analysis are reported in Appendix 1, showing no clear influence of one or the other of the parameters.
As a consequence, the low, central, and high values for the loss rate are based on all values reported in the literature, with loss rates of low/ central/high value of 49/124/245 $\mathrm{mg} / \mathrm{kg}$ textiles washed, respectively.

\subsubsection{System map of the loss to release of textile fibres from specific activities}

The above system map represents what are the different steps in the marine plastic leakage. One activity will greatly influence the loss of microplastics from the product, whether it is done before the marketing of the product or after once it has been purchased. This loss follows different pathways to ultimately end in the marine environment through the release.

The calculation methods for estimating first the losses and then the releases from textiles are described below. Note that these losses only represent household washing. Losses potentially occurring during other life cycle stages are not accounted for here. 


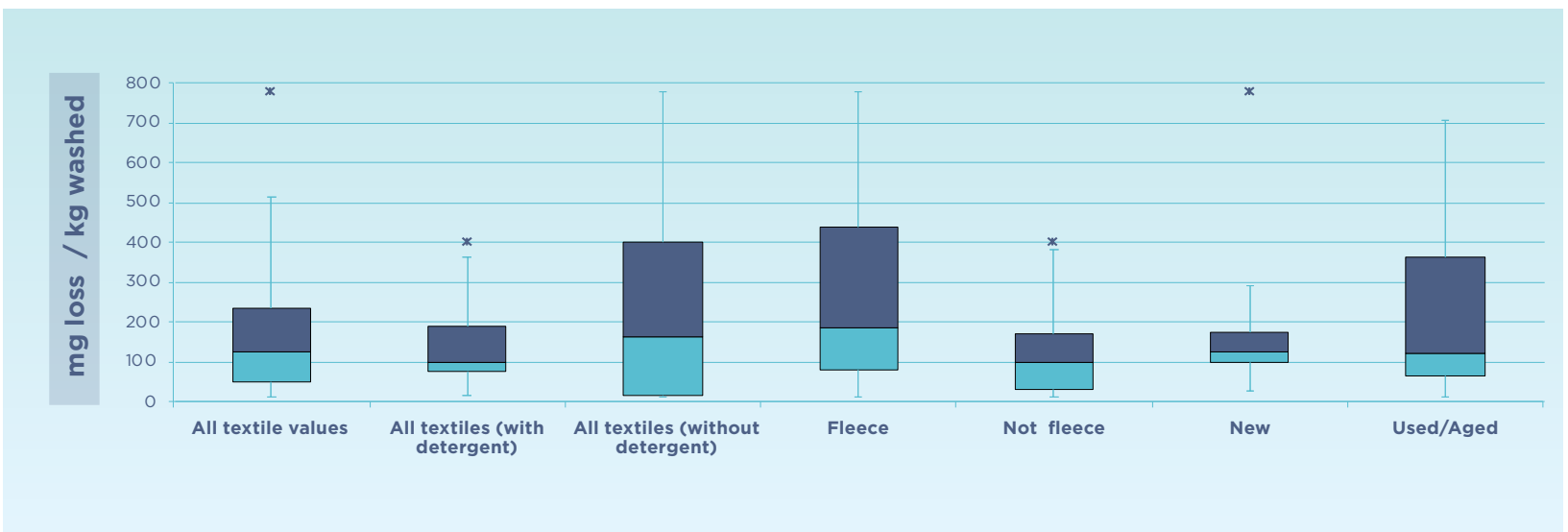

Figure 15: Loss rates reported in the literature for textiles, grouped according to different criteria (washing with/without detergent, fleece versus non-fleece, new versus used garments). All numerical values and references are reported in Table 6 and Appendix 1 . The horizontal line in the middle of the box represents the median (central value), the upper vertical line represents the $95^{\text {th }}$ percentile, and the lower vertical line the $5^{\text {th }}$ percentile. The box itself shows the interquartile range, the upper horizontal line the $75^{\text {th }}$ percentile (high value) and the lower line the $25^{\text {th }}$ percentile (low value). Blue stars are the outliers, the highest values reported.

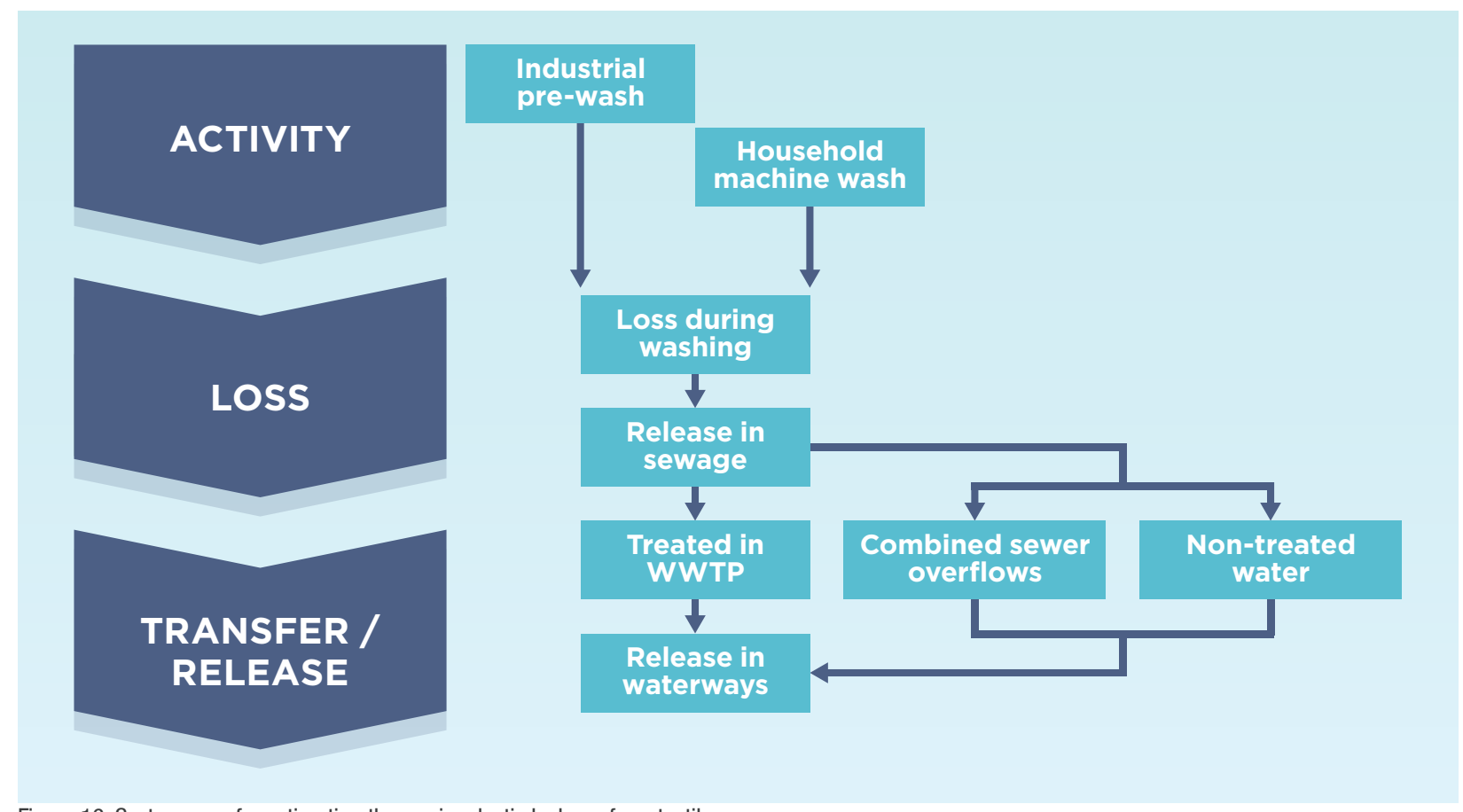

Figure 16: System map for estimating the marineplastic leakage from textiles

\subsubsection{Calculating the loss}

The loss rate can be calculated using the following equation:
If the number of washes per year per item is known, the following simplified equation can be used instead:

Fiber loss $=\frac{\mathrm{P}}{\mathrm{H}} * \mathrm{~W} * \mathrm{~L} * \mathrm{ShSy}_{\text {textile }} * \mathrm{LR}_{\text {textile }}$

Fiber loss $=\mathrm{M}_{\text {item }} * \mathrm{~N}_{\text {wash }} * \mathrm{LR}_{\text {textile }}$ 


\title{
4.2.6. Calculating the release
}

With

The release rate can be calculated using the following equation:

\section{$\mathrm{SWT}=\mathrm{HHWT}-\mathrm{OV}$}

\author{
Leak $_{\text {Textile }}=$ FiberLoss \\ * $\left(1-\mathrm{SWT}+\mathrm{SWT}^{*}\left(1-\mathrm{CR}_{\mathrm{wwtp}}\right)\right)$
}

The calculation can be made with different values for specific levels of water treatment.

Table 9: Parameters used for calculating the release rate of textile fibers.

\begin{tabular}{|c|c|c|c|c|}
\hline & Description & Unit & $\begin{array}{l}\text { Generic } \\
\text { value if, } \\
\text { available }\end{array}$ & Reference \\
\hline$C R_{\text {wwtp }}$ & $\begin{array}{l}\text { Capture rate of microfibres in } \\
\text { wastewater treatment plant } \\
\left(\text { WWTP) ; CR } R_{\text {wwtp }}=1-R_{\text {wwtp }}\right.\end{array}$ & $\%$ & & \\
\hline $\begin{array}{l}C R_{w w t p 1} \\
C R_{w w t p 2} \\
C R_{w w t p 3}\end{array}$ & $\begin{array}{l}\text { Capture rate of microfibres } \\
\text { in WWTP for a given level } \\
\text { of treatment, e.g., primary, } \\
\text { secondary, or tertiary }\end{array}$ & & & \\
\hline$H$ & Average person per household & - & 2.2 & \\
\hline HHWT & $\begin{array}{l}\text { Share of household water } \\
\text { connected to wastewater } \\
\text { treatment }\end{array}$ & $\%$ & & \\
\hline$L$ & Load per wash & $\mathrm{kg}$ & $3.5 \mathrm{~kg}$ & $\begin{array}{l}\text { Energy Efficiency (2010) 3:365-382 DOI } \\
10.1007 / \text { s } 12053-009-9072-8 \text { Electricity } \\
\text { and water consumption for laundry } \\
\text { washing by washing machine worldwide }\end{array}$ \\
\hline$L R_{\text {textile }}$ & $\begin{array}{l}\text { Loss in mg per } \mathrm{kg} \text { of textiles } \\
\text { washed }\end{array}$ & $\begin{array}{c}\mathrm{mg} / \\
\mathrm{kg}\end{array}$ & 124 & Appendix 1 \\
\hline$M_{\text {item }}$ & Mass of the textile garment & $(\mathrm{kg})$ & & \\
\hline$N_{\text {wash }}$ & $\begin{array}{l}\text { Number of washes per year for } \\
\text { a textile garment }\end{array}$ & $(-)$ & & \\
\hline ov & Overflows & $\%$ & $6 \%$ & $\begin{array}{l}\text { Average EU value (European Water } \\
\text { Association) }\end{array}$ \\
\hline $\boldsymbol{P}$ & Population concerned & - & & \\
\hline$R \boldsymbol{R}_{w w t p}$ & $\begin{array}{l}\text { Release rate of microfibres in } \\
\text { wastewater treatment plant } \\
\left(\text { WWTP) } R_{R_{\text {wwtp }}}=1-\mathrm{CR}_{\text {wwtp }}\right.\end{array}$ & $\%$ & Cf. Table 7 & \\
\hline$S h S y_{\text {textile }}$ & $\begin{array}{l}\text { Share of synthetic textiles on } \\
\text { the market }\end{array}$ & $\%$ & $48 \%$ & $\begin{array}{l}\text { Energy Efficiency (2010) 3:365-382 DOI } \\
10.1007 / \text { s } 12053-009-9072-8 \text { Electricity } \\
\text { and water consumption for laundry } \\
\text { washing by washing machine worldwide }\end{array}$ \\
\hline sWT & Share of wastewater treatment & $\%$ & & \\
\hline$S W T_{\text {primary }}$ & $\begin{array}{l}\text { Share of wastewater treatment, } \\
\text { for a given level of treatment, } \\
\text { e.g., primary in this case }\end{array}$ & & & \\
\hline TotWW & $\begin{array}{l}\text { Total wastewater produced in } \\
\text { the country }\end{array}$ & M3 & & \\
\hline$w$ & $\begin{array}{l}\text { Number of wash cycles per } \\
\text { household per year }\end{array}$ & - & 165 & $\begin{array}{l}\text { Energy Efficiency (2010) 3:365-382 DOI } \\
10.1007 / \text { s12053-009-9072-8 Electricity } \\
\text { and water consumption for laundry } \\
\text { washing by washing machine worldwide }\end{array}$ \\
\hline
\end{tabular}




\subsubsection{Calculating the leakage}

Finally, the leakage can be calculated by applying a release rate to the previously calculated loss. polymers, namely styrene butadiene rubber (approximately 60 percent), natural rubber, and other additives (MEPEX, 2014). Tyre dust can then be dispersed by the wind or be washed off the pavement by rain.

\subsubsection{Relevance of the source}

Many modelling studies have highlighted a high contribution of tyres to global microplastic pollution. However, very few studies reveal the actual presence of these particles in the sediments and aqueous environment. This might be related to contemporary sampling methods that do not allow for the measurement of such small particles. Much more knowledge is still required on the fate of tyre dust in the environment.
Tyres erode during driving and release particles from their outer layers. These particles are composed of a matrix of synthetic

\subsection{Calculation route for tyre leakage}

Table 10: Take-home message of the main factors favoring the release of tyre dust. 


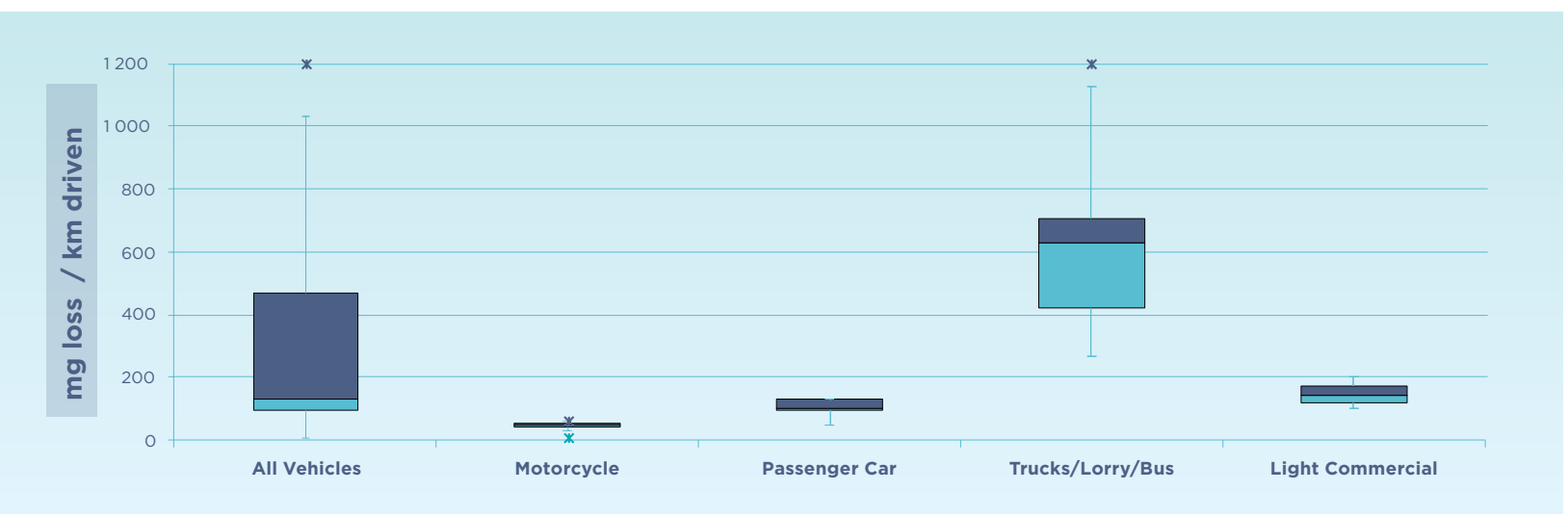

Figure 17: Loss rate reported in literature for tyres from different vehicle types. All numerical values and references are reported in Table 6 and in Appendix 2. The horizontal line in the middle of the box represents the median (central value), the upper vertical line represents the $95^{\text {th }}$ percentile, and the lower vertical line the $5^{\text {th }}$ percentile. The box itself shows the interquartile range, the upper horizontal line the $75^{\text {th }}$ percentile (high value) and the lower line the $25^{\text {th }}$ percentile (low value). Blue stars are the outliers, the highest values reported.

\subsubsection{Release pathway}

Some studies have identified common key parameters that influence the loss of tyre dust (mg/km driven) during driving. These parameters include some characteristics related to the tyre itself (percent synthetic/natural rubber, softness of the gum), as well as to the type of vehicle (light passenger cars versus trucks), infrastructure (type of pavement), and driving habits. However, the influence of these parameters on the loss rate from tyres has not been clearly elucidated yet, except for the type of vehicle, where a clear influence is observed. For the release pathway, it is expected that smaller airborne particles PM10 travel by air, while coarse particles (together with parts of asphalt and other pollutants of concern) follow the road run off pathway (Unice et al. 2018a and b).

\subsubsection{Generic loss rate to be used for calculation of a marine plastic footprint}

The loss rate for rubber from tyres has been inventoried from a handful of available scientific publications (see Appendix 2) and synthesised in Figure 17.

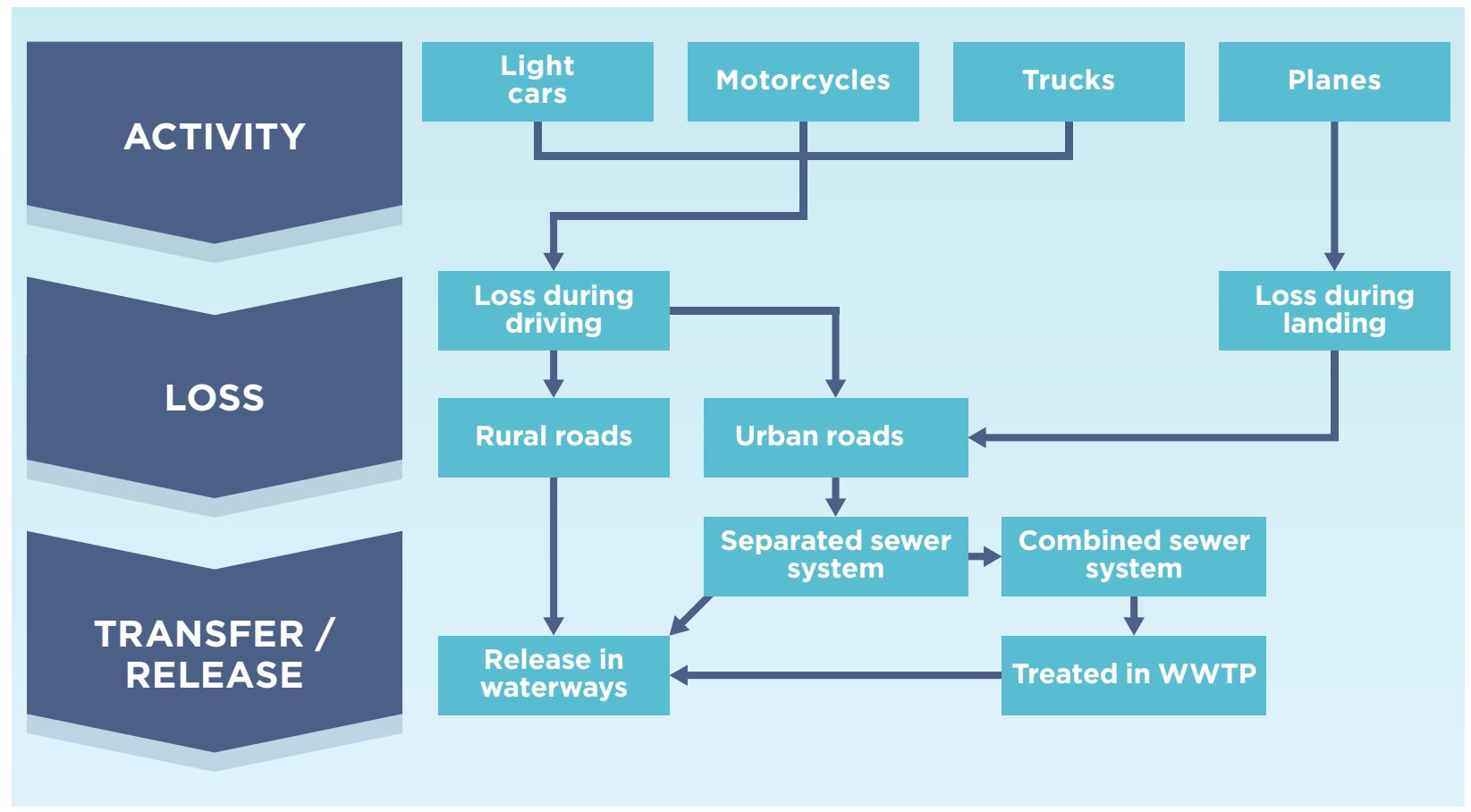

Figure 18: System map for estimating the marine plastic leakage from tyres 
Table 11: A description of the loss and release rates of tyre dust and main parameters influencing these rates.

\begin{tabular}{|c|c|c|c|c|}
\hline & Description & Unit & $\begin{array}{l}\text { Generic value, } \\
\text { if available }\end{array}$ & Reference \\
\hline D & Distance driven & $\mathrm{km}$ & & \\
\hline TyreLoss $_{\text {car }}$ & $\begin{array}{l}\text { Tyre loss from light passenger } \\
\text { vehicles }\end{array}$ & $\mathrm{mg} / \mathrm{km}$ & 102 & Appendix 2 \\
\hline TyreLoss $_{\text {truck }}$ & $\begin{array}{l}\text { Tyre loss from trucks transporting } \\
\text { goods }\end{array}$ & $\mathrm{mg} / \mathrm{km}$ & 629 & Appendix 2 \\
\hline$L R_{\text {tyres }}$ & Loss rate from tyres & $\mathrm{g} / \mathrm{km}$ & Cf. Table 6 & \\
\hline$L_{a v}$ & $\begin{array}{l}\text { Average load from trucks in the } \\
\text { country }\end{array}$ & tonnes & 12 tonnes & Eurostat \\
\hline $\mathbf{Q}$ & Mass of product transported & tonnes & & \\
\hline $\boldsymbol{R}_{\text {tyres }}$ & Release rate for tyres & $\%$ & Cf. Table 7 & \\
\hline$S h S y_{t y r e s}$ & Share of synthetic rubber in tyres & $\%$ & $54 \%$ & $\begin{array}{l}\text { (Kole et al., } 2017 \mathrm{a} \text { )amounts of particles } \\
\text { emitted, pathways in the environment, } \\
\text { and the possible effects on humans. The } \\
\text { estimated per capita emission ranges } \\
\text { from } 0.23 \text { to } 4.7 \mathrm{~kg} / \text { year, with a global } \\
\text { average of } 0.81 \mathrm{~kg} / \mathrm{year} \text {. The emissions } \\
\text { from car tyres }(100 \%) \text {. }\end{array}$ \\
\hline$F U_{\text {multiplier }}$ & $\begin{array}{l}\text { Used to convert actual lifetime } \\
\text { of the considered product to the } \\
\text { functional unit chosen for the } \\
\text { footprint calculation (e.g., } 1 / 3 \text { if the } \\
\text { lifetime of the product is three years } \\
\text { and the functional unit is one year) }\end{array}$ & $(-)$ & & \\
\hline
\end{tabular}

\subsubsection{System map of the loss to release of tyre dust from specific activities}

The calculation routes for estimating first the losses and then the releases from tyre particles are described below.

\subsubsection{Calculating the loss}

The loss rate can be calculated using the following equation:

$$
\begin{gathered}
\text { TyreLoss }_{\text {car }}=\mathrm{D}^{*} \mathrm{LR}_{\mathrm{tyres}} * \mathrm{ShSy}_{\mathrm{tyre}} \\
\text { TyreLoss }_{\text {trucks }}=\mathrm{D} * \mathrm{LR}_{\mathrm{tyres}} * \frac{\mathrm{Q}}{\mathrm{L}_{\mathrm{av}}} \\
* \mathrm{ShSy}_{\mathrm{tyre}} * \mathrm{FU}_{\text {multiplier }}
\end{gathered}
$$

\subsubsection{Calculating the release}

Finally, the leakage can be calculated by applying a release rate to the previously calculated loss.

$$
\begin{gathered}
\text { Leak }_{\text {Tyres }}= \\
\left(\text { TyreLoss }_{\text {trucks }}+\text { TyreLoss }_{\text {cars }}\right) * \mathrm{RR}_{\text {tyres }}
\end{gathered}
$$

\subsection{Calculating the total leakage from microplastics}

Once the leakage from each source has been estimated, the total leakage from microplastics can then be estimated from the different sources:

$$
\begin{aligned}
& \text { Leak }_{\text {Micro }}=\text { Leak }_{\text {tyres }}+\text { Leak }_{\text {textile }} \\
& + \text { Leak }_{\text {pellets }}+\text { Leak }_{\text {cosmetics }}
\end{aligned}
$$

The leakage from cosmetics and plastic pellets has not been detailed in this report, but the generic loss rates and release rates to be used are reported in Table 6 and in Appendices 1 and 2. 


\section{Modelling marine plastic leakage from fishing devices and other maritime sources}

The majority of marine plastic pollution originates from mismanaged terrestrial waste reaching oceans and seas through different transport pathways, such as waterways or surface run-off. The remaining fraction is directly generated at sea, through maritime activities such as fishing and aquaculture, shipping, and recreational activities close to shore.

One of the most common types of debris is altered or discarded fishing nets or lost cargo from ships, as well as fragmented macro debris and microfibres in the form of microplastics. The main factors contributing to the loss of this debris are usually marine hydrodynamic events such as wave intensity, wind and currents, and riverine transport for terrestrial environments.

The debate over whether marine sources represent a significant contribution to the overall marine plastic leakage is still ongoing. While it is obvious from field studies and beach cleanups that the remains of ropes and fishing nets are a ubiquitous source of pollution, very little quantitative data are available.

An often-cited estimate is a ratio of 80 percent of marine litter coming from land, usually from uncollected waste, with the remaining 20 percent directly generated at sea, through marine activities such as fisheries, for example (McKinsey Center and Ocean Conservancy, 2015).

Although the disposal of general waste at sea is prohibited by numerous agreements and conventions (e.g. MARPOL 73/78), illegal dumping still occurs, and the possibility of proper waste management on ships will be dependent on suitable port facilities (Mouat et al., 2010).

The estimate on the global input of debris generated at sea is about 0.6 million tonnes per year, with different sources presenting values of $0.6 \mathrm{Mt} / \mathrm{y}$ (Boucher and Friot, 2017) or $1.15 \mathrm{Mt} / \mathrm{y}$ for derelict fishing gear (EUNOMIA, 2016). Without conducting a specific inventory and a worldwide assessment, there is no possibility of calculating an additional and more precise estimate. Data on maritime sources are still scarce, as the vastness of the oceans and the multiple possible disposal scenarios prevent a sound tracing of sources. Therefore, the following methodology for footprint calculation focuses on land-based sources of macroplastic waste. 


\section{Modelling the fate of plastics to move from marine leakage calculation to footprint}

Moving from the concept of plastic leakage to the concept of a Marine Plastic Footprint requires introducing the notion of "fate". Different plastics may persist for very different amounts of time in the environment, depending on factors such as polymer types or the shape/size of the objects.

In other words, $1 \mathrm{~kg}$ of plastic with a lifetime of one year should not be accounted in the same way as $1 \mathrm{~kg}$ of plastic with a lifetime of 100 years. This is especially important when comparing biodegradable and bio-based plastics with conventional plastics, as the time that they remain in the environment may vary widely.

Here the concept of "plastic equivalents" is suggested, similar to the way $\mathrm{CO}_{2}$ equivalents are used in the context of climate change to compare and aggregate different greenhouse gases with different warming potentials.

One current knowledge gap concerns the amount of time it takes plastic to degrade in the marine environment and the fact that degradation needs to be defined based not on size (e.g., oxo-degradables) but on proven mineralisation of the polymers, which is currently not the case. The other limitation is the absence of a standardised metric to measure this degradation period. Commonly accepted values of polymer degradation in the environment are estimated in Table 12 below.

These degradation times are likely to be different in the marine environment. All polymers will degrade to some extent during their lifetime; however, the rate will fluctuate depending on the polymer family. This degradation is favoured by changes to the molecular weight distribution of the polymer.

Polyethylene, polypropylene, and P.E.T are susceptible to photo/thermal degradation at different rates (Fotopoulou and Karapanagioti, 2017). The key parameters governing degradation appear to be geographically dependent, where oxygen levels will have a significant impact on the degradation process (there will be a longer degradation rate at the bottom of the ocean than in terrestrial, UV-exposed areas). The main agents favouring the degradation of polyethylene are photodegradation and chemical degradation (Ali Shah et al., 2008).

Thus, the Marine Plastic Footprint can be calculated using the following equation, with 100 years chosen as the norm. Note that it is an attempt to better account for plastics that are degraded in the environment. It could be applied in the future pending data on timescale

Table 12: Conventional degradation rates of different categories of plastic and plastic applications. Sources: (1) MOTE Marine Laboratory Marine Debris Biodegradation time line, 1993. (2) BIOTEC Environmental, 2019.

\begin{tabular}{lll} 
Common plastic object & Reference polymer & Degradation time (years) \\
Cigarette filter & Cellulose acetate & $1-5^{(1)}$ \\
\hline Plastic bag & Polyethylene & $10-20^{(1)}$ \\
\hline Marine buoy & Styrofoam & $80^{(1)}$ \\
\hline Plastic bottle & Polyethylene terephthalate & $450^{(1)}$ \\
\hline Fishing line & Nylon & $600^{(2)}$ \\
\hline Building insulation & Extruded polystyrene foam & $5,000^{(2)}$ \\
\hline
\end{tabular}


for full mineralization of plastic in the marine environement becomes available. The Plastic Leak Project and the MariLCA project will hopefully allow considerable progress in this field in the coming months or years.

\section{MarinePlasticFootprint $=$}

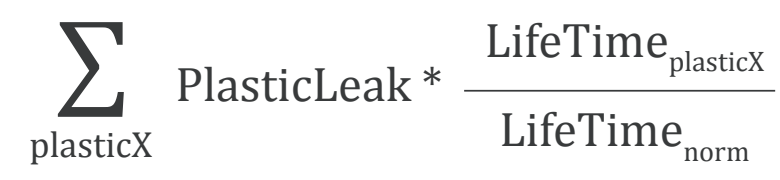

In the following sections, three case studies of how to apply the Marine Plastic Footprint methodology are presented:
- Case Study 1 applies the Marine Plastic Footprint at the company level, in the textile industry.

- Case Study 2 applies the Marine Plastic Footprint at the product level, focusing on glass vs. plastic bottles.

- Case Study 3 applies the Marine Plastic Footprint at the country level, within the Baltic Sea region.

Detailed calculations for these case studies are provided in Appendices 5, 6, 7 respectively. 


\section{Case study 1: The textile industry}

The life cycle of textiles and the related marine plastic leakage is depicted in Figure 19, below. This release is geographically dependent and varies greatly from production up until the end of life. The highest losses occur during usage and end of life, with high discrepancies between countries at the final stage of the product's life; the quantities also vary significantly from one country to another. The method used in this case study allows for sound identification of the marine plastic leakage in each country for plastic industries exporting in different markets, based on the equations provided in Section 5.2.

Detailed calculations are provided in Appendix 5.

\section{Functional unit: Objective of the study: System boundaries:}

\section{One t-shirt company To identify markets with higher Marine Plastic Footprints All t-shirts and packaging sold by the company in the different markets}

\section{Reference flows description:}

Production site in Estonia

Use in Germany, Sweden, and the Russian Federation

1 million t-shirts

Total quantity

Product

Packaging

Lifetime of the t-shirt
Per individual t-shirt

$150 \mathrm{~g}$

$10 \mathrm{~g}$

3 years

\section{Take-home message:}

- Different markets show different hotspots, enabling a company to set priorities for action.

- The use phase is dominant in some markets, while in other markets with less-adapted waste management, the end-of-life phase contributes most to the Marine Plastic Footprint.

- Increasing the share of wastewater treatment, as well as reducing storm overflows, are efficient interventions to mitigate the marine plastic leakage from textiles.

- Current loss rate data do not allow for differentiation between different fibres or washing settings. Further research is needed to identify best practices and develop ecodesign guidelines for this industry. 


\section{PLASTIC FOOTPRINT}
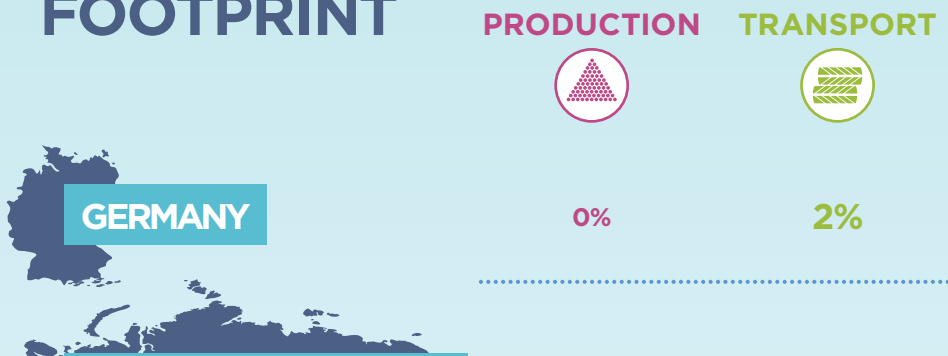

RUSSIAN FEDERATION RUSSIANTEDER
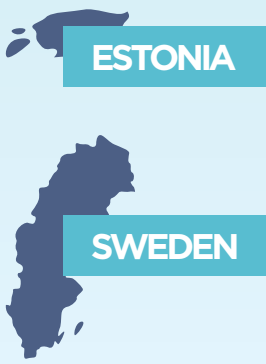

USE PHASE

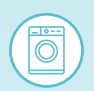

$0 \%$

$0 \%$

$0 \%$

$33 \%$

$17 \%$

$0 \%$

$0 \%$

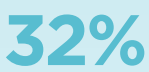

$1 \%$
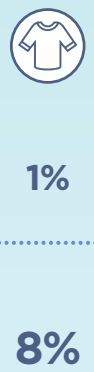

$0 \%$

$2 \%$

$5 \%$

0\%

Figure 19: Differences in leakage of plastics throughout the life cycle. The main losses appear to occur during the use phase of the products.

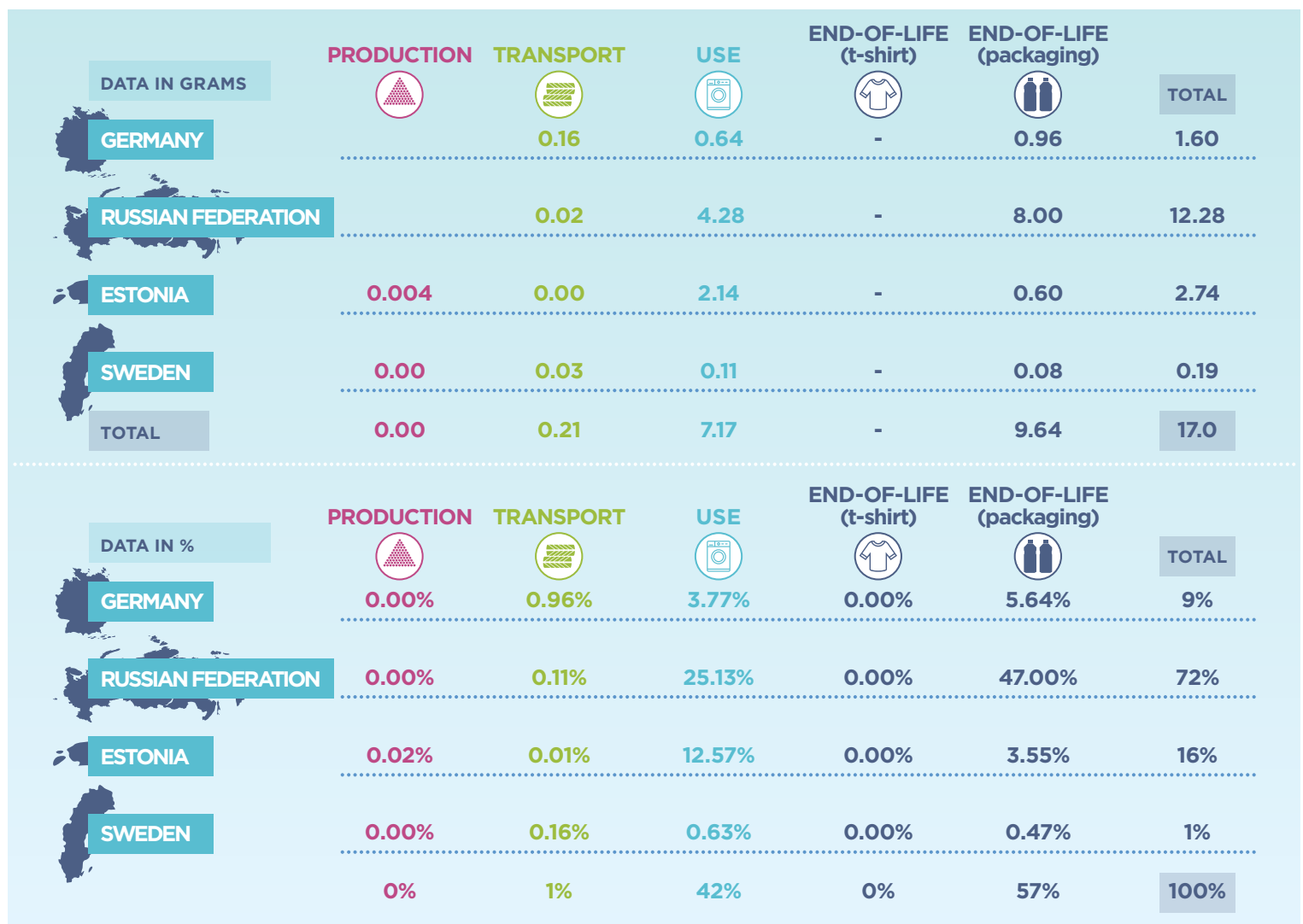

Figure 20: Spatial and temporal differences in loss rates of products of the textile industry. 


\section{Case study 2: The packaging industry}

\section{The footprint of a glass bottle vs. a plastic bottle}

The same methodology as used to evaluate the textile industry can be applied to the packaging industry. Plastic waste generation appears to be significantly different than the leakage in this industry, mainly related to waste management efficiency. The Marine Plastic Footprint is again geographically dependent, and its reduction usually relies on the implementation of waste management strategies and infrastructures.

Detailed calculations are provided in Appendix 6.

\section{Functional unit: Objective of the study: System boundaries:}

\section{1 litre of drink delivered to the client To identify the best packaging option The drink itself is excluded from the analysis.}

\section{Take-home message:}

- For plastic bottles, the end-of-life stage dominates the overall Marine Plastic Footprint.

- Glass bottles can have a greater Marine Plastic Footprint than plastic bottles, due to a higher footprint from transportation. Their plastic footprint arises from tyre dust during transportation.

- Ensuring recycling or re-use of plastic bottles is a good way to reduce the Marine Plastic Footprint

- Using biodegradable plastic is also a good way to reduce the Marine Plastic Footprint. However, current degradation rates are just estimates used to demonstrate the capacity of the methodology to capture this parameter. 


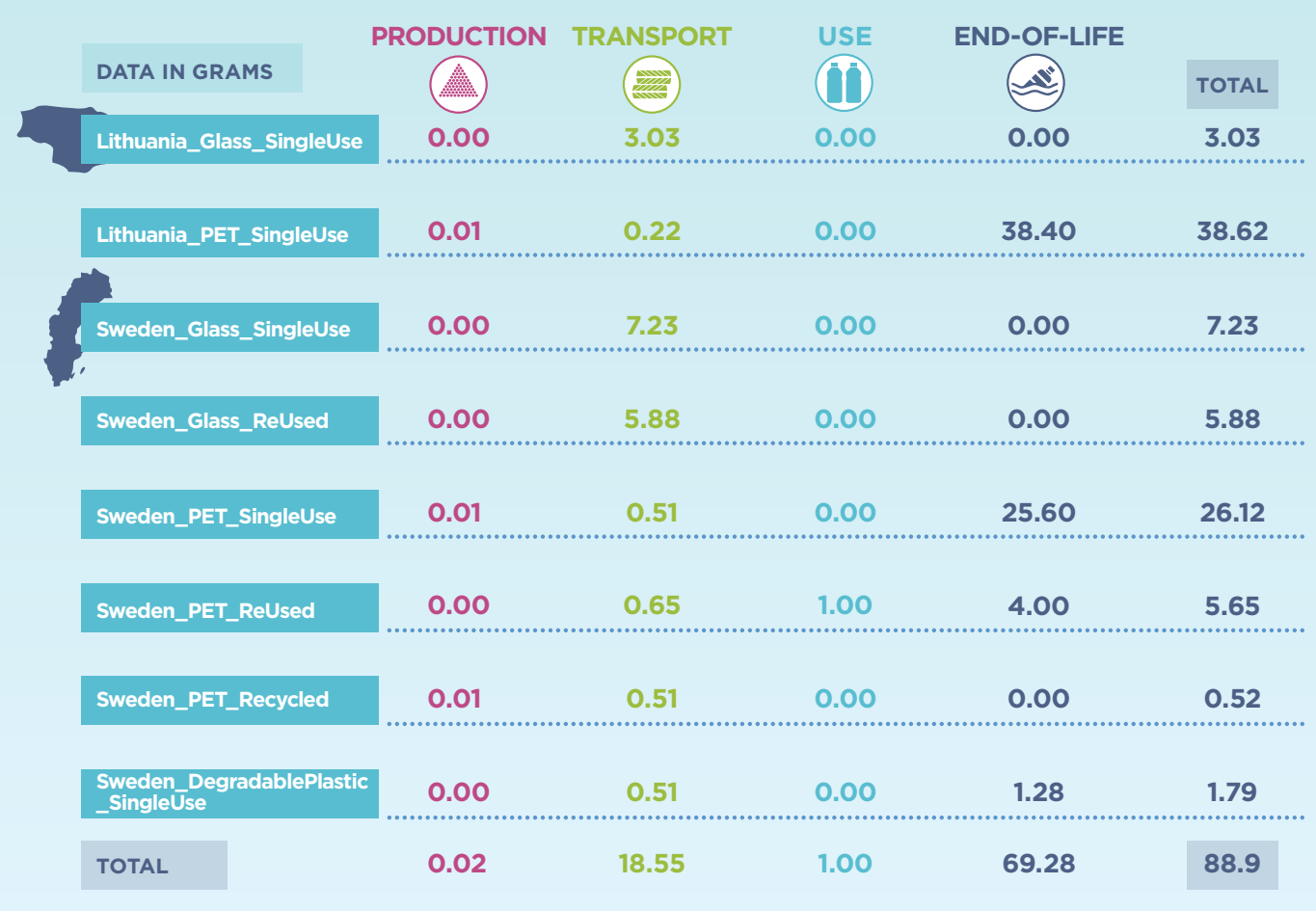

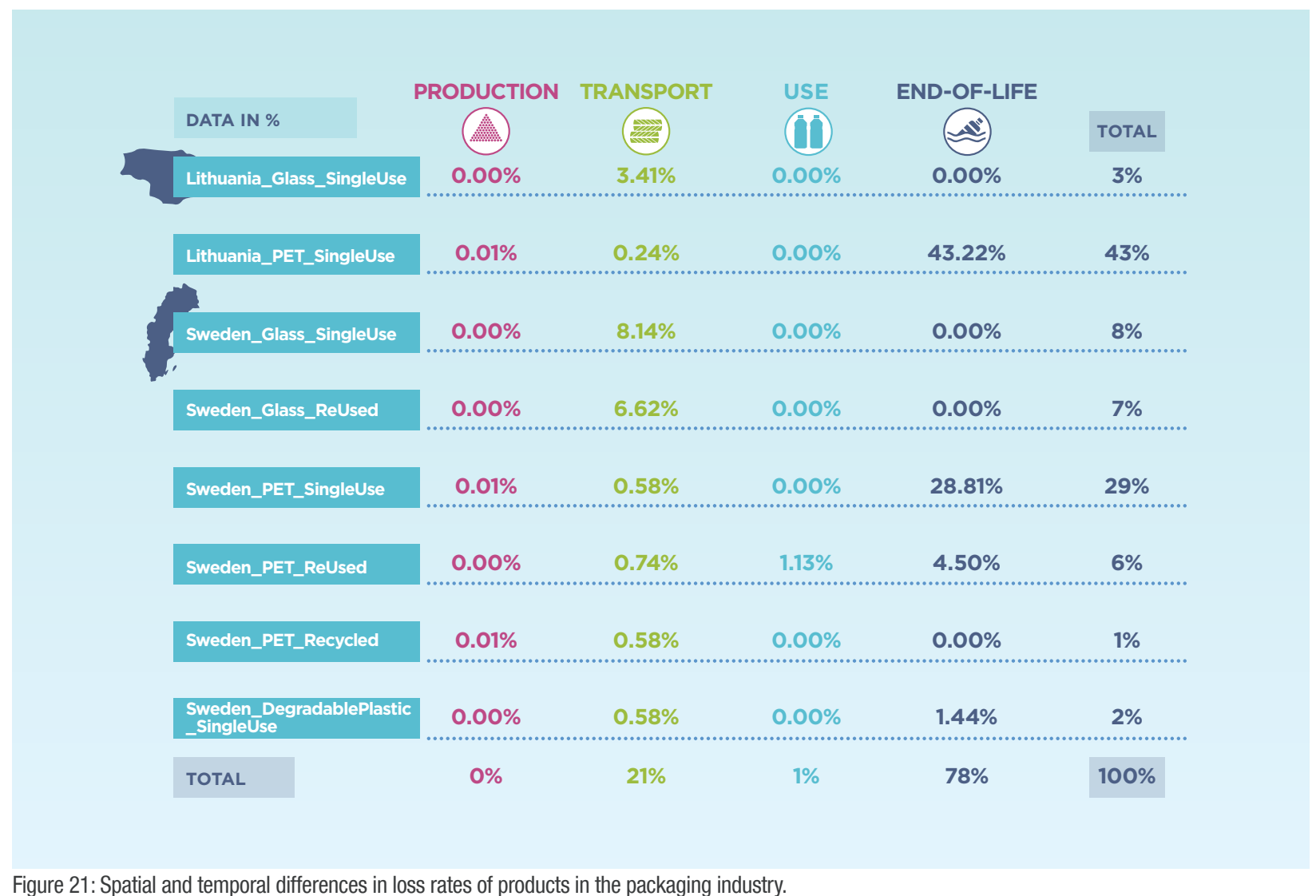

Figure 21: Spatial and temporal differences in loss rates of products in the packaging industry. 


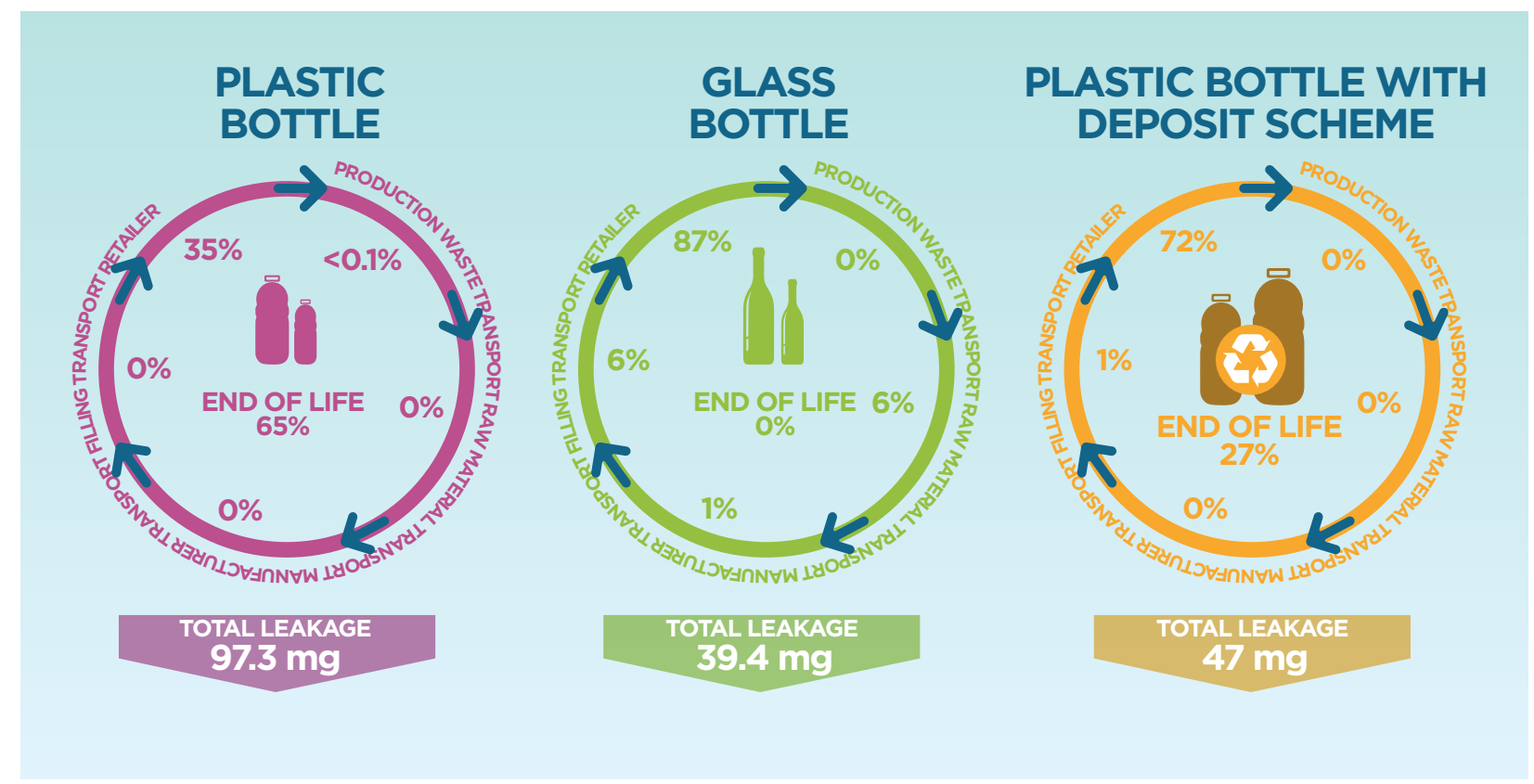

Figure 22: Marine Plastic Footprint of plastic versus glass bottles. 


\section{Case study 3: The Baltic Basin}

\subsection{Introduction}

This case study presents a practical application of the Marine Plastic Footprint methodology to a set of countries sharing either a coastline, a watershed, or a river connecting to the Baltic Sea. For the purpose of the study, twelve countries were selected for evaluation to visually represent the Marine Plastic Footprint inside what is referred to here as the Baltic Basin.

The Baltic Sea is located in northern Europe, and is bordered by nine countries (Denmark, Germany, Poland, Lithuania, Latvia, Estonia, Russia, Finland, and Sweden) with a total surface of approximatively $370,000 \mathrm{~km}^{2}$. In addition, the sea receives water from three additional noncoastal countries (Belarus, Czech Republic, and Slovakia).
This sea is home to many human activities, such as fishing and merchant navigation, and has important human densities along its coasts. Consequently, the environment is affected by many types of pollution, such as municipal and industrial waste inputs, and inorganic plant nutrients (e.g., NOx) (Rheinheimer, 1998). Additionally, plastic pollution in this region has been reported at the surface, on the sea floor, and along the shoreline, and seems to be present in higher densities close to shore and urbanised areas (Gewert et al., 2017).

\subsection{Objective and methodology}

The goal of this study is to identify and map potential plastic leakage hotspots into the marine environment using the methodology

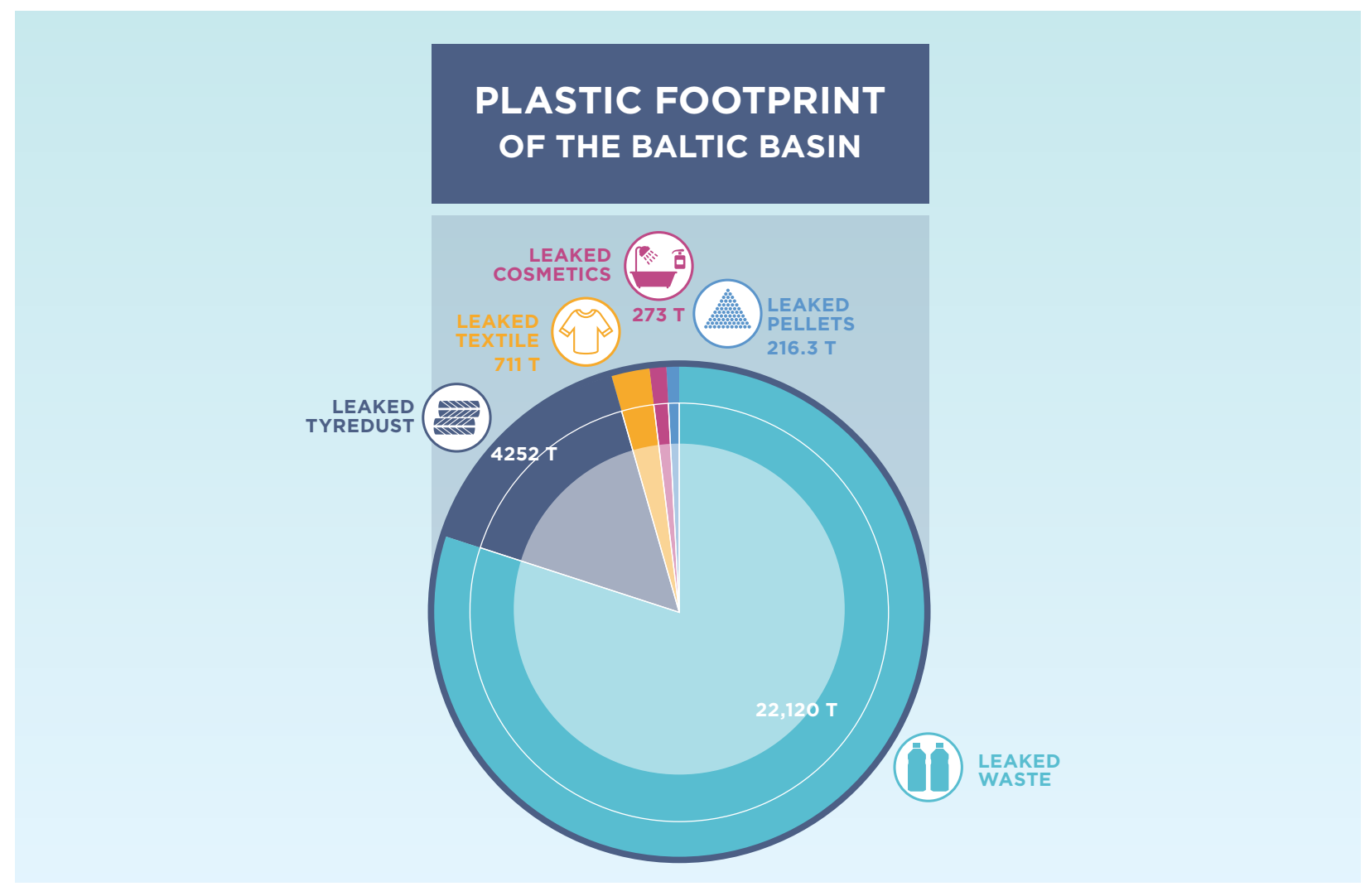

Figure 23: Contribution of different plastic sources to the overall marine plastic leakage in the Baltic Basin 


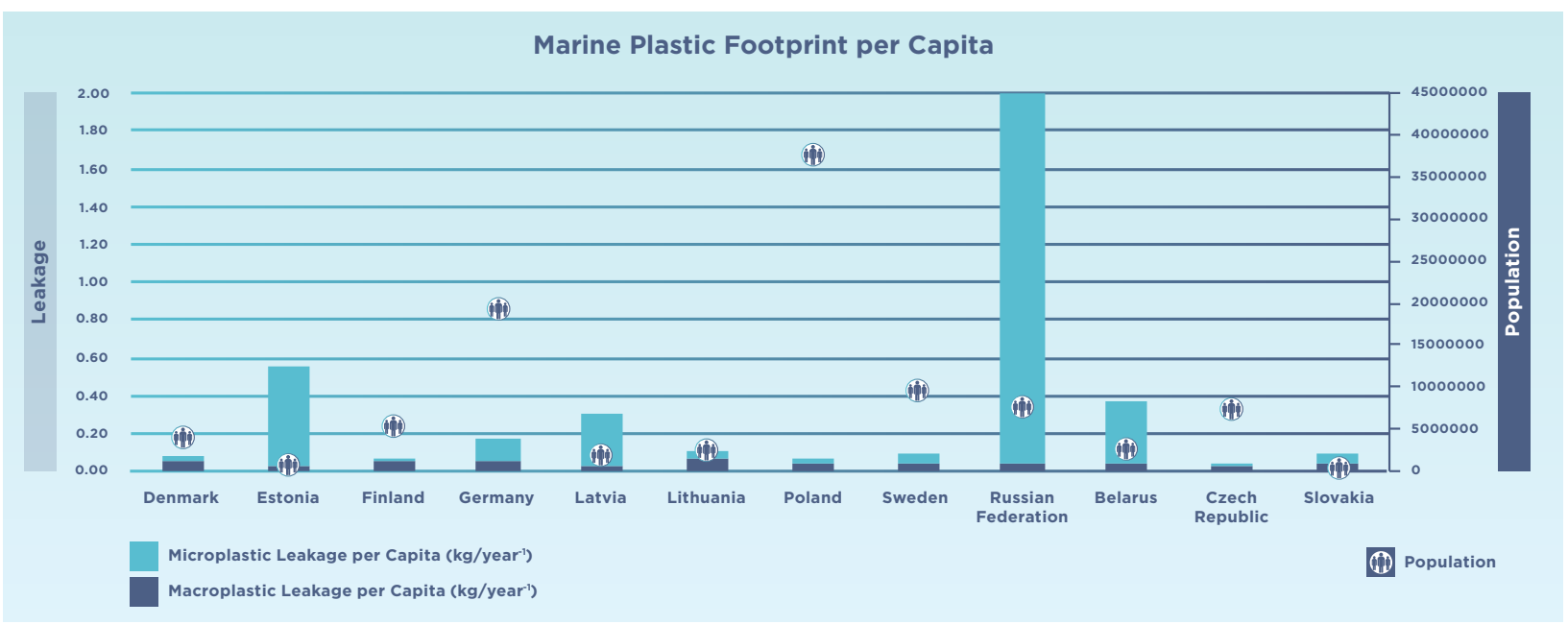

Figure 24: Marine Plastic Footprint per capita for countries in the Baltic Basin.

described in this report. All 12 coastal and noncoastal states listed above were included. To map the leakage, the approach was based on the calculation methodology described in Sections 4 and 5 of this report, with the final aim of obtaining a leakage rate for mismanaged macroplastic waste and the four categories of microplastics (textile fibres, tyre dust, cosmetics, and primary production pellets).

The leakage calculation was performed through GIS modelling, as detailed in Appendix 7, combining different parameters, including population density, distance to shore, waste generation rate, mismanaged waste index, watershed configuration, and surface water run-off.

The results were presented within the GIS model in three formats: on a country scale, representing the total footprint of each of the considered countries, by locality (cities/towns/villages), and by watersheds.

\subsection{Outputs and interpretation}

\subsubsection{Global results: Marine Plastic Footprint per source}

The global results yielded for micro- and macroplastic leakages in the Baltic Basin are shown in Figure 23.
In terms of mass, macroplastics ( Leak $_{\text {waste }}$ ) appear to be the main contributor to the overall marine plastic leakage, originating in high quantities in several identified countries. For the purpose of the analysis, three hypotheses were tested regarding release rates, translated into high, central, and low values. It is an attempt to synthesize the different values presented in the literature. Throughout the study, the central value (RR of 20\%) was kept to present the results (e.g., Figure 23). Therefore, the central value for the macroplastic leakage is estimated at 22,120 tonnes/year-1 with low and high values of 11,060/ 44,240 tonnes/year ${ }^{-1}$ respectively. Background data and key hypotheses are reported in Appendix 7. Leak $\mathbf{k}_{\text {waste }}$ represents macro-sized, municipal waste, which can be mismanaged and released into the marine environment through several pathways. Additionally, the central value for the microplastic leakage ( Leak $_{\text {micro }}$ ) is estimated at 5,452 tonnes/year ${ }^{-1}$ with low and high values of 1,377 / 15,475 tonnes/year respectively. Background data and key hypotheses are reported in Appendix 7.

Two main results were obtained when calculating the leakage: a per capita leakage, which is the amount each individual inhabitant contributes to the overall leakage, and a global leakage per country (the leakage is a function of the release rate and the amount of mismanaged plastic waste (MPW)). These two results present very contrasting patterns, as highlighted by Figure 24 and Figure 25. 


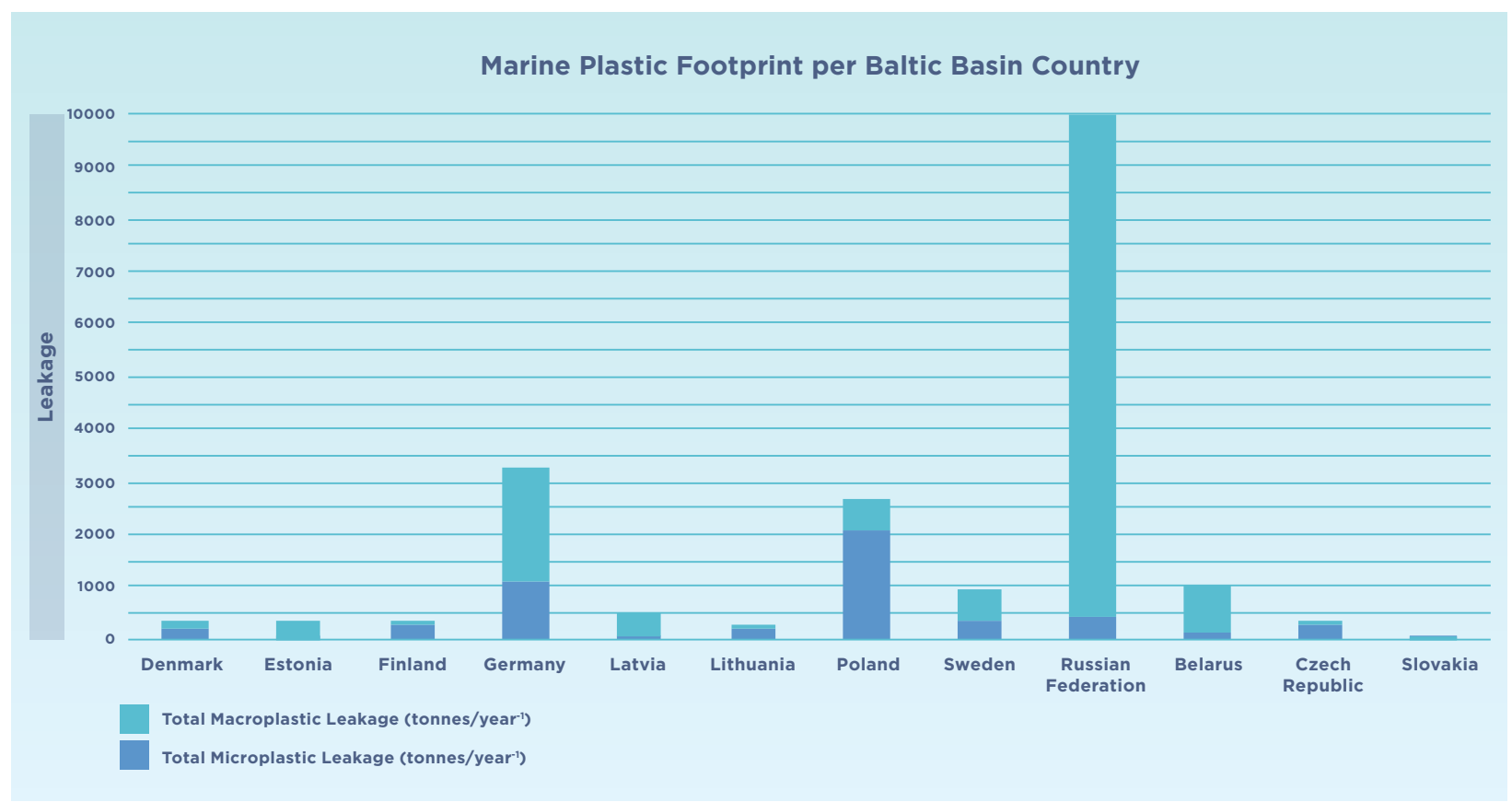

Figure 25: Regional differences in the Marine Plastic Footprint leakage of the Baltic Basin states considered in this study.

The amount of annual plastic waste generation per capita is lowest for Scandinavian states (Denmark: 12.7kg; Sweden: 29.3kg). The Russian Federation has the highest leakage, with high plastic waste generation per capita $(59.9 \mathrm{~kg}$ ), coupled with deficient waste collection schemes and a large share of plastic in the waste stream (14 percent). Potential hotspots appear to be correlated with high population densities/ urbanised areas with poor waste management schemes.

Figure 24 suggests that, in some cases, countries with a relatively low population can contribute significantly to the total marine plastic leakage (e.g., Estonia), whereas densely populated countries such as Germany may emit less plastic due to efficient infrastructures. In other cases, countries with a combination of high population densities and poor waste management infrastructures are responsible for a greater share in the overall leakage.
The maps in the next section visually represent the Marine Plastic Footprint in the Baltic Basin. They suggest that, in some cases, micro- and macroplastic leakages generated in coastal areas and/or close to waterways are likely to be exported towards the marine environment.

The results below are presented in three formats: per country, per locality, and per watershed, in order to represent probable hotspots. Population points in the GIS environment have been appended their corresponding value of $\boldsymbol{L}_{\boldsymbol{e}} \boldsymbol{k}_{\text {waste }}$ and $\boldsymbol{L e a}_{\text {micro }}$ based on the methodology described above and in Appendix 7.

In watershed maps, each leakage point in a watershed was added together to obtain a total value for each individual watershed. A clear imbalance in the marine plastic leakage can be observed between the northern and southern states of the Baltic Basin. Scandinavia has low leakage, as the percentage of non-collected waste is minimal. 


\subsubsection{Contribution of the different countries to the leakage: macroplastics}

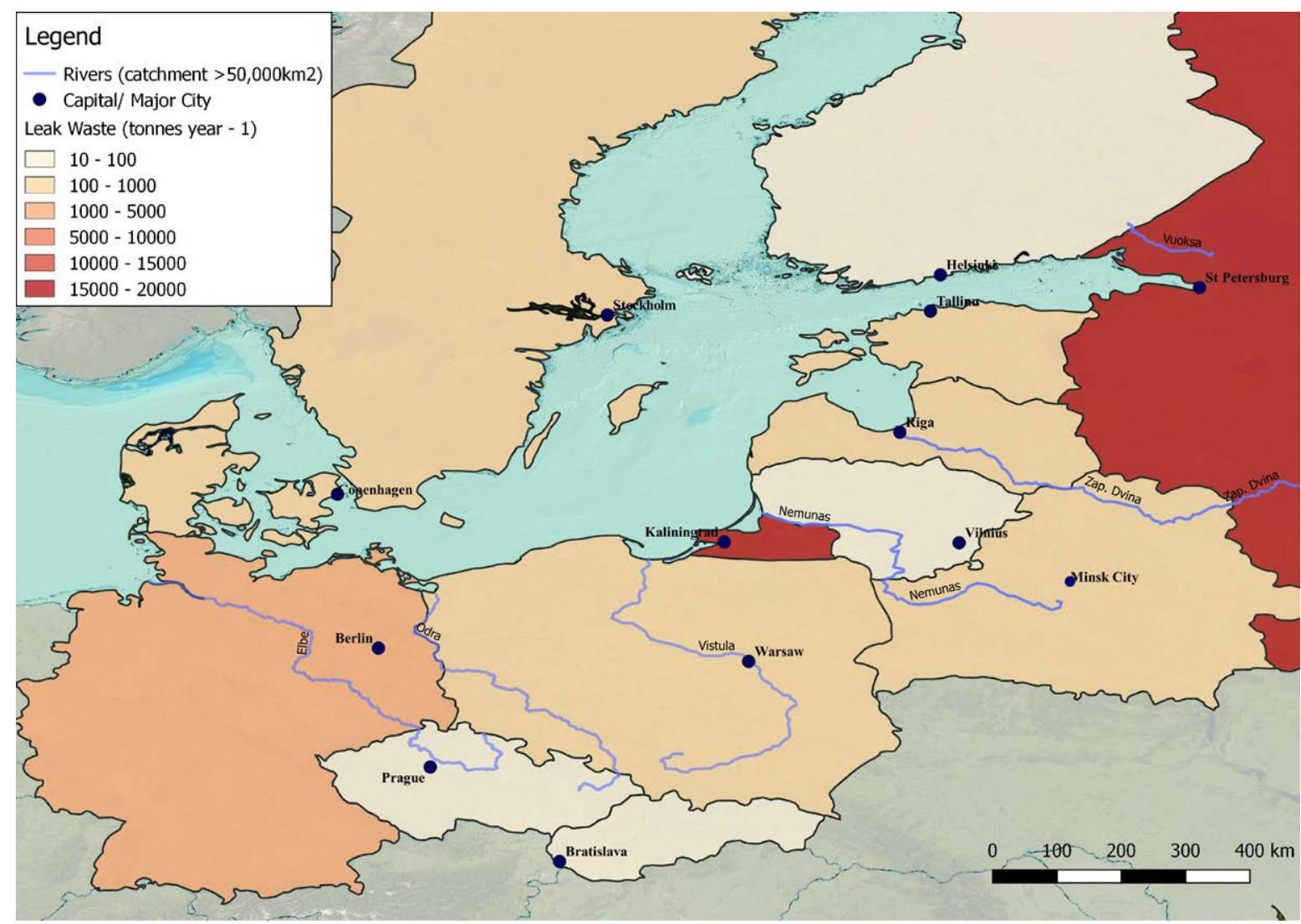

Figure 26: Macro Marine Plastic Footprint, Leak ${ }_{\text {waste }}$, in the Baltic Basin per country.

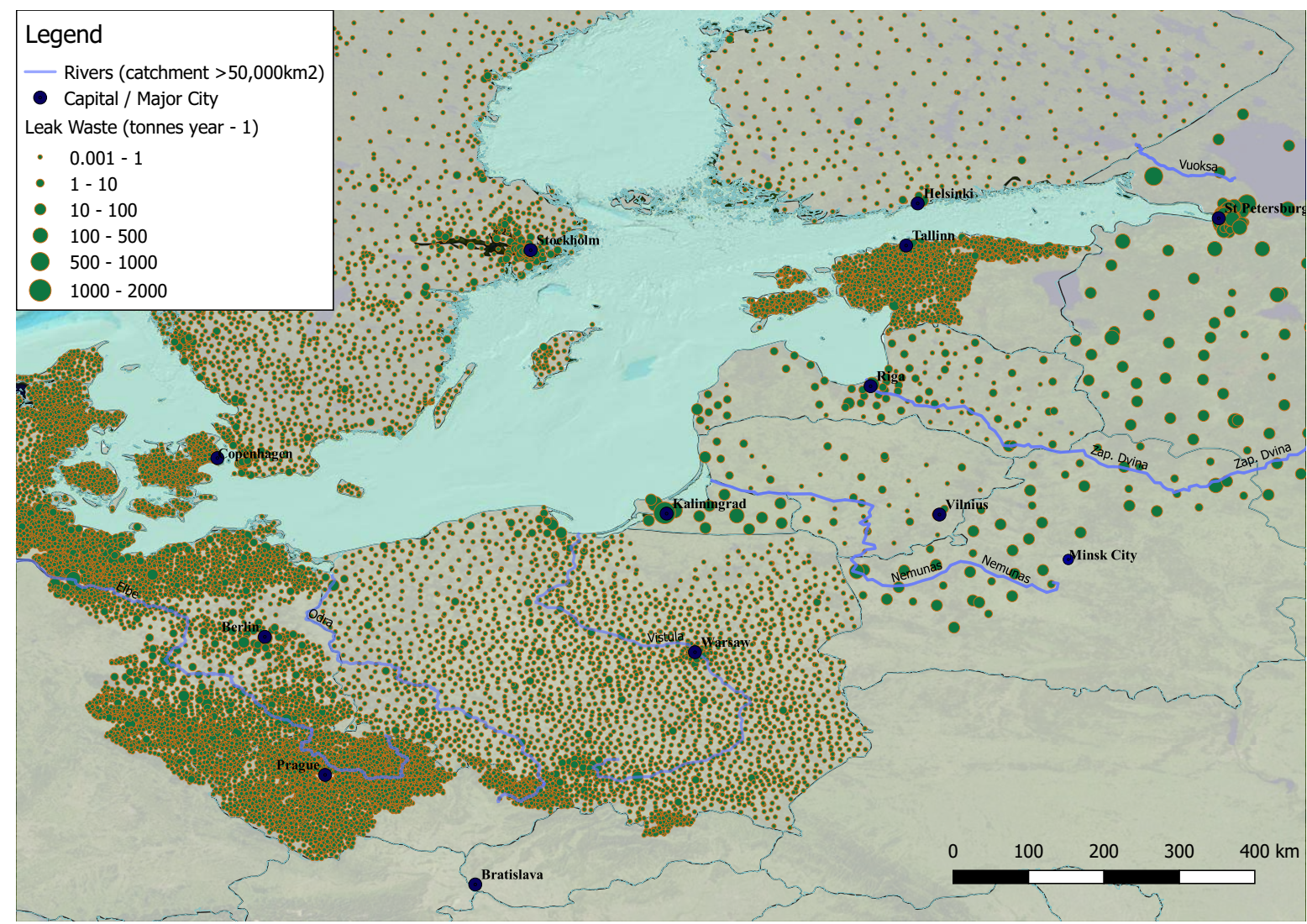

Figure 27: Macro Marine Plastic Footprint, Leak ${ }_{\text {waste }}$, in the Baltic Basin per locality. 


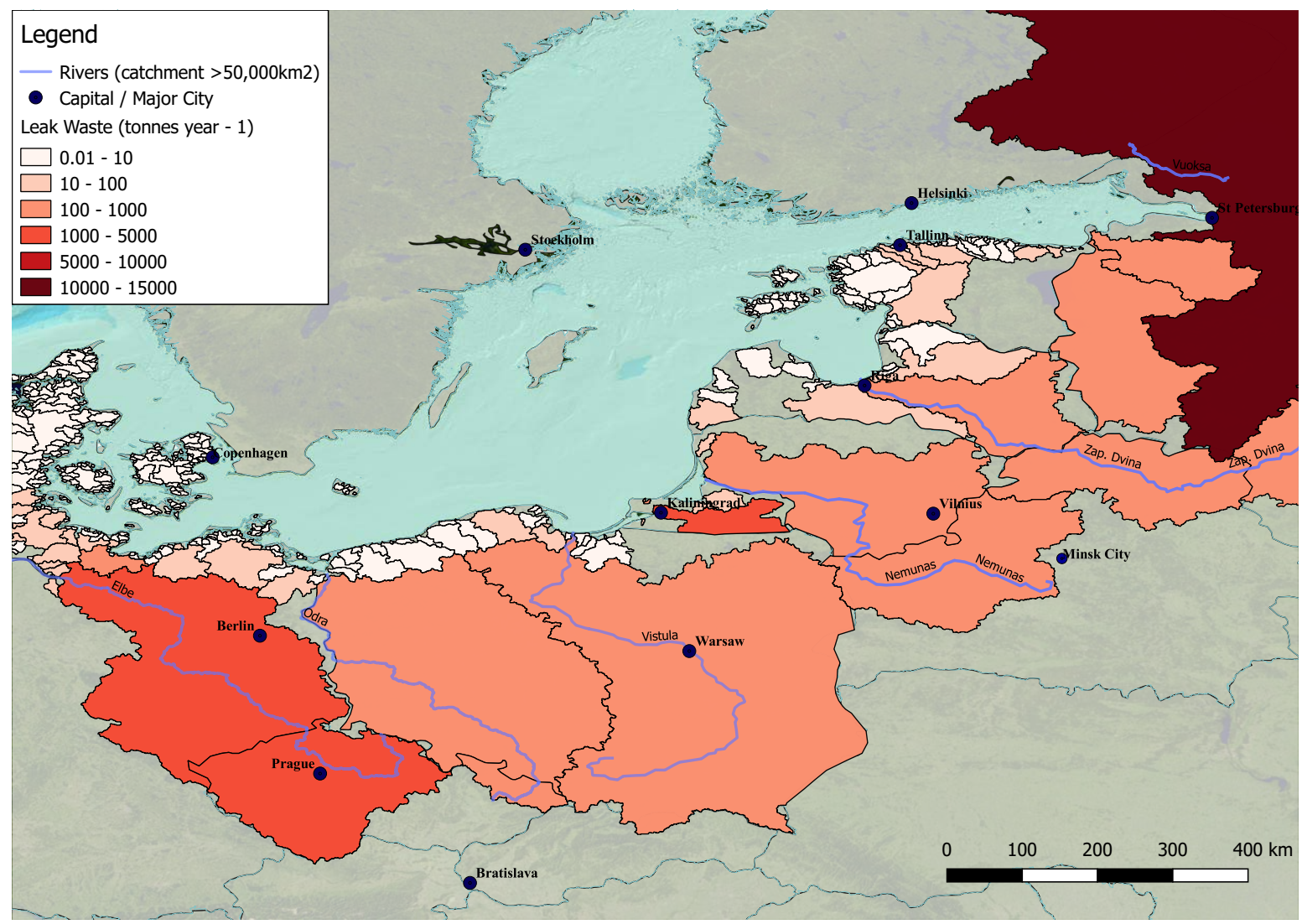

Figure 28: Macro Marine Plastic Footprint, Leak ${ }_{\text {waste }}$, in the Baltic Basin per watershed. Due to model limitations, no watershed data is available above 60 degrees north latitude (except for the Neva watershed).

\section{Summary: Baltic Basin Macroplastic Marine Plastic Footprint}

A clear imbalance in the marine plastic leakage can be observed between the northern and southern states of the Baltic Basin.

Overall, macroplastics dominate the leakage, with an estimated Leak waste, of 22,120 tonnes/ year $^{-1}$. This leakage is usually a combination of above-average waste generation rates (e.g., 81 kg/hab year ${ }^{-1}$ in Germany), high population densities, and/or inefficient waste management infrastructures (with the absence of a collected waste scheme in Russia, (Silpa et al., 2018)).

As an example, two coastal countries (Germany and Poland) are likely exporting between 600 and 2,000 tonnes/year ${ }^{-1}$ of plastic waste alone. This can be explained by the fact that they are amongst the most densely populated countries of the considered area.

This trend shifts, however, when calculating a per capita leakage, i.e., the leakage generated by each individual inhabitant of a country. In some cases, as shown in Figure 24, the leakage per capita appears to be higher in less-populated countries, due to inefficient waste management infrastructures. In contrast, countries that are important contributors to overall marine plastic leakage (e.g., Germany) shift towards a smaller per capita microplastic leakage, due to efficient infrastructures. Overall, when comparing micro and macroplastic leakage, urbanised areas appear to be the main emission hotspots (Figure 27).

$$
\text { Leak }_{\text {waste }}: 22,120 \text { tonnes/year }{ }^{-1}
$$

Low/high values of $11,060 / 44,240$ tonnes/year ${ }^{-1}$ 


\subsubsection{Contributions of the different countries to the leakage: microplastics}

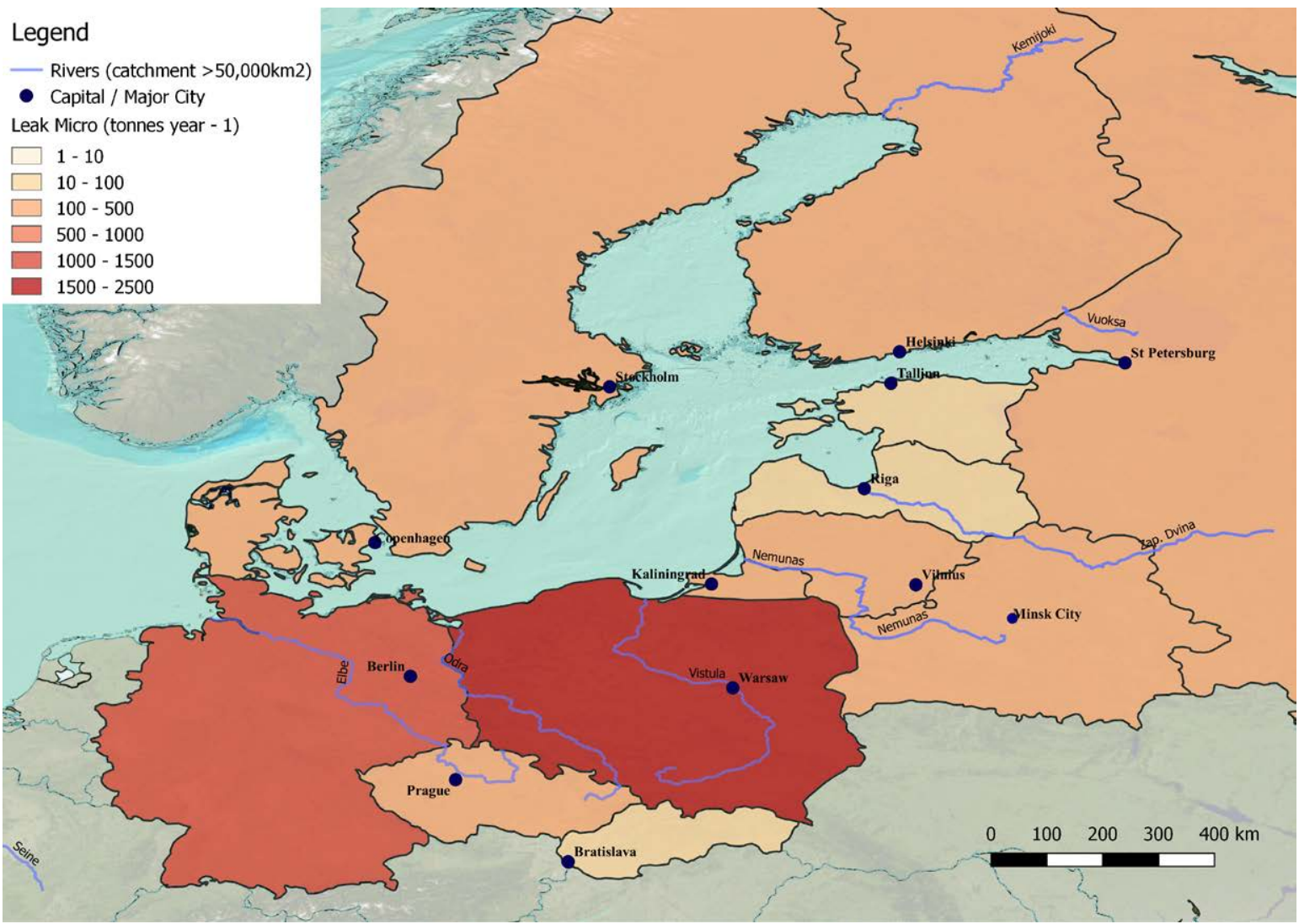

Figure 29: Microplastic Marine Plastic Footprint, Leak micro of the Baltic Basin per country.

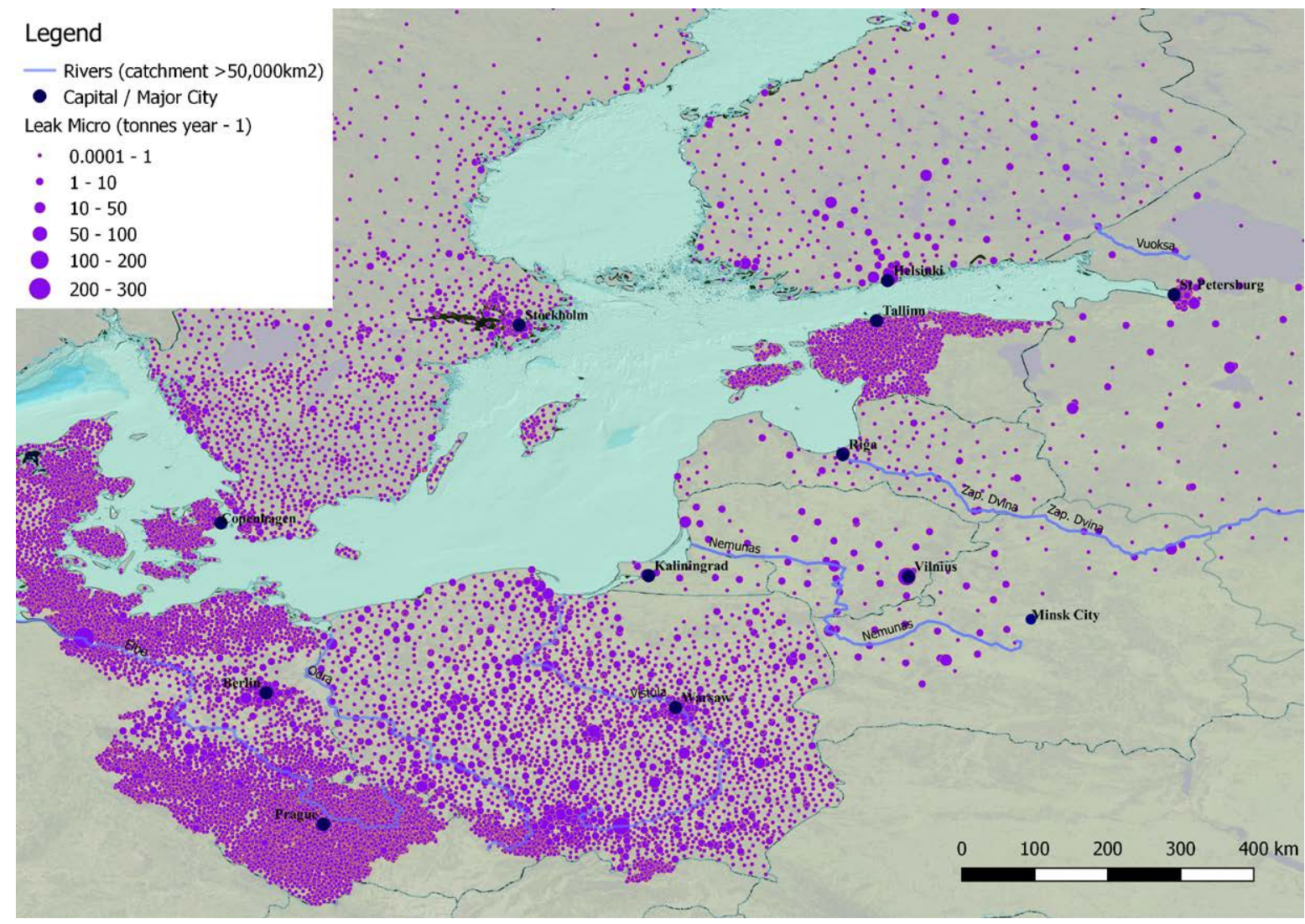

Figure 30: Microplastic Marine Plastic Footprint, Leak micro of the Baltic Basin per population points. 


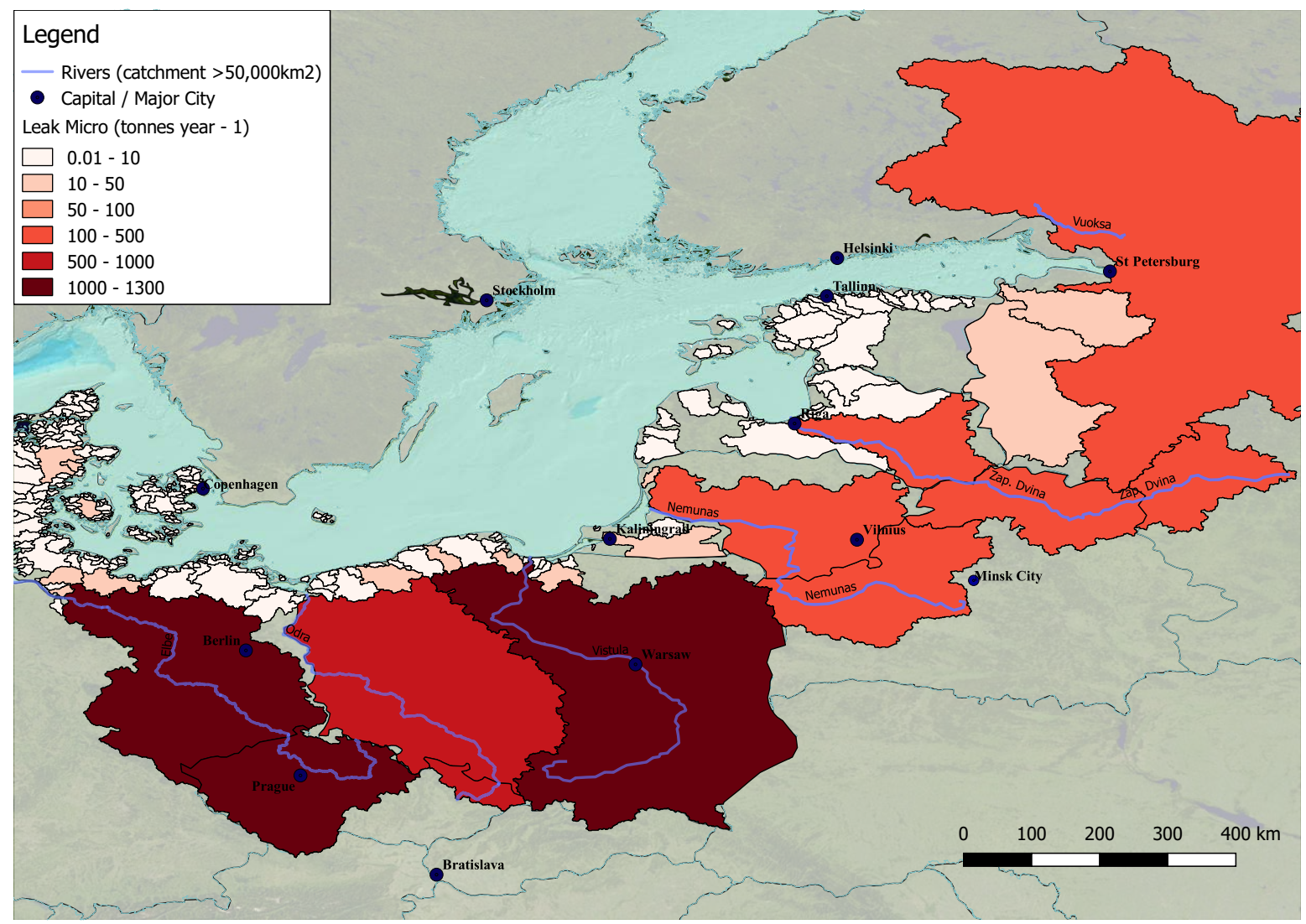

Figure 31: Microplastic Marine Plastic Footprint, Leak micro of the Baltic Basin per watershed. Due to model limitations, no watershed data is available above 60 degrees north latitude, except for the Neva watershed.

\section{Summary: Baltic Basin Microplastic Marine Plastic Footprint}

- Overall, microplastics leakage $\left(\right.$ Leak $_{\text {micro }}$ ) is estimated at 5,452 tonnes/year ${ }^{-1}$. Through the four sources investigated in this report, tyre dust dominates (4,252 tonnes/ year ${ }^{-1}$ ), followed by textile fibres ( 711 tonnes/ year ${ }^{-1}$ ), cosmetics ( 273 tonnes/ year $^{-1}$ ), and lastly plastic pellets (0.9 tonnes/ year ${ }^{-1}$ ). Detailed data per country is available in Appendix 7.

- The main hotspots of microplastic emissions are usually linked with urbanised areas and high population densities as for macroplastic exports. Contributions of plastic pellets to the overall leakage is comparatively low. Another point to consider is that important rivers (e.g., Vistula) pass through urbanised areas and are potential transport vectors for these particles.

- For example, high amounts of textile fibres are likely to be released in countries with a low share of wastewater treatment (e.g., Russia). Refer to Appendix 7 for detailed data wastewater treatment.

$$
\text { Leak }_{\text {micro }}: 5,452 \text { tonnes/year }{ }^{-1}
$$

Low/high values of $1,377 / 15,475$ tonnes/year ${ }^{-1}$ 


\subsection{Estimating the fate of the leaked plastic: how much is floating?}

Plastic debris can be found at different layers of the water column, mainly dependent on its density and shape. Figure 32 below shows an assessment of the fraction of plastic expected to float and/or sink, for both macro- and microplastics. Plastic densities were obtained from Cincinelli et al. (2019), with the hypothesis that the fraction with density above 1.1 is sinking and the fraction below 0.9 is floating. Particles with density between 0.9 and 1.1 are expected to have a neutral buoyancy and/or be largely affected by bio-fouling effects, thus with unpredictable behaviours.

Thus, out of a macroplastic Leak $_{\text {waste }}$ total of 22,120 tonnes/year ${ }^{-1}, 27$ percent (5,972 tonnes) would be prone to float on the surface, while 66 percent (14,600 tonnes) would adopt a more neutral pattern and oscillate in the water column, and the remaining 7 percent (1,548 tonnes) would sink to the sea floor.

For microplastic leakage, Leak $_{\text {micro, a study by }}$ Cozar et al. (2014) suggests a size-selective removal of debris at the surface, meaning that, while bigger microplastics can accumulate on the surface layer, smaller debris $(<2 \mathrm{~mm})$ is prone to sink. This can be due to biofouling processes, as microplastics require less algal development than larger microplastics to start their journey from surface to seabed (Kooi et al., 2017). Even if this smaller debris can resurface, it is believed that nano particles (10 $\mu \mathrm{m})$ do not. Our estimate of 5,452 tonnes/year ${ }^{-1}$, which does not account for biofouling, would indicate that tyre dust (4,252 tonnes) could be the main microplastic type to sink, while cosmetics (polypropylene) would float (273 tonnes), and fibres (711 tonnes) would show a more neutral pattern. It is considered that pellets (216 tonnes) would adopt the same patterns as macroplastics, where 27 percent (58 tonnes) could float on the surface layer, 66 percent (142 tonnes) could be neutrally buoyant, and 7 percent (16 tonnes) could be sinking.

\subsection{Limitations and conclusions}

The aim of this case study was to map the Marine Plastic Footprint of the Baltic Basin, using best available data and applying the model and equations presented in this report. As many parameters are likely to vary from one country or time period to another, these maps must be seen as indicators of potential hotspots, and not as a pure reflection of the on-the ground reality. Displayed concentrations can evolve or dissipate, due to cleaning campaigns, wind or rain events, and general environmental dynamics.

There are huge discrepancies among waste collection schemes around the Baltic Sea, with some countries generating high levels of mismanaged plastic waste and having few to no waste collection schemes. However, as a general conclusion, the study shows that the Baltic Basin is likely to be more impacted by microplastics than by municipal macro-sized waste.

Given the current state of knowledge on plastic pollution, limitations to this study include:

- Tyre dust: If loss rates for tyres are relatively accurate, this is not the case for the release rates, which are based on only a handful of studies and datasets. In the current model, the hypothesis that the release rates are higher in urban areas (with a higher level of rain run-off making its way towards waterways due to covered terrain) than in rural environments (with a higher fraction of rain run-off being directly channelled towards road adjacent soils) was tested. In addition to the uncertainties on the release rates in urban (12 percent) and rural areas ( 2 percent) used in the model, the share of transport occurring in rural versus urban environments is based on the share of rural versus urban population, which does not necessarily depict the reality of transportation.

- Textiles: Due to a lack of available data, textile washing behaviour has been considered constant for the different countries (average 
load of machines, number of wash cycles per household, share of synthetic textiles), which again may not reflect reality.

- Waste: The mismanaged waste index (MWI) has been calculated from the What a Waste 2.0 report (c.f. Silpa et al., 2018), using the equations proposed in this report. Attention must be paid to the fact that What a Waste 2.0 provides generic waste management statistics, which may differ slightly by location, due to different plastic waste collection schemes or recycling pathways. Furthermore, the release matrix developed to calculate the leakage has not been calibrated. Therefore, it is more pertinent to compare the leakage from different regions in a relative way, rather than providing absolute values. Calibrating the release rate matrix and making it more specific for different types of waste should be a main focus of improvement for future studies. The current approach was based on the best data available to date.

- $\quad$ Littering: The littering rate was assumed to be identical (2 percent), to other authors as in previous studies (Jambeck et al., 2015). Thus, in some countries with a low MWI, this 2 percent littering rate can dominate the leakage calculation and distort the reality. However, for the whole Baltic Basin, 3 percent of the $\mathbf{L e a k}_{\text {waste }}$ is explained by the 2 percent littering rate derived from Jambeck et al. (2015), which seems acceptable in terms of drawing conclusions from the study. It is mainly explained by the fact that the Russian Federation presents considerable mismanaged waste schemes, with very high mismanaged waste indexes, in both rural and urban settings.

\section{HOW MUCH OF THE LEAKING PLASTIC IS FLOATING?}

\section{FLOATING FRACTION} NEUTRAL

\section{SINKING FRACTION}

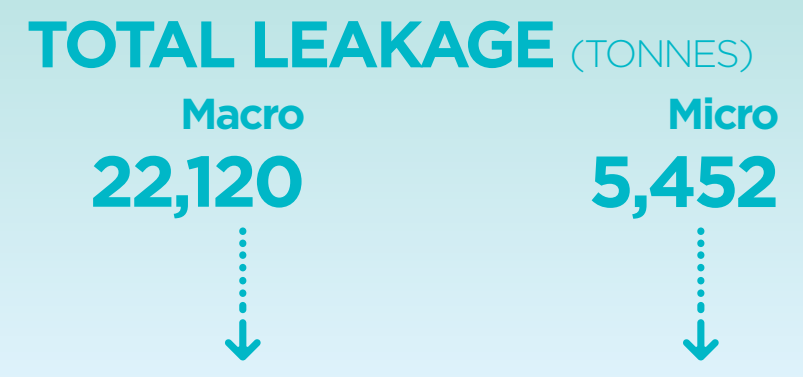

331

853 4,268
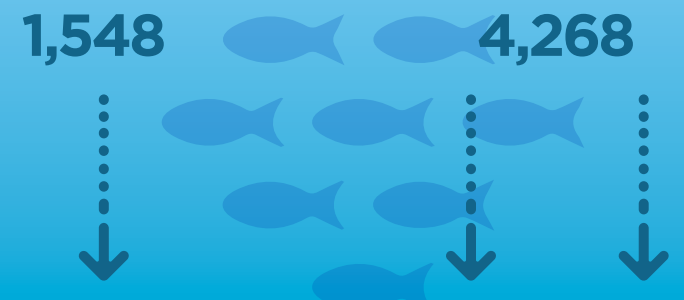

Figure 32: Behaviour of plastic debris in the water column; probable water column loading of the Baltic Sea. 


\section{Outlook for the future}

This report is intended to provide clarity on marine plastic leakage modelling and a first comprehensive set of equations and data to make the methodology applicable.

The report is based on the current knowledge status and the data available. The framework provided should allow further research on key elements that will make this accounting framework even more actionable in the future.

The following areas of focus for future improvements to the methodology are suggested:

- $\quad$ Building a consensus with industries (mainly the tyre/automotive industry and the textile industry) on calculation rules and loss rates, as well as generic data to be used for calculations.

- Developing a more granular set of data to allow for the methodology to become more actionable, for example by capturing the influence of different textile fibres, knitting techniques, or washing parameters, in the case of textiles. In the case of mismanaged waste, it will be essential to refine our understanding of the leakage pathways, considering different waste characteristics as well as local parameters (e.g., wind, slope, urban infrastructure, etc.). Increasing the granularity of the data and improving the understanding of the leakage pathway are key in order to use the Marine Plastic Footprint methodology to guide eco-design projects.

- There may be a need to refine the two percent littering rate adopted by Jambeck et al. (2015), which, in some cases, can be overestimated. A case-by-case, country-specific estimation would greatly help calculations used for estimating local and global Marine Plastic Footprints.
- The methodology allows the user to integrate the degradation rates of different plastics. However, there is no reliable method to measure these degradation times in the marine environment. Therefore, this issue should be resolved, to harness the development of the Marine Plastic Footprint methodology.

- What about plastic neutrality and offsetting? An emerging offsetting scheme concerning plastic is emerging, but it is still applied at a rather small scale. The plastic methodology could be used to scale-up and monitor plastic offsetting projects. This should be investigated further in the future.

- These "top-down" approaches would benefit from a level of validation in the field, to compare the modelled predictions with the reality ("bottom-up" approach). Riverine systems, known to be vectors of plastic pollution, would be ideal sampling environments to calibrate modelled predictions.

- $\quad$ There is now sufficient evidence to say that plastic pollution is ubiquitous in the marine environment. Allocating resources to shift towards a more circular economy would be greatly beneficial, as would adopting measures to reduce the usage of single-use plastics.

- Integrating an impact assessment aspect in the future would expand and strengthen this footprinting methodology. However, this aspect still requires years of research to understand the full scale of threats presented by plastic pollution. Linking this impact assessment to ecosystem services could create a tool to evaluate the damages to both wildlife and human well-being, to help reduce negative impacts on the environment. 


\section{References}

American Chemistry Council (2016). Plastics and Sustainability: A Valuation of Environmental Benefits, Costs and Opportunities for Continuous Improvement. American Chemistry Council.

Aoustin, E., Vargas-Gonzalez, M., Thevenet, C. and Bussard, A. (2015). Economie circulaire: concepts et méthodes d'évaluation. Villeurbanne, France: SCORELCA

Boucher, J., Faure, F., Pompini, O., Plummer, Z., Wieser, O. and Felippe de Alencastro, L. (2019). '(Micro) plastic fluxes and stocks in Lake Geneva basin'. TrAC Trends Anal. Chem. 112, 66-74. https:// doi.org/10.1016/i.trac.2018.11.037

Boucher, J. and Friot, D. (2017). Primary

Microplastics in the Oceans: a Global Evaluation of Sources. Gland, Switzerland: IUCN. https://doi. org/10.2305/IUCN.CH.2017.01.en

Boucher, J., Dubois, C. Kounina, A. and Puydarrieux, P. (2019). Review of plastic footprint methodologies: laying the foundation for the development of a standardised plastic footprint measurement tool. Gland, Switzerland: IUCN. https://doi.org/10.2305/IUCN.CH.2019.10.en

Browne, M.A., Crump, P., Niven, S.J., Teuten, E., Tonkin, A., Galloway, T. and Thompson, R. (2011). 'Accumulation of Microplastic on Shorelines Worldwide: Sources and Sinks'. Environ. Sci. Technol. 45, 9175-9179. https://doi.org/10.1021/ $\underline{\text { es201811s }}$

Camatini, M., Crosta, G.F., Dolukhanyan, T., Sung, C., Giuliani, G., Corbetta, G.M., Cencetti, S. and Regazzoni, C. (2001). 'Microcharacterization and identification of tire debris in heterogeneous laboratory and environmental specimens'. Mater Charact 46, 271-283. https://doi.org/10.1016/S10445803(00)00098-X

Carr, S.A. (2017). 'Sources and dispersive modes of micro-fibers in the environment: Environmental Microfiber Sources'. Integr. Environ. Assess. Manag. 13, 466-469. https://doi.org/10.1002/ieam.1916

Cascadia Consulting Group Inc. (2005).

Washington 2004 State Litter Study: Litter Generation and Composition Report. Washing State Department of Ecology.

Center for International Environmental Law (CIEL) (2017). How Fracked Gas, Cheap Oil and Umburnable Coal are Driving the Plastics Boom. Washington, D.C., USA: CIEL.

Charters, F.J., Cochrane, T.A. and O'Sullivan, A.D. (2015). 'Particle size distribution variance in untreated urban runoff and its implication on treatment selection'. Water Res. 85, 337-345. https://doi.org/10.1016/i.watres.2015.08.029

Cincinelli, A., Martellini, T., Guerranti, C., Scopetani, C., Chelazzi, D. and Giarrizzo, T. (2019). 'A potpourri of microplastics in the sea surface and water column of the Mediterranean Sea'. TrAC Trends Anal. Chem. 110, 321-326. https://doi.org/10.1016/j. trac.2018.10.026

De Falco, F., Gullo, M.P., Gentile, G., Di Pace, E., Cocca, M., Gelabert, L., Brouta-Agnésa, M., Rovira, A., Escudero, R., Villalba, R., Mossotti, R., Montarsolo, A., Gavignano, S., Tonin, C. and Avella, M. (2018). 'Evaluation of microplastic release caused by textile washing processes of synthetic fabrics'. Environ. Pollut. 236, 916-925. https://doi. org/10.1016/j.envpol.2017.10.057

Ellen MacArthur Foundation (EMF) (2015). Circularity Indicators For Measuring Circularity In A Circular Economy. Available at: https://www. ellenmacarthurfoundation.org/programmes/ insight/circularity-indicators/ (Accessed: 19 May 2018).

Energy Efficiency (2010) 3:365-382 DOI 10.1007/ s12053-009-9072-8 Electricity and water consumption for laundry washing by washing machine worldwide

Essel, R., Engel, L., Carus, M. and Ahrens, D.R.H. (2015). Sources of microplastics relevant to marine protection in Germany. Texte 64/2015. Germany: Federal Environment Agency. Available at: https:// www.umweltbundesamt.de/sites/default/files/ medien/378/publikationen/texte_64_2015_ sources of microplastics relevant to marine protection_1.pdf

Eunomia (2016). Plastics in the Marine Environment. Bristol, U.K.: Eunomia.

Gewert, B., Ogonowski, M., Barth, A. and MacLeod, M. (2017). 'Abundance and composition of near surface microplastics and plastic debris in the Stockholm Archipelago, Baltic Sea'. Mar. Pollut. Bull. 120, 292-302. https://doi.org/10.1016/j. marpolbul.2017.04.062

Geyer, R., Jambeck, J.R. and Law, K.L. (2017). 'Production, use, and fate of all plastics ever made'. Sci. Adv. 3, e1700782. https://doi.org/10.1126/ sciadv.1700782

Global Reporting Initiative (GRI) (2016). Defining What Matters - Do companies and investors agree on what is material?. Amsterdam, the Netherlands: GRI.

Gustafsson, M., Blomqvist, G., Gudmundsson, A., Swietlicki, E., Bohgard, M., Lindbom, J. and 
Ljungman, A. (2008). 'Properties and toxicological effects of particles from the interaction between tyres, road pavement and winter traction material'. Sci Total Env. 393, 226-240. https://doi. org/10.1016/i.scitotenv.2007.12.030

Hartline, N.L., Bruce, N.J., Karba, S.N., Ruff, E.O., Sonar, S.U., Holden, P.A., (2016). 'Microfiber masses recovered from conventional machine washing of new or aged garments'. Environ. Sci. Technol. 50, 11532-11538. https://doi.org/10.1021/acs. est. $6 \mathrm{~b} 03045$

Hernandez, E., Nowack, B. and Mitrano, D.M. (2017). 'Polyester Textiles as a Source of Microplastics from Households: A Mechanistic Study to Understand Microfiber Release During Washing'. Environ. Sci. Technol. 51, 7036-7046. https://doi. org/10.1021/acs.est.7b01750

Hurley, R., Woodward, J. and Rothwell, J.J. (2018). 'Microplastic contamination of river beds significantly reduced by catchment-wide flooding'. Nat. Geosci. 11, 251-257. https://doi.org/10.1038/ s41561-018-0080-1

International Organization for Standardization (ISO) (2006). Management environnemental Analyse du cycle de vie - Principes et cadre. ISO 14040:2006(fr)

ISO (2013). Plastics - Vocabulary. ISO 472:2013

Available at: https://www.iso.org/obp/

ui/\#iso:std:iso:472:ed-4:v1:en (Accessed: 2 January 2018).

Jambeck, J. R., Geyer, R., Wilcox, C., Siegler, T.R., Perryman, M. and Andrady, A. (2015). 'Plastic waste inputs from land into the ocean'. Science 347. https://doi.org/10.1126/science.1260352

Jambeck, Jenna R., Geyer, R., Wilcox, C., Siegler, T.R., Perryman, M., Andrady, A., Narayan, R. and Law, K.L. (2015). 'Plastic waste inputs from land into the ocean'. Science 347, 768-771. https://doi. org/10.1126/science.1260352

Keep Australia Beautiful (2017). National litter index 2016-2017. https://kab.org.au/

Kole, P.J., Löhr, A. and Ragas, A. (2015)

'Autobandenslijtstof: Een verwaarloosde bron van microplastics?' Milieu Opinieblad Van Ver. Van Milieuprofessionals Vvm 5, 39-41.

Kole, P.J., Löhr, A.J., Van Belleghem, F.G.A.J. and Ragas, A.M.J. (2017a). 'Wear and Tear of Tyres: A Stealthy Source of Microplastics in the Environment'. Int. J. Environ. Res. Public. Health 14, 1265. https://doi.org/10.3390/ijerph14101265

Kooi, M., Nes, E.H. van, Scheffer, M. and Koelmans, A.A. (2017). 'Ups and Downs in the Ocean: Effects of Biofouling on Vertical Transport of Microplastics'. Environ. Sci. Technol. 51, 7963-7971. https://doi.org/10.1021/acs.est.6b04702
Krauss, R.M., Freedman, J.L. and Whitcup, M (1978). 'Field and laboratory studies of littering'. J. Exp. Soc. Psychol. 14, 109-122. https://doi. org/10.1016/0022-1031(78)90064-1

Kwak, J.H., Kim, H., Lee, J. and Lee, S. (2013). Characterization of non-exhaust coarse and fine particles from on-road driving and laboratory measurements'. Sci Total Env. 458-460, 273-282. https://doi.org/10.1016/i.scitotenv.2013.04.040

Lassen, C., Hansen, S.F., Magnusson, K., Hartmann, N.B., Pernille, R.J., Nielsen, T.G. and Brinch, A. (2015). Microplastics - Occurrence, effects and sources of releases to the environment in Denmark. Copenhagen, Denmark: Danish Environment Protection Agency.

Lebreton, L.C.M., van der Zwet, J., Damsteeg, J.W., Slat, B., Andrady, A. and Reisser, J. (2017). 'River plastic emissions to the world's oceans'. Nat. Commun. 8, 15611. https://doi.org/10.1038/ ncomms15611

Linder, M., Sarasini, S. and Loon, P. (2017). 'A Metric for Quantifying Product-Level Circularity'. J. Ind. Ecol. 21, 545-558. https://doi.org/10.1111/iiec.12552

Magnusson, K., Eliasson, K., Fråne, A., Haikonen, K., Hultén, J., Olshammar, M., Stadmark, J. and Voisin, A. (2016). Swedish Sources and Pathways for Microplastics to the Marine Environment. Stockholm, Sweden: IVL Svenska Miljöinstitutet.

McKinsey Center for Business and Environment and Ocean Conservancy (2015). Stemming the Tide. Land-based strategies for a plastic - free ocean. Available at: https://www.mckinsey.com/ business-functions/sustainability/our-insights/ stemming-the-tide-land-based-strategies-for-aplastic-free-ocean

Medellin declaration (2016). Medellin Declaration on Marine Litter in Life Cycle Assessment and Management.

Napper, I.E. and Thompson, R.C. (2016). 'Release of synthetic microplastic plastic fibres from domestic washingmachines: Effects of fabric type and washing conditions'. Mar. Pollut. Bull. 112, 39-45. https://doi.org/10.1016/i.marpolbul.2016.09.025

Otero, J.C. and Pizarro, I.O. (2017). 'Circularity assessment in companies: conceptual elements for developing assessment tools'. Delivered at the 23rd Annu. Int. Sustain. Dev. Res. Soc. ISDRS Conf.

Pirc, U., Vidmar, M., Mozer, A. and Kržan, A. (2016). Emissions of microplastic fibers from microfiber fleece during domestic washing'. Environ. Sci. Pollut. Res. 23, 22206-22211. https://doi. org/10.1007/s11356-016-7703-0

PlasticsEurope (2014). Plastics - the Facts 2014/2015 An analysis of European plastics production, demand and waste data. 
Rheinheimer, G. (1998). 'Pollution in the Baltic Sea'. Nat. Wiss. Rev. Artic. 11.

Ryan, P.G. (2015). 'A Brief History of Marine Litter Research'. In: Marine Anthropogenic Litter pp. 1-25. Springer. https://doi.org/10.1007/978-3-319-165103ـ1

Saidani, M., Yannou, B., Leroy, Y. and Cluzel, F. (2017). 'How to Assess Product Performance in the Circular Economy? Proposed Requirements for the Design of a Circularity Measurement Framework'. Recycling 2. https://doi.org/10.3390/ recycling2010006

Schmidt, C., Krauth, T. and Wagner, S. (2017). 'Export of Plastic Debris by Rivers into the Sea'. Environ. Sci. Technol. 51, 12246-12253. https://doi. org/10.1021/acs.est.7b02368

Schultz, P.W. (2009). Littering Behavior in America: Results of a National Study. Prepared for Keep America Beautiful.

Silpa, K., Yao, L., Bhada-Tata, P. and Van Woerden, F. (2018). What a Waste 2.0: A Global Snapshot of Solid Waste Management to 2050, Urban Development Series. Washington, D.C.: World Bank.

Sundt, P., Schulze, P.-E. and Syversen, F. (2014). Sources of microplastic-pollution to the marine environment. Norway: Norwegian Environment Agency.

TOBIN Consulting Engineers (2016). Litter Monitoring Body System Results 2016.

United Nations (UN) Environment (2018). Mapping of global plastics value chain and plastics losses to the environment (with a particular focus on marine environment). Nairobi, Kenya: UN Environment.

UNEP (2016). Marine plastic debris and microplastics - Global lessons and research to inspire action and guide policy change. Nairobi, Kenya: UNEP.

Cheshire, A.C., Adler, E., Barbière, J., Cohen, Y., Evans, S., Jarayabhand, S., Jeftic, L., Jung, R.T., Kinsey, S., Kusui, E.T., Lavine, I., Manyara, P., Oosterbaan, L., Pereira, M.A., Sheavly, S., Tkalin, A., Varadarajan, S., Wenneker, B. and Westphalen, G. (2009). UNEP/IOC Guidelines on Survey and Monitoring of Marine Litter. UNEP Regional Seas Reports and Studies No. 186; IOC Technical Series No. 83. Available at: http://wedocs.unep.org/xmlui/ handle/20.500.11822/13604

Unice, K.M., Weeber, M.P., Abramson, M.M., Reid, R.C.D., van Gils, J. A. G., Markus, A.A., Vethaak, A.D. and Panko, J.M. (2018a). 'Characterizing export of land-based microplastics to the estuary - Part I: Application of integrated geospatial microplastic transport models to assess tire and road wear particles in the Seine watershed'. Sci. Total Environ. https://doi.org/10.1016/i.scitotenv.2018.07.368
Unice, K.M., Weeber, M.P., Abramson, M.M., Reid, R.C.D., van Gils, J.A.G., Markus, A.A., Vethaak, A.D., Panko, J.M., 2018b. Characterizing export of land-based microplastics to the estuary - Part II: Sensitivity analysis of an integrated geospatial microplastic transport modeling assessment of tire and road wear particles. Sci. Total Environ. https:// doi.org/10.1016/j.scitotenv.2018.08.301

Van Duijnhove, N., Denier van der Gon, H. and Hulskotte, J. (2014). Emissieschattingen Diffuse Bronnen Emissieregistratie-Bandenslijtage Wegverkeer. Delft, the Netherlands: DELTARES en TNO.

Velis, C., Lerpiniere, D. and Tsakona, M. (2017). How to prevent marine plastic litter - now! An ISWA facilitated partnership to prevent marine litter, with a global call to action for investing in sustainable waste and resources management worldwide. Vienna, Austria.

Verschoor, A., De Poorter, L., Dröge, R., Kuenen, J. and De Valk, E. (2016). Emission of Microplastics and Potential Mitigation Measures. Abrasive Cleaning Agents, Paints and Tyre Wear. Bilthoven, the Netherlands: National Institute for Public Health and the Environment (RIVM).

Wagner, S., Hüffer, T., Klöckner, P., Wehrhahn, M., Hofmann, T. and Reemtsma, T. (2018). 'Tire wear particles in the aquatic environment - A review on generation, analysis, occurrence, fate and effects'. Water Res. 139, 83-100. https://doi.org/10.1016/j. watres.2018.03.051

Woods, J.S., Veltman, K., Huijbregts, M.A.J., Verones, F. and Hertwich, E.G. (2016). 'Towards a meaningful assessment of marine ecological impacts in life cycle assessment (LCA)'. Environ. Int. 89-90, 48-61. https://doi.org/10.1016/i. envint.2015.12.033

World Economic Forum (WEF) (2016). The New Plastic Economy. Rethinking the future of plastics. Geneva, Switzerland: WEF. Available at: http:// www3.weforum.org/docs/WEF_The New_ Plastics Economy.pdf. 


\section{Appendices}

\section{Appendix 1. Textile loss rates}

Figure 33: Summary of the different textile loss rates reported in the literature. A central loss value of $124 \mathrm{mg} / \mathrm{kg}$ was chosen for the purpose of this report.

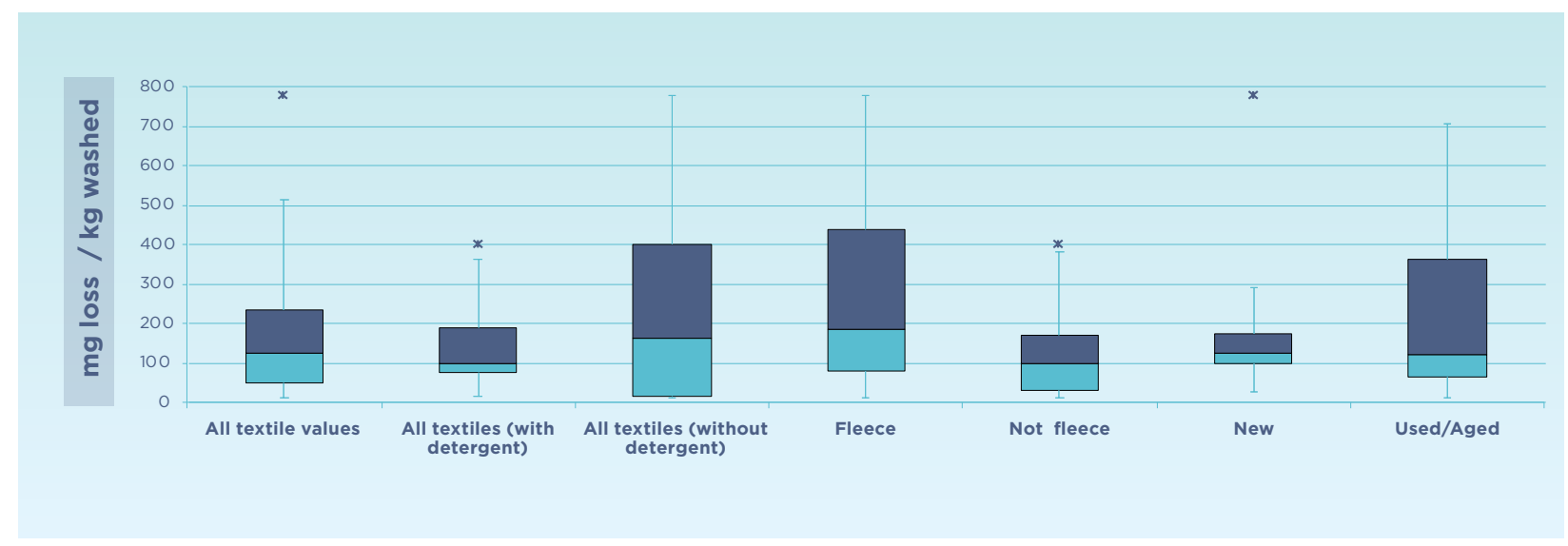

\section{Appendix 2. Tyre dust loss rates}

Figure 34: Summary of the different loss rates of tyres reported in the literature. A central loss value of $102 \mathrm{mg} / \mathrm{km}$ was chosen for the purpose of this report.

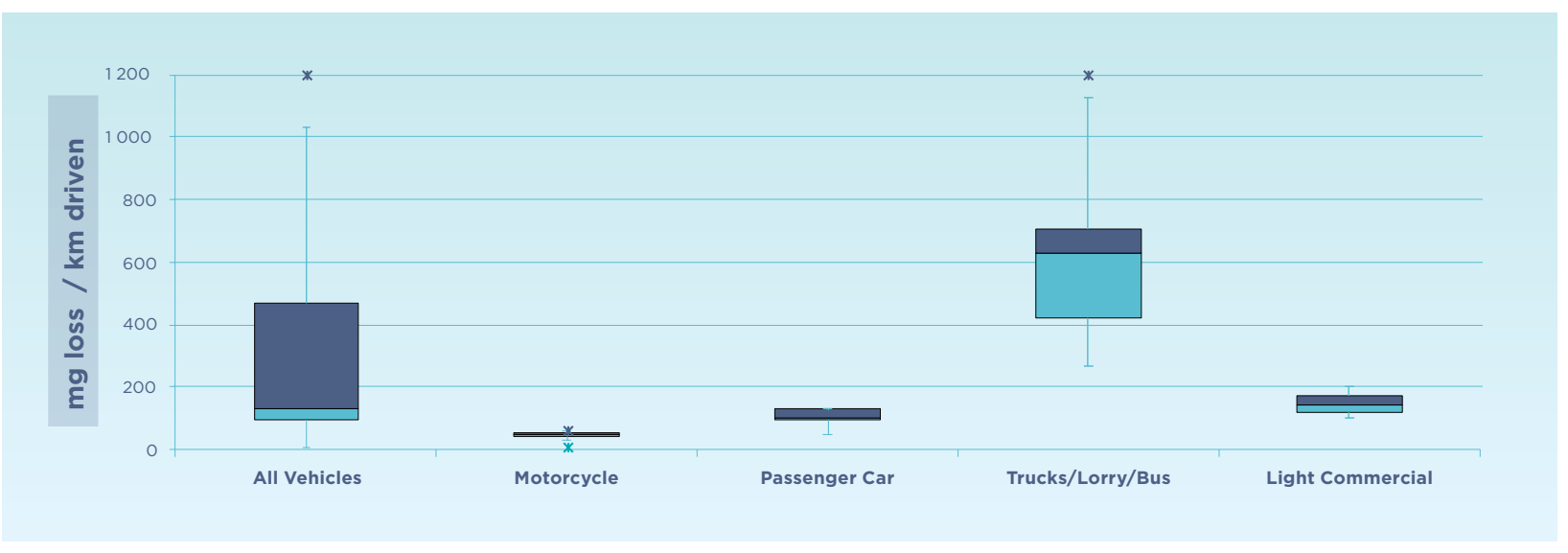




\section{Appendix 3. Wastewater pathway release rate}

\subsection{Efficiency of wastewater treatment plants in removing microplastics}

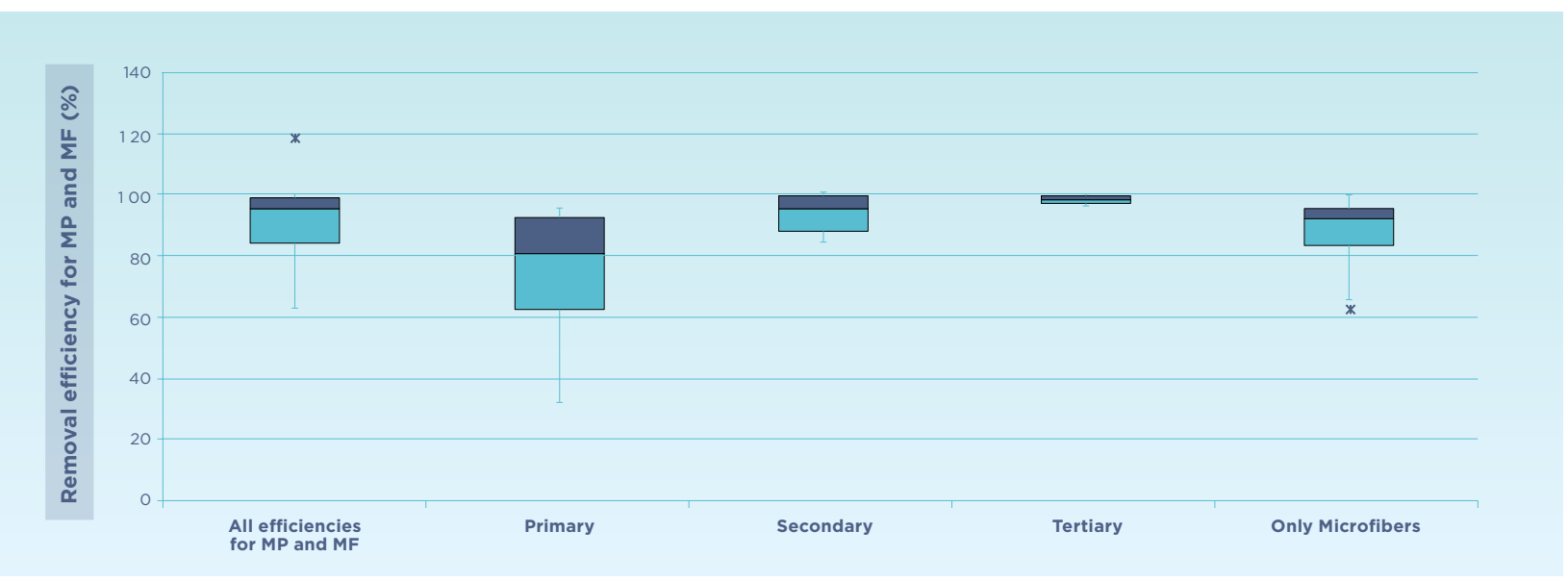

Figure 35: Efficiency of wastewater treatment plants in the removal of microplastics (including microfibres).

Table 13: Share of treated wastewater by country

\begin{tabular}{|c|c|c|c|c|c|}
\hline \multirow{2}{*}{ Country } & $\begin{array}{c}\text { Connection to } \\
\text { sewage system } \\
(\%)\end{array}$ & $\begin{array}{c}\text { Fraction of treatment } \\
\text { levels of collected } \\
\text { wastewater }(\%)\end{array}$ & (\%) & (\%) & (\%) \\
\cline { 2 - 6 } & Non-treated & Primary & Secondary & Tertiary \\
\hline
\end{tabular}

\begin{tabular}{lrrrrr} 
Afghanistan & 1 & 0 & 100 & 0 & 0 \\
\hline Albania & 66.7 & 34.9 & 32.6 & 32.6 & 0 \\
\hline Algeria & 78.7 & 44.4 & 55.6 & 0 & 0 \\
\hline American Samoa & 1 & 100 & 0 & 0 & 0 \\
\hline Andorra & 98 & 0 & 0 & 100 & 0 \\
\hline Angola & 1 & 100 & 0 & 0 & 0 \\
\hline
\end{tabular}

Anguilla $\quad 0 \quad 100$

\begin{tabular}{lll}
\hline Antarctica & 0 & 100
\end{tabular}

\begin{tabular}{lrrrrr}
\hline Antigua \& Barbuda & 65 & 0 & 66.7 & 33.3 & 0 \\
\hline Argentina & 42.5 & 0 & 100 & 0 & 0 \\
\hline Armenia & 62.6 & 70.2 & 14.9 & 14.9 & 0 \\
\hline Aruba & 0 & 100 & & &
\end{tabular}

\begin{tabular}{lrrrrr}
\hline Aruba & 0 & 100 & & & \\
\hline Australia & 88.5 & 8.5 & 34.6 & 51.9 & 5.1 \\
\hline Austria & 96.6 & 3.3 & 0 & 10.1 & 86.6 \\
\hline Azerbaijan & 4.5 & 74.1 & 25.9 & 0 & 0 \\
\hline Bahrain & 91.6 & 0 & 50 & 50 & 0 \\
\hline Bangladesh & 2.8 & 100 & 0 & 0 & 0 \\
\hline Barbados & 0 & 100 & & & 0 \\
\hline Belarus & 46 & 0 & 0 & 100 & 33.4 \\
\hline Belgium & 87.9 & 20.7 & 0 & 45.9 & 0 \\
\hline Belize & 15.1 & 0 & 100 & 0 & 0 \\
\hline Benin & 1.3 & 100 & 0 & 0 & 0
\end{tabular}




\begin{tabular}{|c|c|c|c|c|c|}
\hline \multirow[t]{2}{*}{ Country } & \multirow{2}{*}{$\begin{array}{l}\text { Connection to } \\
\text { sewage system } \\
(\%)\end{array}$} & $\begin{array}{l}\text { Fraction of treatment } \\
\text { levels of collected } \\
\text { wastewater (\%) }\end{array}$ & $(\%)$ & $(\%)$ & $(\%)$ \\
\hline & & Non-treated & Primary & Secondary & Tertiary \\
\hline Bermuda & 5 & 0 & 100 & 0 & 0 \\
\hline Bhutan & 1 & 0 & 100 & 0 & 0 \\
\hline Bolivia & 39.5 & 91.7 & 8.3 & 0 & 0 \\
\hline Bosnia and Herzegovina & 5 & 0 & 50 & 50 & 0 \\
\hline Botswana & 2.6 & 100 & 0 & 0 & 0 \\
\hline Bouvet I. & 0 & 100 & & & \\
\hline Brazil & 53 & 70.5 & 29.5 & 0 & 0 \\
\hline $\begin{array}{l}\text { British Indian Ocean } \\
\text { Territory }\end{array}$ & 0 & 100 & & & \\
\hline British Virgin Islands & 24.5 & 0 & 66.7 & 33.3 & 0 \\
\hline Brunei & 0 & 100 & & & \\
\hline Bulgaria & 70.4 & 55.6 & 1.2 & 43.2 & 0 \\
\hline Burkina Faso & 1 & 100 & 0 & 0 & 0 \\
\hline Burundi & 1 & 100 & 0 & 0 & 0 \\
\hline Cambodia & 12.1 & 100 & 0 & 0 & 0 \\
\hline Cameroon & 1 & 100 & 0 & 0 & 0 \\
\hline Canada & 78.3 & 0.5 & 19.6 & 37.8 & 42 \\
\hline Cape Verde & 0 & 100 & & & \\
\hline Cayman Is. & 40 & 0 & 100 & 0 & 0 \\
\hline Central African Republic & 1 & 100 & 0 & 0 & O \\
\hline Chad & 1 & 100 & 0 & 0 & 0 \\
\hline Chile & 96.7 & 0.2 & 99.8 & 0 & 0 \\
\hline China & 51.2 & 86 & 14 & 0 & 0 \\
\hline Christmas I. & 0 & 100 & & & \\
\hline Cocos Is. & O & 100 & & & \\
\hline Colombia & 72.6 & 76.2 & 23.8 & 0 & $\mathrm{O}$ \\
\hline Comoros & 0 & 100 & & & \\
\hline Congo & 5 & 100 & 0 & 0 & 0 \\
\hline Congo, DRC & 1.6 & 100 & 0 & 0 & O \\
\hline Cook Is. & 1 & 100 & 0 & 0 & 0 \\
\hline Costa Rica & 30.8 & 96 & 4 & 0 & 0 \\
\hline Cote d'Ivoire & 4.6 & 100 & 0 & 0 & 0 \\
\hline Croatia & 45.2 & 62.7 & 18.65 & 18.65 & O \\
\hline Cuba & 44 & 39.5 & 60.5 & 0 & 0 \\
\hline Cyprus & 60.5 & 34.4 & 0 & 0 & 65.6 \\
\hline Czech Republic & 81.5 & 10.5 & 2.5 & 18.6 & 68.4 \\
\hline Denmark & 87.9 & 0 & 2.2 & 3.4 & 94.4 \\
\hline Djibouti & 5.2 & 100 & 0 & 0 & 0 \\
\hline Dominica & 23 & 100 & 0 & 0 & 0 \\
\hline Dominican Republic & 32.6 & 77.6 & 22.4 & 0 & O \\
\hline Ecuador & 56.3 & 95 & 5 & 0 & 0 \\
\hline Egypt & 46.8 & 17.5 & 82.5 & 0 & 0 \\
\hline El Salvador & 42.7 & 98 & 2 & 0 & 0 \\
\hline
\end{tabular}




\begin{tabular}{|c|c|c|c|c|c|}
\hline \multirow[t]{2}{*}{ Country } & \multirow{2}{*}{$\begin{array}{l}\text { Connection to } \\
\text { sewage system } \\
(\%)\end{array}$} & $\begin{array}{l}\text { Fraction of treatment } \\
\text { levels of collected } \\
\text { wastewater (\%) }\end{array}$ & (\%) & (\%) & (\%) \\
\hline & & Non-treated & Primary & Secondary & Tertiary \\
\hline Equatorial Guinea & 1 & 100 & 0 & 0 & 0 \\
\hline Eritrea & 1 & 100 & 0 & 0 & 0 \\
\hline Estonia & 75.2 & 14 & 1.2 & 34.9 & 49.9 \\
\hline Ethiopia & 0.9 & 100 & 0 & 0 & 0 \\
\hline Falkland Is. & 0 & 100 & & & \\
\hline Faroe Is. & 0 & 100 & & & \\
\hline Fiji & 1 & 100 & 0 & O & $\mathrm{O}$ \\
\hline Finland & 84.1 & 9.1 & 0 & 0 & 90.9 \\
\hline France & 82 & 9.8 & 2.3 & 57.5 & 30.4 \\
\hline French Guiana & 44 & 0 & 100 & 0 & O \\
\hline French Polynesia & 0 & 100 & & & \\
\hline $\begin{array}{l}\text { French Southern \& } \\
\text { Antarctic Lands }\end{array}$ & 41 & 0 & 66.7 & 33.3 & $\mathrm{O}$ \\
\hline Gabon & 1 & 100 & 0 & 0 & 0 \\
\hline Georgia & 1 & 0 & 100 & 0 & $\mathrm{O}$ \\
\hline Germany & 97.3 & 1.9 & O & 5.3 & 92.8 \\
\hline Ghana & 5.4 & 100 & 0 & 0 & 0 \\
\hline Gibraltar & 0 & 100 & & & \\
\hline Greece & 86 & 9.3 & 55.8 & 24.4 & 10.5 \\
\hline Greenland & 0 & 100 & & & \\
\hline Grenada & 65 & 0 & 100 & 0 & 0 \\
\hline Guadeloupe & 38.9 & 0 & 100 & 0 & 0 \\
\hline Guam & 0 & 100 & & & \\
\hline Guatemala & 42.5 & 99 & 1 & 0 & $\mathrm{O}$ \\
\hline Guinea & 11 & 100 & O & 0 & 0 \\
\hline Guinea-Bissau & 1 & 100 & 0 & 0 & 0 \\
\hline Guyana & 0 & 100 & & & \\
\hline Haiti & 1.7 & 100 & 0 & 0 & 0 \\
\hline Heard I. \& McDonald Is. & 0 & 100 & & & \\
\hline Honduras & 34.1 & 97 & 3 & 0 & 0 \\
\hline Hungary & 66 & 18.7 & 5.1 & 61 & 15.2 \\
\hline Iceland & 93.5 & 35.2 & 32.4 & 32.4 & 0 \\
\hline India & 6.5 & 100 & 0 & 0 & 0 \\
\hline Indonesia & 5 & 100 & & 100 & \\
\hline Iran & 28.6 & 95.8 & 2.1 & 2.1 & 0 \\
\hline Iraq & 25.2 & 74.3 & 12.85 & 12.85 & 0 \\
\hline Ireland & 67.2 & 6 & 57.3 & 29.8 & 6.9 \\
\hline Isle of Man & 0 & 100 & & & \\
\hline Israel & 100 & 17 & 41.5 & 41.5 & 0 \\
\hline Italy & 69 & 0 & 4.8 & 57.1 & 38.1 \\
\hline Jamaica & 16.5 & 84.7 & 15.3 & 0 & 0 \\
\hline Jan Mayen & 0 & 100 & & & \\
\hline Japan & 67 & 0 & 0 & 84.4 & 15.6 \\
\hline Jordan & 53.6 & 39 & 30.5 & 30.5 & 0 \\
\hline
\end{tabular}




\begin{tabular}{|c|c|c|c|c|c|}
\hline \multirow[t]{2}{*}{ Country } & \multirow{2}{*}{$\begin{array}{c}\text { Connection to } \\
\text { sewage system } \\
(\%)\end{array}$} & $\begin{array}{l}\text { Fraction of treatment } \\
\text { levels of collected } \\
\text { wastewater (\%) }\end{array}$ & $(\%)$ & $(\%)$ & (\%) \\
\hline & & Non-treated & Primary & Secondary & Tertiary \\
\hline Kazakhstan & 40.3 & 42 & 58 & 0 & 0 \\
\hline Kenya & 7.4 & 95.1 & 4.9 & 0 & 0 \\
\hline Kiribati & 1 & 100 & 0 & 0 & 0 \\
\hline Korea, Republic of & 87 & 22.6 & 77.4 & 0 & $\mathrm{O}$ \\
\hline Kuwait & 96 & 0 & 50 & 50 & O \\
\hline Kyrgyzstan & 16.6 & 99.9 & 0.1 & 0 & 0 \\
\hline Laos & 3.3 & 100 & 0 & 0 & 0 \\
\hline Latvia & 71 & 35.8 & 2 & 26.7 & 35.6 \\
\hline Lebanon & 13 & 0 & 50 & 50 & 0 \\
\hline Lesotho & 1.5 & 100 & 0 & 0 & O \\
\hline Liberia & 1 & 100 & 0 & 0 & 0 \\
\hline Libya & 8 & 0 & 100 & 0 & $\mathrm{O}$ \\
\hline Liechtenstein & 0 & 100 & & & \\
\hline Lithuania & 58.5 & 25 & 47.6 & 8.7 & 18.8 \\
\hline Luxembourg & 95 & 1.9 & 7.2 & 77.4 & 13.4 \\
\hline Macedonia & 0 & 100 & & & \\
\hline Madagascar & 2.9 & 100 & 0 & 0 & 0 \\
\hline Malawi & 0.8 & 100 & 0 & 0 & 0 \\
\hline Malaysia & 15 & 100 & 0 & 0 & 0 \\
\hline Maldives & 49.4 & 55.8 & 44.2 & 0 & 0 \\
\hline Mali & 1 & 100 & 0 & 0 & 0 \\
\hline Malta & 99.7 & 53.1 & 23.5 & 23.5 & 0 \\
\hline Marshall Islands & 44 & 100 & 0 & 0 & O \\
\hline Martinique & 46.4 & 53.7 & 46.3 & 0 & 0 \\
\hline Mauritania & 1.2 & 100 & 0 & 0 & O \\
\hline Mauritius & 27.8 & 72.2 & 27.8 & 0 & 0 \\
\hline Mayotte & 0 & 100 & & & \\
\hline Mexico & 77.3 & 46.1 & 0 & 53.9 & 0 \\
\hline Micronesia & 1 & 100 & 0 & 0 & 0 \\
\hline Monaco & 100 & 0 & 66.7 & 33.3 & 0 \\
\hline Mongolia & 20.5 & 100 & 0 & 0 & 0 \\
\hline Montserrat & 100 & 0 & 66.7 & 33.3 & 0 \\
\hline Morocco & 57.1 & 59.4 & 40.6 & 0 & 0 \\
\hline Mozambique & 1.2 & 100 & 0 & 0 & 0 \\
\hline Myanmar & 5.9 & 100 & 0 & 0 & 0 \\
\hline Namibia & 31 & 98.3 & 1.7 & 0 & 0 \\
\hline Nauru & 1 & 100 & 0 & 0 & 0 \\
\hline Nepal & 6.7 & 100 & 0 & 0 & O \\
\hline Netherlands & 99.7 & 0.2 & 0 & 17.3 & 82.5 \\
\hline Netherlands Antilles & 17 & 0 & 100 & 0 & 0 \\
\hline New Caledonia & 0 & 100 & & & \\
\hline New Zealand & 80 & 0 & 8.8 & 41.3 & 50 \\
\hline Nicaragua & 19.6 & 99.7 & 0.3 & 0 & 0 \\
\hline Niger & 1 & 100 & 0 & 0 & 0 \\
\hline
\end{tabular}




\begin{tabular}{|c|c|c|c|c|c|}
\hline \multirow[t]{2}{*}{ Country } & \multirow[t]{2}{*}{$\begin{array}{l}\text { Connection to } \\
\text { sewage system } \\
\text { (\%) }\end{array}$} & $\begin{array}{l}\text { Fraction of treatment } \\
\text { levels of collected } \\
\text { wastewater (\%) }\end{array}$ & (\%) & $(\%)$ & $(\%)$ \\
\hline & & Non-treated & Primary & Secondary & Tertiary \\
\hline Nigeria & 1 & 100 & 0 & 0 & 0 \\
\hline Nive & 1 & 100 & 0 & 0 & 0 \\
\hline Norfolk I. & 0 & 100 & & & \\
\hline North Korea & 20 & 0 & 100 & 0 & 0 \\
\hline Northern Mariana Is. & 0 & 100 & & & \\
\hline Norway & 83.1 & 9.6 & 27.2 & 1.2 & 61.9 \\
\hline Oman & 49 & 0 & 50 & 50 & 0 \\
\hline Pakistan & 25.6 & 98.8 & 1.2 & 0 & 0 \\
\hline Palau & 1 & 100 & 0 & 0 & 0 \\
\hline Panama & 52.4 & 41.2 & 58.8 & 0 & O \\
\hline Papua New Guinea & 1 & 100 & 0 & 0 & 0 \\
\hline Paraguay & 12.7 & 54.3 & 45.7 & 0 & 0 \\
\hline Peru & 62.7 & 0 & 100 & 0 & 0 \\
\hline Philippines & 37.3 & 100 & 0 & 0 & 0 \\
\hline Pitcairn Is. & 0 & 100 & & & \\
\hline Poland & 62.1 & 32.6 & 3.7 & 35.5 & 28.2 \\
\hline Portugal & 80.8 & 12.7 & 27.7 & 55.4 & 4.3 \\
\hline Puerto Rico & 100 & 0 & 100 & 0 & 0 \\
\hline Qatar & 70 & 0 & 50 & 50 & 0 \\
\hline Republic of Moldova & 35.3 & 19.7 & 40.2 & 40.2 & 0 \\
\hline Réunion & 41.3 & 100 & 0 & 0 & 0 \\
\hline Romania & 41.8 & 70.4 & 29.6 & 0 & 0 \\
\hline Russia & 60.5 & 87.8 & 6.1 & 6.1 & O \\
\hline Rwanda & 1 & 100 & 0 & 0 & 0 \\
\hline Samoa & 1 & 0 & 66.7 & 33.3 & 0 \\
\hline San Marino & 100 & 0 & 66.7 & 33.3 & 0 \\
\hline Sao Tome \& Principe & 0 & 100 & & & \\
\hline Saudi Arabia & 28 & 0 & 50 & 50 & 0 \\
\hline Senegal & 9.1 & 100 & 0 & 0 & 0 \\
\hline Serbia & 53.6 & 81.7 & 12.2 & 6.1 & 0 \\
\hline Seychelles & 100 & 100 & 0 & 0 & 0 \\
\hline Sierra Leone & 0.1 & 100 & 0 & 0 & 0 \\
\hline Singapore & 100 & 0 & 0 & 19 & 81 \\
\hline Slovakia & 58.3 & 21.3 & 0 & 78.7 & 0 \\
\hline Slovenia & 68.8 & 25.7 & 35.2 & 19.6 & 19.6 \\
\hline Solomon Is. & 1 & 100 & 0 & 0 & 0 \\
\hline Somalia & 11.1 & 100 & 0 & 0 & 0 \\
\hline South Africa & 49.8 & 20 & 0 & 80 & 0 \\
\hline $\begin{array}{l}\text { South Georgia \& the } \\
\text { South Sandwich Is. }\end{array}$ & 0 & 100 & & & \\
\hline Spain & 97.3 & 3.4 & 10.7 & 69.8 & 16.1 \\
\hline Sri Lanka & 1 & 0 & 100 & 0 & 0 \\
\hline St. Helena & 0 & 100 & & & \\
\hline St. Kitts \& Nevis & 0 & 100 & & & \\
\hline
\end{tabular}




\begin{tabular}{|c|c|c|c|c|c|}
\hline \multirow[t]{2}{*}{ Country } & \multirow{2}{*}{$\begin{array}{l}\text { Connection to } \\
\text { sewage system } \\
(\%)\end{array}$} & $\begin{array}{l}\text { Fraction of treatment } \\
\text { levels of collected } \\
\text { wastewater (\%) }\end{array}$ & $(\%)$ & $(\%)$ & (\%) \\
\hline & & Non-treated & Primary & Secondary & Tertiary \\
\hline St. Lucia & 0 & 100 & & & \\
\hline St. Pierre \& Miquelon & 0 & 100 & & & \\
\hline $\begin{array}{l}\text { St. Vincent \& the } \\
\text { Grenadines }\end{array}$ & 46.1 & 0 & 100 & 0 & 0 \\
\hline Sudan & 1 & 100 & 0 & 0 & 0 \\
\hline Suriname & 0.5 & 99.9 & 0.1 & 0 & 0 \\
\hline Svalbard & 0 & 100 & & & \\
\hline Swaziland & 10.5 & 100 & 0 & 0 & 0 \\
\hline Sweden & 82.9 & 16.5 & 0 & 4.9 & 78.6 \\
\hline Switzerland & 97.4 & 1.4 & 0 & 22.6 & 76 \\
\hline Syria & 16 & 0 & 50 & 50 & 0 \\
\hline Taiwan & 49 & 0 & 100 & 0 & 0 \\
\hline Tajikistan & 15.4 & 100 & 0 & 0 & 0 \\
\hline Tanzania & 1 & 100 & 0 & 0 & 0 \\
\hline Thailand & 7.4 & 76.1 & 0 & 23.9 & 0 \\
\hline The Bahamas & 0 & 100 & & & \\
\hline The Gambia & 5.6 & 100 & 0 & 0 & 0 \\
\hline Togo & 0 & 100 & & & \\
\hline Tokelau & 0 & 100 & & & \\
\hline Tonga & 0 & 100 & & & \\
\hline Trinidad and Tobago & 27.6 & 72.4 & 27.6 & 0 & 0 \\
\hline Tunisia & 61.3 & 39 & 61 & 0 & 0 \\
\hline Turkey & 88 & 56.5 & 21.8 & 21.8 & 0 \\
\hline Turkmenistan & 0 & 100 & & & \\
\hline Turks \& Caicos Is. & 0 & 100 & & & \\
\hline Tuvalu & 1 & 100 & 0 & 0 & 0 \\
\hline Uganda & 4.9 & 100 & 0 & 0 & O \\
\hline Ukraine & 56.5 & 100 & 0 & 0 & 0 \\
\hline United Arab Emirates & 78.3 & 21.7 & 39.2 & 39.2 & 0 \\
\hline United Kingdom & 96.6 & 1.5 & 10.2 & 72.5 & 15.9 \\
\hline United States & 74.7 & 1.5 & 8.6 & 44.3 & 45.7 \\
\hline Uruguay & 53.5 & 39.6 & 60.4 & 0 & 0 \\
\hline Uzbekistan & 0 & 100 & & & \\
\hline Vanuatu & 1 & 100 & 0 & 0 & 0 \\
\hline $\begin{array}{l}\text { Venezuela (Bolivarian } \\
\text { Republic of) }\end{array}$ & 89.1 & 76.7 & 23.3 & 0 & 0 \\
\hline Vietnam & 1.6 & 100 & 0 & 0 & 0 \\
\hline Virgin Is. & 0 & 100 & & & \\
\hline Wallis \& Futuna & 0 & 100 & & & \\
\hline Western Sahara & 1 & 0 & 100 & 0 & 0 \\
\hline Yemen & 14.1 & 96.7 & 1.7 & 1.7 & 0 \\
\hline Zambia & 10.2 & 100 & 0 & 0 & O \\
\hline Zimbabwe & 1 & 0 & 100 & 0 & 0 \\
\hline
\end{tabular}

Source: Compiled by authors from Williams et al. (2012), Baum et al. (2013), and Van Drecht et al. (2009). 


\section{Appendix 4. Road run-off pathway release rate}

Very few values have been reported for the release rate of tyre dust through road run-off. Key findings from the literature are reported below:

- The mass of TWP ultimately entering the aquatic environment strongly depends on the extent of collection and treatment of road run-off, which is highly variable. For German highways, it is estimated that up to 11,000 t/a of TWP reach surface waters (Wagner et al., 2018a).

- A study performed in the Netherlands showed that the extremely porous asphalt used for highways there can capture up to 95 percent of TWP (Van Duijnhove et al., 2014).

- The amount and size of the particles released depend on factors such as climate (temperature), composition and structure of the tyre, road surface, driving speed and style, and the nature of the contact (e.g., rolling versus slipping) (Alexandrova et al., 2011).

- Once generated and deposited, TWP are subjected to interaction with other traffic-related particles from brakes, tyres, pavement, and street furniture, as well as with atmospheric deposition, which results in the formation of aggregates (Charters et al., 2015).

- The speed of driving and the pavement material have been reported to influence the amount of particles emitted, rather than their size distribution (Gustafsson et al., 2008; Kwak et al., 2013).

The most common values for tyre wear are reported in Appendix 2, Figure 34.

Roughly 12 percent of microparticles from tyre wear are ultimately released into surface waters (Kole et al., 2015) (Van Duijnhove et al., 2014).

State-of-the-art values to be used are reported below (Unice et al., 2018a, 2018b).

Table 14: Differences in the release rates published in the literature. Based on these numbers it was chosen a 2/12/22\% set of values for the low/central/high scenarios of the release rates.

\begin{tabular}{lll}
$\mathbf{R R}$ & Source & Comment \\
$\mathbf{2 \%}$ & (Unice et al., 2018a, 2018b) & To the Seine estuary (thus accounting for river transport | 11\%) \\
\hline $\mathbf{1 2 \%}$ & (Unice et al., 2018a, 2018b) & From rural roads \\
\hline $\mathbf{1 7 \%}$ & (Unice et al., 2018a, 2018b) & $\begin{array}{l}\text { To the Seine River through run-off (accounting for the different } \\
\text { types of roads (rural/highways/urban roads) }\end{array}$ \\
\hline $\mathbf{1 6 \%}$ & (Unice et al., 2018a, 2018b) & From urban roads \\
\hline $\mathbf{2 5 \%}$ & (Unice et al., 2018a, 2018b) & From highways (Europe) \\
\hline $\mathbf{1 2 \%}$ & (Kole et al., 2017b) & Generic value \\
\hline $\mathbf{6 - 2 2} \%$ & (Wagner et al., 2018b) & Germany example \\
\hline $\mathbf{3 2 \%}$ & Boucher and Friot, 2017 & Generic value \\
\hline
\end{tabular}

Note: More recent publications highlight high seasonal variability in these loss rates and estimate these losses as per unit of road surface, rather than per km driven (Gustafsson et al., 2008). The data in this arena is expected to evolve quickly and should be refined based on the latest available literature. 
Appendix 5. Data for Case Study 1: The textile industry Figure 36: Example of a company Marine Plastic Footprint calculator for the textiles sector

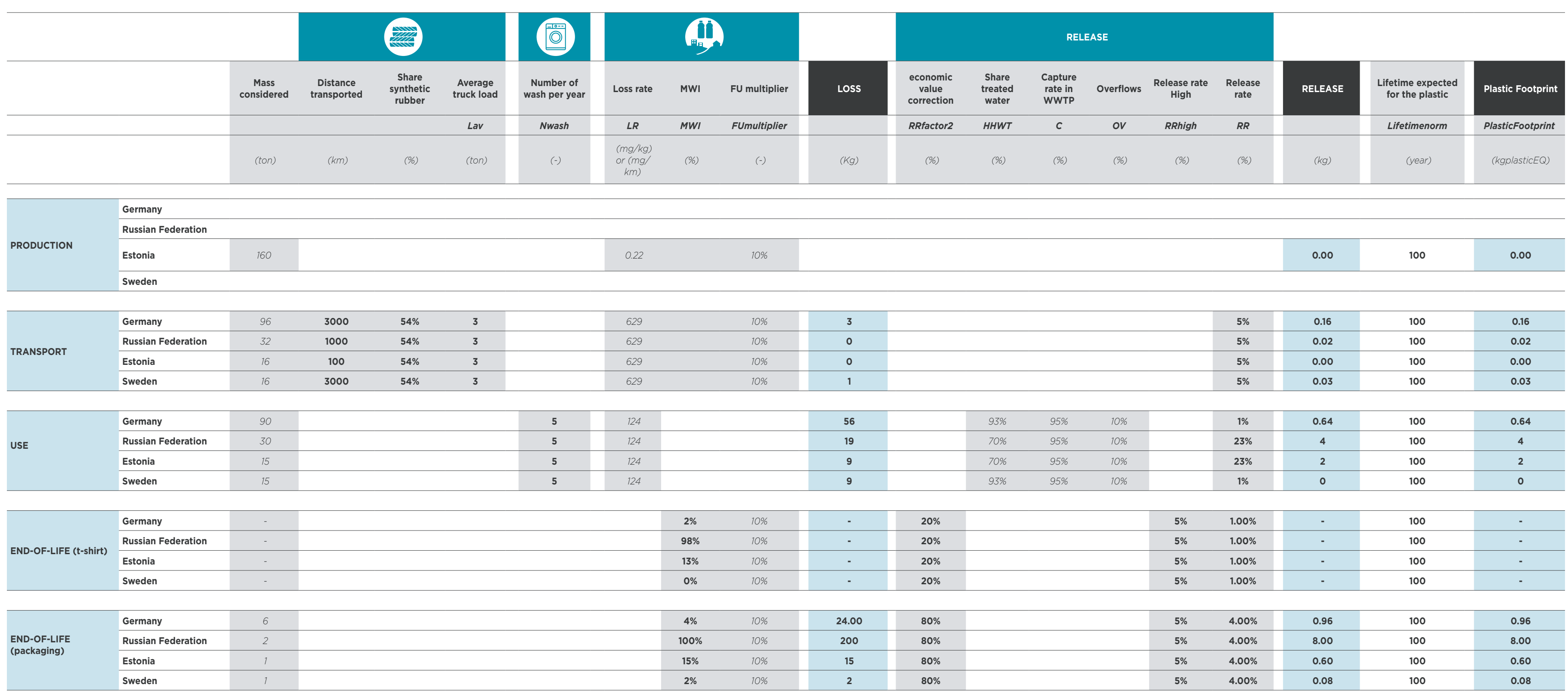


Appendix 6. Data for Case Study 2: the packaging industry Figure 37: Example of a company Marine Plastic Footprint calculator for the packaging sector.

\section{을}

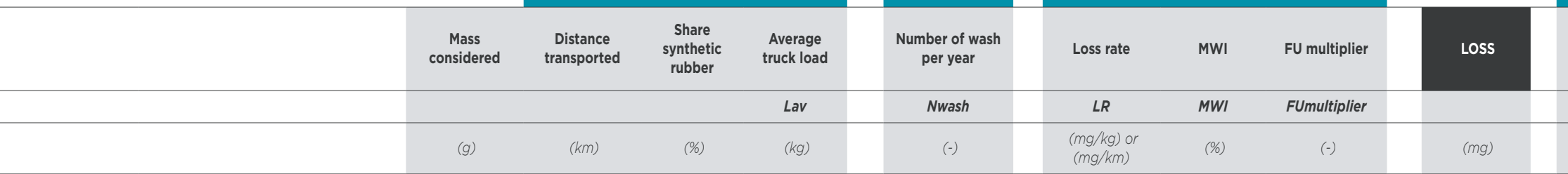

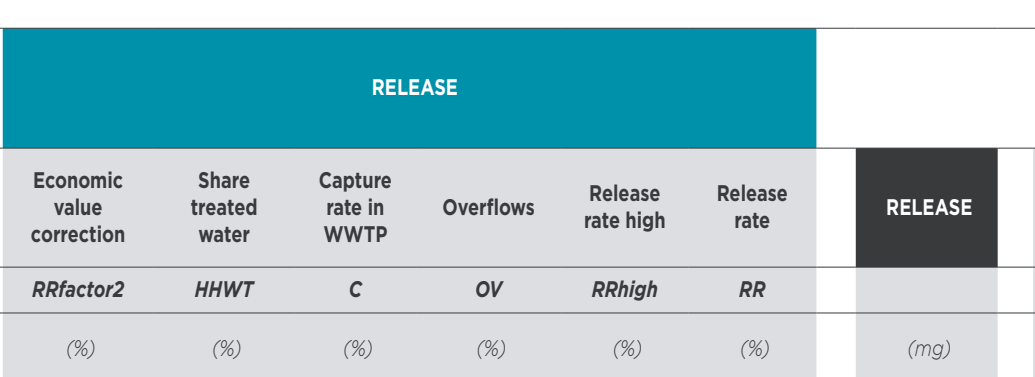

Lifietime
expected for

the plastic

Lifetimenorm PlasticFootp

\begin{tabular}{|c|c|c|c|c|c|c|c|}
\hline \multirow{8}{*}{ PRODUCTION } & Lithuania_Glass__SingleUse & - & - & $100 \%$ & - & 100 & $\cdot$ \\
\hline & Lithuania_PET__ingleuse & 32 & 0.22 & $100 \%$ & 0.01 & 100 & 0.01 \\
\hline & Sweden_Glass_SingleUse & - & - & $100 \%$ & - & 100 & $\cdot$ \\
\hline & Sweden_Glass_Reused & - & - & $4 \%$ & - & 100 & - \\
\hline & Sweden_PET__Singleuse & 32 & 0.22 & $100 \%$ & 0.01 & 100 & 0.01 \\
\hline & Sweden_PET_ReUsed & 50 & 0.22 & $10 \%$ & 0.00 & 100 & 0.00 \\
\hline & Sweden_PET_Recycled & 32 & 0.22 & $100 \%$ & 0.01 & 100 & 0.01 \\
\hline & Sweden_DegradablePlastic_SingleUse & 32 & 0.22 & $100 \%$ & 0.01 & 5 & 0.00 \\
\hline
\end{tabular}

\begin{tabular}{|c|c|c|c|c|c|c|c|c|c|c|c|c|}
\hline \multirow{8}{*}{ TRANSPORT } & Lithuania_Glass_SingleUse & 450 & 1,080 & $54 \%$ & 12000 & 629 & $100 \%$ & 14 & $22 \%$ & 3 & 100 & 3.03 \\
\hline & Lithuania_PET_SingleUse & 32 & 1,080 & $54 \%$ & 12000 & 629 & $100 \%$ & 1 & $22 \%$ & 0 & 100 & 0.22 \\
\hline & Sweden_Glass_SingleUse & 450 & 2,580 & $54 \%$ & 12000 & 629 & $100 \%$ & 33 & $22 \%$ & 7 & 100 & 7.23 \\
\hline & Sweden_Glass_Reused & 450 & 2,100 & $54 \%$ & 12000 & 629 & $100 \%$ & 27 & $22 \%$ & 6 & 100 & 5.88 \\
\hline & Sweden_PET_Singleuse & 32 & 2,580 & $54 \%$ & 12000 & 629 & $100 \%$ & 2 & $22 \%$ & 1 & 100 & 0.51 \\
\hline & Sweden_PET_ReUsed & 50 & 2,100 & $54 \%$ & 12000 & 629 & $100 \%$ & 3 & $22 \%$ & 1 & 100 & 0.65 \\
\hline & Sweden_PET_Recycled & 32 & 2,580 & $54 \%$ & 12000 & 629 & $100 \%$ & 2 & $22 \%$ & 1 & 100 & 0.51 \\
\hline & Sweden_DegradablePlastic_SingleUse & 32 & 2,580 & $54 \%$ & 12000 & 629 & $100 \%$ & 2 & $22 \%$ & 1 & 100 & 0.51 \\
\hline
\end{tabular}

\begin{tabular}{|c|c|c|c|c|c|c|c|c|c|c|c|}
\hline \multirow{8}{*}{ END-OF-LIFE } & Lithuania_Glass_SingleUse & - & $3 \%$ & $100 \%$ & - & $80 \%$ & $5 \%$ & $4.00 \%$ & - & 100 & - \\
\hline & Lithuania_PET_Single euse & 32 & $3 \%$ & $100 \%$ & 960 & $80 \%$ & $5 \%$ & 4.00\% & 38 & 100 & 38.40 \\
\hline & Sweden_llass_Singleuse & $\cdot$ & $2 \%$ & $100 \%$ & $\cdot$ & $80 \%$ & $5 \%$ & $4.00 \%$ & . & 100 & $\cdot$ \\
\hline & Sweden_Glass_RRused & . & $2 \%$ & $4 \%$ & . & $80 \%$ & $5 \%$ & 4.00\% & . & 100 & . \\
\hline & Sweden_PET_Singleuse & 32 & $2 \%$ & $100 \%$ & 640 & $80 \%$ & $5 \%$ & $4.00 \%$ & 26 & 100 & 25.60 \\
\hline & Sweden_PET_ReUsed & 50 & $2 \%$ & $10 \%$ & 100 & $80 \%$ & $5 \%$ & $4.00 \%$ & 4 & 100 & 4.00 \\
\hline & Sweden_PET_Reycyled & 32 & $0 \%$ & $100 \%$ & $\cdot$ & $80 \%$ & $5 \%$ & $4.00 \%$ & $\cdot$ & 100 & $\cdot$ \\
\hline & Sweden DegradablePlastic, Singleuse & 32 & $2 \%$ & $100 \%$ & 640 & $80 \%$ & $5 \%$ & $4.00 \%$ & 26 & 5 & 1.28 \\
\hline
\end{tabular}




\section{Appendix 7. Data for Case Study 3: The Baltic Basin}

The aim of this case study was to visually represent the marine plastic leakage in the Baltic Basin, using updated waste management data and calculating a leakage rate for each, based on its population, distance to shore, and surface run-off. The two different approaches originate from two articles: Jambeck et al., 2015, Plastic waste inputs from land to the ocean; and Lebreton et al., 2017, River plastics emissions to the world's oceans. Surface run-off and riverine export did not account for natural or artificial barriers. The data was input into a base map, and then layers of information were added, including demographics of each town/city, watersheds, or main rivers.

\subsection{Detailed description of the methodology}

All of the information added to the software was found online, from official sources such as the U.S. National Aeronautics and Space Administration (NASA) (http://sedac.ciesin. columbia.edu/data/collection/gpw-v4), the World Wide Fund for Nature (WWF) (https:// www.hydrosheds.org/page/hydrobasins), and scientific, peer-reviewed journals such as Nature. This plethora of information was freely available and used for scientific purposes only. Once the data, in the form of shapefiles, was downloaded, it was input into a GIS environment (QGIS 2.18), so that multiple layers of information could be stacked and analysed. Each shapefile contains a series of data that were used to calculate the leakage (see Figure 39).

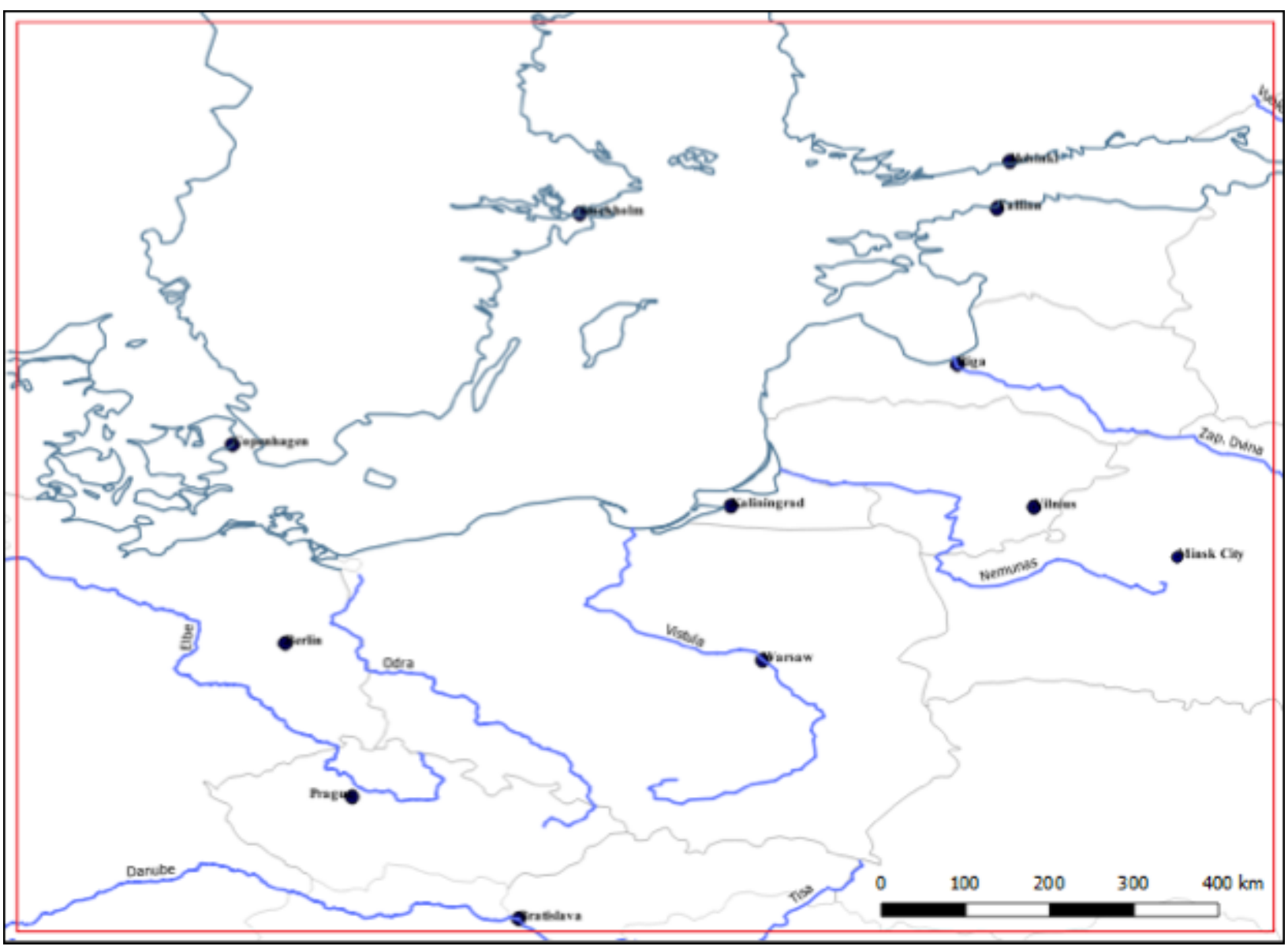

Figure 38: Base map of the Baltic region considered in this study (red rectangle). 


\begin{tabular}{|c|c|c|c|c|c|c|}
\hline 1 & $\begin{array}{l}\text { ADMINID } \\
\qquad 1246001\end{array}$ & $\begin{array}{l}\text { ISOALPHA } \\
\text { FIN }\end{array}$ & $\begin{array}{l}\text { COUNTRYNM } \\
\text { Finland }\end{array}$ & $\begin{array}{l}\text { NAME1 } \\
\text { Southwest Finland }\end{array}$ & $\begin{array}{l}\text { NAME2 } \\
\text { Lieto }\end{array}$ & $\begin{array}{r}\text { UN_2015_E } \\
18055\end{array}$ \\
\hline 2 & 1246002 & FIN & Finland & Uusimaa & Pukdia & 2142 \\
\hline
\end{tabular}

Figure 39: Key information provided in the Gridded Population of the World shapefile.

- ADMINID: Provides a code for each village/ town/city

- ISOALPHA: Code of the country

- COUNTRYNM: Country name

- NAME 1, NAME 2: Region, town

- UN_2015_E: United Nations population estimates

As population censuses are not conducted at the same time in all countries, annual growth rates were used to adjust census counts to the year 2010 (GPW Documentation), to allow for global comparison. In this study, the United Nations World Populations Prospects 2015, which often corrects for over- or under-reporting in the nationally reported figures, was used.

Once basic geographical/anthropogenic information (see Table 15) was inserted into the software, a series of geoprocessing tools specific to the software were used to make the multiple layers of information interact with each other. A description of some of the tools used in the analysis is provided in Table 16 below.

The aim was to create a database containing the following information: see Table 16.

Some of the geoprocessing tools used in the analysis included: see Table 17.

A Masterfile was then created with all the information extracted from the software, as well as waste management data. This led to the creation of a matrix, using distance to shore, waste generation rates, population densities, run-off, and other parameters to calculate a leakage rate depending on these parameters.

Table 15: Description of the steps followed in the implementation of the GIS methodology and the sources of data.

\begin{tabular}{|c|c|c|}
\hline Information Targeted & Source/Provider & Render \\
\hline $\begin{array}{l}\text { Demographics (including } \\
\text { villages/towns/cities, UN } \\
\text { population estimates, } \\
\text { GPS coordinates) }\end{array}$ & $\begin{array}{l}\text { NASA SEDAC Gridded Population } \\
\text { of the World ( } 4 \text { ). } \\
\text { http://sedac.ciesin.columbia.edu/ } \\
\text { data/collection/gpw-v4 }\end{array}$ & \\
\hline Watersheds & $\begin{array}{l}\text { WWF HydroSHEDS model. https:// } \\
\text { www.hydrosheds.org/page/ } \\
\text { hydrobasins }\end{array}$ & \\
\hline $\begin{array}{l}\text { Run-off data (red points } \\
\text { attached to every } \\
\text { watershed with an outlet } \\
\text { to the sea) }\end{array}$ & $\begin{array}{l}\text { Lebreton et al., 2017, River plastics } \\
\text { emissions to the world's oceans. } \\
\text { https://www.nature.com/articles/ } \\
\text { ncomms15611\#supplementary- } \\
\text { information }\end{array}$ & \\
\hline
\end{tabular}


Table 16: Example of the information used for the creation of the data matrix

\begin{tabular}{cccccccc} 
Country & Locality & Population & $\begin{array}{c}\text { Watershed } \\
\text { ID }\end{array}$ & $\begin{array}{c}\text { Distance to } \\
\text { Shore(km) }\end{array}$ & $\begin{array}{c}\text { Run-off } \\
\text { (mm/day) }\end{array}$ & $\begin{array}{c}\text { Waste Generation } \\
\text { rate (kg/hab/year) }\end{array}$ \\
\hline Example & Denmark & Lundtofte & 12,495 & 29,472 & 5.1 & 0.47 & 12.70 \\
\hline
\end{tabular}

Table 17: Geoprocessing tools used for additional data extraction

\begin{tabular}{ll}
\hline Information Targeted & Geoprocessing Tool \\
\hline $\begin{array}{l}\text { Distance to shore of } \\
\text { each village/town/city }\end{array}$ & Distance to nearest hub \\
\hline $\begin{array}{l}\text { Population per } \\
\text { watershed }\end{array}$ & Join attributes by location \\
$\begin{array}{l}\text { Join distance to } \\
\text { shore, population per } \\
\text { watershed, and run-off } \\
\text { per watershed in one } \\
\text { file }\end{array}$ & Join attributes by location
\end{tabular}

The output of this methodology led to the

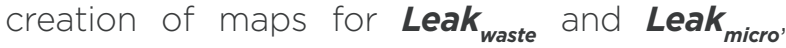
as shown in section 13.7.3 below. The output of the matrix ultimately inserted into the GIS environment highlights the Marine Plastic Footprint of the Baltic Basin (for example, Figure 42 shows the levels of tyre dust leakage). 


\subsection{Raw data tables for the central scenario}

Table 18: Detailed results for the central values of the plastic footprint of the Baltic Basin states considered in this study.

\begin{tabular}{|c|c|c|c|c|c|c|c|c|c|c|}
\hline & & Leakage & Leakage & $\begin{array}{c}\text { Per Capita } \\
\text { Leakage }\end{array}$ & $\begin{array}{c}\text { Per Capita } \\
\text { Leakage }\end{array}$ & Leakage & Leakage & Leakage & Leakage & $\begin{array}{l}\text { Dominant } \\
\text { Source }\end{array}$ \\
\hline \multirow[t]{2}{*}{ Country } & $\begin{array}{l}\text { Population } \\
\text { Considered }\end{array}$ & Waste & Micro & Waste & Micro & $\begin{array}{l}\text { Tyre } \\
\text { Dust }\end{array}$ & Textile & Cosmetics & Pellets & \\
\hline & & $\begin{array}{l}\text { tonnes/ } \\
\text { year }\end{array}$ & $\begin{array}{l}\text { tonnes/ } \\
\text { year }\end{array}$ & $\begin{array}{l}\text { g/hab/ } \\
\text { year }\end{array}$ & $\begin{array}{l}\text { g/hab/ } \\
\text { year }\end{array}$ & $\begin{array}{c}\text { tonnes/ } \\
\text { year-1 }\end{array}$ & $\begin{array}{c}\text { tonnes/ } \\
\text { year-1 }\end{array}$ & $\begin{array}{c}\text { tonnes/ } \\
\text { year-1 }\end{array}$ & $\begin{array}{l}\text { tonnes/ } \\
\text { year-1 }\end{array}$ & \\
\hline Denmark & 4146909 & 101 & 231.3 & 24 & 52.1 & 211 & 12 & 5 & 2.8 & Micro \\
\hline Estonia & 628753 & 331 & 23.0 & 526 & 26.8 & 15 & 4 & 2 & 2.2 & Macro \\
\hline Finland & 5474233 & 57 & 315.6 & 10 & 52.6 & 278 & 25 & 10 & 2.1 & Micro \\
\hline Germany & 19214371 & 2138 & 1183.7 & 111 & 55.3 & 1049 & 37 & 14 & 84.0 & Macro \\
\hline Latvia & 1749945 & 477 & 64.2 & 272 & 25.9 & 39 & 16 & 6 & 3.0 & Macro \\
\hline Lithuania & 2394864 & 92 & 190.7 & 38 & 68.0 & 154 & 22 & 9 & 5.6 & Micro \\
\hline Poland & 37615729 & 620 & 2126.5 & 16 & 45.1 & 1559 & 361 & 139 & 67.4 & Micro \\
\hline Sweden & 9779422 & 525 & 409.9 & 54 & 34.7 & 318 & 55 & 21 & 15.2 & Macro \\
\hline $\begin{array}{c}\text { Russian } \\
\text { Federation }\end{array}$ & 7735374 & 16832 & 492.4 & 2176 & 46.1 & 313 & 113 & 43 & 23.2 & Macro \\
\hline Belarus & 2690891 & 895 & 142.4 & 333 & 41.1 & 101 & 24 & 9 & 7.5 & Macro \\
\hline $\begin{array}{l}\text { Czech } \\
\text { Republic }\end{array}$ & 7547117 & 42 & 262.0 & 6 & 29.2 & 206 & 39 & 15 & 2.8 & Micro \\
\hline Slovakia & 205383 & 12 & 10.3 & 58 & 39.2 & 7 & 2 & 1 & 0.4 & Macro \\
\hline Total & 99182991 & 22120 & 5452.0 & & & 4252 & 711 & 273 & 216.3 & \\
\hline Average & & & & 302 & 43 & & & & & \\
\hline
\end{tabular}

Table 19: Updated waste management data for the Baltic Basin states considered in this study

\begin{tabular}{|c|c|c|c|c|c|c|}
\hline $\begin{array}{c}\text { TPW (kg/hab/ } \\
\text { year) }\end{array}$ & TPW & \% ShareP & $\begin{array}{l}\% \text { MWI } \\
\text { Urban }\end{array}$ & $\begin{array}{l}\text { \% MWI } \\
\text { Rural }\end{array}$ & $\begin{array}{c}\% \text { Non- } \\
\text { Collected Rural }\end{array}$ & $\begin{array}{c}\% \text { Non- } \\
\text { Collected Urban }\end{array}$ \\
\hline Denmark & 12,70 & 2 & 2,2 & 3,0 & 0,2 & 1 \\
\hline Estonia & 66.88 & 19 & 14,8 & 15,5 & 0,2 & 1 \\
\hline Finland & 7.25 & 1 & 2,2 & 3,0 & 0,2 & 1 \\
\hline Germany & 81.24 & 13 & 4,1 & 4,9 & 0,2 & 1 \\
\hline Latvia & 33.37 & 8 & 17,5 & 18,1 & 0,2 & 1 \\
\hline Lithuania & 45.42 & 10 & 13,2 & 7,3 & 10 & 4 \\
\hline Poland & 34.69 & 12 & 2,2 & 3,0 & 0,2 & 1 \\
\hline Sweden & 29.39 & 7 & 2,2 & 3,0 & 0,2 & 1 \\
\hline $\begin{array}{l}\text { Russian } \\
\text { Federation }\end{array}$ & 59.54 & 14 & 98,8 & 96,4 & 71,9 & 18,9 \\
\hline Belarus & 54.12 & 12 & 37,6 & 9,0 & 30,8 & 0 \\
\hline $\begin{array}{l}\text { Czech } \\
\text { Republic }\end{array}$ & 6.96 & 2 & 2,2 & 3,0 & 0,2 & 1 \\
\hline Slovakia & 36.18 & 11 & 14,8 & 15,5 & 0,2 & 1 \\
\hline
\end{tabular}


Table 20: Tyre dust leakage data and leakage rates.

\begin{tabular}{|c|c|c|c|c|c|c|c|c|}
\hline \multicolumn{2}{|c|}{ Tyre dust } & $\begin{array}{c}D_{\text {car }} \\
(\mathbf{k m} / \mathbf{h a b})\end{array}$ & $\begin{array}{c}D_{\text {truck }} \\
(\mathrm{km} / \mathrm{hab})\end{array}$ & $\begin{array}{l}\text { TyreLoss }_{\text {car }} \\
(\mathrm{mg} / \mathbf{k m})\end{array}$ & $\begin{array}{l}\text { TyreLoss }_{\text {rruck }} \\
\text { (mg/km) }\end{array}$ & $\%_{\text {RRtyres }}^{\text {urban }}$ & $\%$ RRtyres ${ }_{\text {rural }}$ & $\begin{array}{l}\text { LRtyres } \\
\text { (kg/hab) }\end{array}$ \\
\hline DNK & Denmark & 7,954 & 224 & 55 & 340 & 2 & 12 & 0.51 \\
\hline EST & Estonia & 1,570 & 392 & 55 & 340 & 2 & 12 & 0.22 \\
\hline FIN & Finland & 8,167 & 423 & 55 & 340 & 2 & 12 & 0.59 \\
\hline DEU & Germany & 8,570 & 316 & 55 & 340 & 2 & 12 & 0.58 \\
\hline LVA & Latvia & 778 & 643 & 55 & 340 & 2 & 12 & 0.26 \\
\hline LTU & Lithuania & 6,881 & 1,152 & 55 & 340 & 2 & 12 & 0.77 \\
\hline POL & Poland & 4,325 & 736 & 55 & 340 & 2 & 12 & 0.49 \\
\hline SWE & Sweden & 8,574 & 346 & 55 & 340 & 2 & 12 & 0.59 \\
\hline CZE & $\begin{array}{l}\text { Czech } \\
\text { Republic }\end{array}$ & 5,373 & 348 & 55 & 340 & 2 & 12 & 0.41 \\
\hline SVK & $\begin{array}{l}\text { Slovak } \\
\text { Republic }\end{array}$ & 4,268 & 542 & 55 & 340 & 2 & 12 & 0.42 \\
\hline RUS & $\begin{array}{l}\text { Russian } \\
\text { Federation }\end{array}$ & 5,949 & 496 & 55 & 340 & 2 & 12 & 0.50 \\
\hline BLR & Belarus & 5,949 & 496 & 55 & 340 & 2 & 12 & 0.50 \\
\hline
\end{tabular}

Table 21: Textiles leakage data and corresponding leakage rates

\begin{tabular}{|c|c|c|c|c|c|c|c|c|c|}
\hline & Textiles & $\mathbf{H}$ & $\mathbf{w}$ & $\mathbf{L}$ & $\% \mathrm{~S}$ & $\begin{array}{c}\mathrm{LR}_{\text {textile }} \\
(\mathrm{mg} / \mathrm{kg})\end{array}$ & \%SWT & $\begin{array}{l}\text { \%Efficiency of } \\
\text { WWTP }\end{array}$ & $\begin{array}{l}\text { Leak }_{\text {Textile }} \\
(\mathrm{kg} / \mathrm{hab})\end{array}$ \\
\hline DNK & Denmark & 2.2 & 165.0 & 3.5 & 48 & 124 & 88 & 92 & 0.003 \\
\hline EST & Estonia & 2.2 & 165.0 & 3.5 & 48 & 124 & 65 & 92 & 0.006 \\
\hline FIN & Finland & 2.2 & 165.0 & 3.5 & 48 & 124 & 76 & 92 & 0.005 \\
\hline DEU & Germany & 2.2 & 165.0 & 3.5 & 48 & 124 & 95 & 92 & 0.002 \\
\hline LVA & Latvia & 2.2 & 165.0 & 3.5 & 48 & 124 & 46 & 92 & 0.009 \\
\hline LTU & Lithuania & 2.2 & 165.0 & 3.5 & 48 & 124 & 44 & 92 & 0.009 \\
\hline POL & Poland & 2.2 & 165.0 & 3.5 & 48 & 124 & 42 & 92 & 0.010 \\
\hline SWE & Sweden & 2.2 & 165.0 & 3.5 & 48 & 124 & 69 & 92 & 0.006 \\
\hline CZE & $\begin{array}{l}\text { Czech } \\
\text { Republic }\end{array}$ & 2.2 & 165.0 & 3.5 & 48 & 124 & 73 & 92 & 0.005 \\
\hline SVK & $\begin{array}{l}\text { Slovak } \\
\text { Republic }\end{array}$ & 2.2 & 165.0 & 3.5 & 48 & 124 & 46 & 92 & 0.009 \\
\hline RUS & $\begin{array}{l}\text { Russian } \\
\text { Federation }\end{array}$ & 2.2 & 165.0 & 3.5 & 48 & 124 & 7 & 92 & 0.015 \\
\hline BLR & Belarus & 2.2 & 165.0 & 3.5 & 48 & 124 & 46 & 92 & 0.009 \\
\hline
\end{tabular}


Table 22: Pellets leakage data and corresponding leakage rates

\begin{tabular}{|c|c|c|c|c|c|c|}
\hline & Pellets & $\begin{array}{c}\text { Primary plastic } \\
\text { production }\end{array}$ & LR (low) & LR (med) & LR (high) & $\begin{array}{l}\text { Leak }_{\text {Pellets }} \\
\text { (kg/hab) }\end{array}$ \\
\hline DNK & Denmark & 12.7 & 0.04 & 0.22 & 0.4 & 0.000001 \\
\hline EST & Estonia & 66.8 & 0.04 & 0.22 & 0.4 & 0.000004 \\
\hline FIN & Finland & 7.2 & 0.04 & 0.22 & 0.4 & 0.000000 \\
\hline DEU & Germany & 81.2 & 0.04 & 0.22 & 0.4 & 0.000004 \\
\hline LVA & Latvia & 33.3 & 0.04 & 0.22 & 0.4 & 0.000002 \\
\hline LTU & Lithuania & 45.4 & 0.04 & 0.22 & 0.4 & 0.000002 \\
\hline POL & Poland & 34.6 & 0.04 & 0.22 & 0.4 & 0.000002 \\
\hline SWE & Sweden & 29.3 & 0.04 & 0.22 & 0.4 & 0.000002 \\
\hline CZE & Czech Republic & 6.9 & 0.04 & 0.22 & 0.4 & 0.000003 \\
\hline SVK & Slovak Republic & 36.1 & 0.04 & 0.22 & 0.4 & 0.000003 \\
\hline RUS & $\begin{array}{l}\text { Russian } \\
\text { Federation }\end{array}$ & 59.5 & 0.04 & 0.22 & 0.4 & 0.000000 \\
\hline BLR & Belarus & 54.1 & 0.04 & 0.22 & 0.4 & 0.000002 \\
\hline
\end{tabular}

Table 23: Cosmetics leakage data and corresponding leak rates.

\begin{tabular}{|c|c|c|c|c|c|c|c|}
\hline \multicolumn{2}{|c|}{ Cosmetics } & $\begin{array}{l}\text { LR } \\
\text { (low) }\end{array}$ & $\begin{array}{c}\text { LR } \\
\text { (med) }\end{array}$ & $\begin{array}{c}\text { LR } \\
\text { (high) }\end{array}$ & \%SWT & $\begin{array}{c}\% \text { Efficiency } \\
\text { of WWTP }\end{array}$ & Leakage (kg/hab) \\
\hline DNK & Denmark & 1 & 13 & 46 & 92 & 0.003 & 0.001 \\
\hline EST & Estonia & 1 & 13 & 73 & 92 & 0.002 & 0.002 \\
\hline FIN & Finland & 1 & 13 & 88 & 92 & 0.001 & 0.002 \\
\hline DEU & Germany & 1 & 13 & 65 & 92 & 0.002 & 0.001 \\
\hline LVA & Latvia & 1 & 13 & 76 & 92 & 0.002 & 0.003 \\
\hline LTU & Lithuania & 1 & 13 & & 92 & 0.001 & 0.004 \\
\hline $\mathrm{POL}$ & Poland & 1 & 13 & 95 & 92 & 0.003 & 0.004 \\
\hline SWE & Sweden & 1 & 13 & 46 & 92 & 0.004 & 0.002 \\
\hline CZE & Czech Republic & 1 & 13 & 42 & 92 & 0.004 & 0.002 \\
\hline SVK & Slovak Republic & 1 & 13 & 7 & 92 & 0.006 & 0.003 \\
\hline RUS & $\begin{array}{l}\text { Russian } \\
\text { Federation }\end{array}$ & 1 & 13 & 46 & 92 & 0.003 & 0.006 \\
\hline BLR & Belarus & 1 & 13 & 69 & 92 & 0.002 & 0.003 \\
\hline UKR & Ukraine & 1 & 13 & 0 & 92 & 0.006 & 0.006 \\
\hline
\end{tabular}


Table 24: Summary table of Leakwaste and Leakmicro for each Baltic Basin country

\begin{tabular}{|c|c|c|c|c|c|c|c|}
\hline & & & Leakage & Leakage & Leakage & Leakage & Leakage \\
\hline \multirow[t]{2}{*}{ Country } & $\begin{array}{l}\text { Population } \\
\text { Considered }\end{array}$ & MPW & Waste & Tyre dust & Textile & Cosmetics & Pellets \\
\hline & & & $\begin{array}{l}\text { (tonnes/ } \\
\text { year-1) }\end{array}$ & $\begin{array}{l}\text { (tonnes/ } \\
\text { year-1) }\end{array}$ & $\begin{array}{l}\text { (tonnes/ } \\
\text { year-1) }\end{array}$ & $\begin{array}{l}\text { (tonnes/ } \\
\text { year-1) }\end{array}$ & $\begin{array}{l}\text { (tonnes/ } \\
\text { year-1) }\end{array}$ \\
\hline Denmark & 4146909 & 1054 & 101 & 211 & 12 & 5 & 3 \\
\hline Estonia & 628753 & 6308 & 331 & 15 & 4 & 2 & 2 \\
\hline Finland & 5474233 & 793 & 57 & 278 & 25 & 10 & 2 \\
\hline Germany & 19214371 & 62437 & 2138 & 1049 & 37 & 14 & 84 \\
\hline Latvia & 1749945 & 10511 & 477 & 39 & 16 & 6 & 3 \\
\hline Lithuania & 2394864 & 3263 & 92 & 154 & 22 & 9 & 6 \\
\hline Poland & 37615729 & 26096 & 620 & 1559 & 361 & 139 & 67 \\
\hline Sweden & 9779422 & 5749 & 525 & 318 & 55 & 21 & 15 \\
\hline Russian Federation & 7735374 & 469763 & 16832 & 313 & 113 & 43 & 23 \\
\hline Belarus & 2690891 & 22384 & 895 & 101 & 24 & 9 & 8 \\
\hline Czech Republic & 7547117 & 1051 & 42 & 206 & 39 & 15 & 3 \\
\hline Slovakia & 205383 & 594 & 12 & 7 & 2 & 1 & $\mathrm{O}$ \\
\hline Total & 99182991 & 610004 & 22120 & 4252 & 711 & 273 & 216 \\
\hline
\end{tabular}

\subsection{Additional maps with details on different sources and key parameters of the model}

Figure 40: Output of the GIS methodology/data matrix; map representing the potential Marine Plastic Footprint of tyre dust for the Baltic Basin per population points (cities, towns, villages).

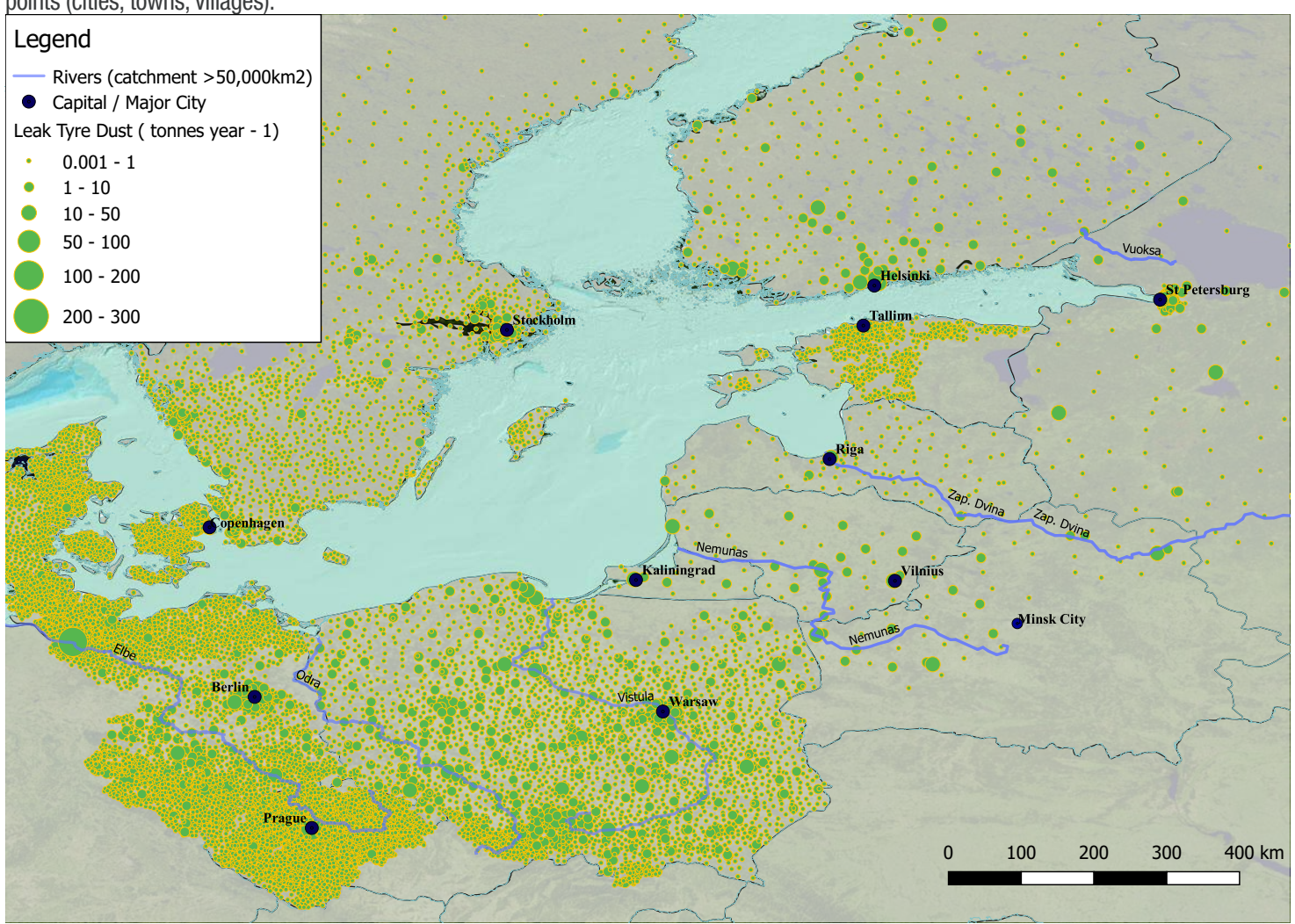


Figure 41: Output of the GIS methodology with the potential Marine Plastic Footprint of textile fibers for the Baltic Basin per population points (cities, towns, villages).

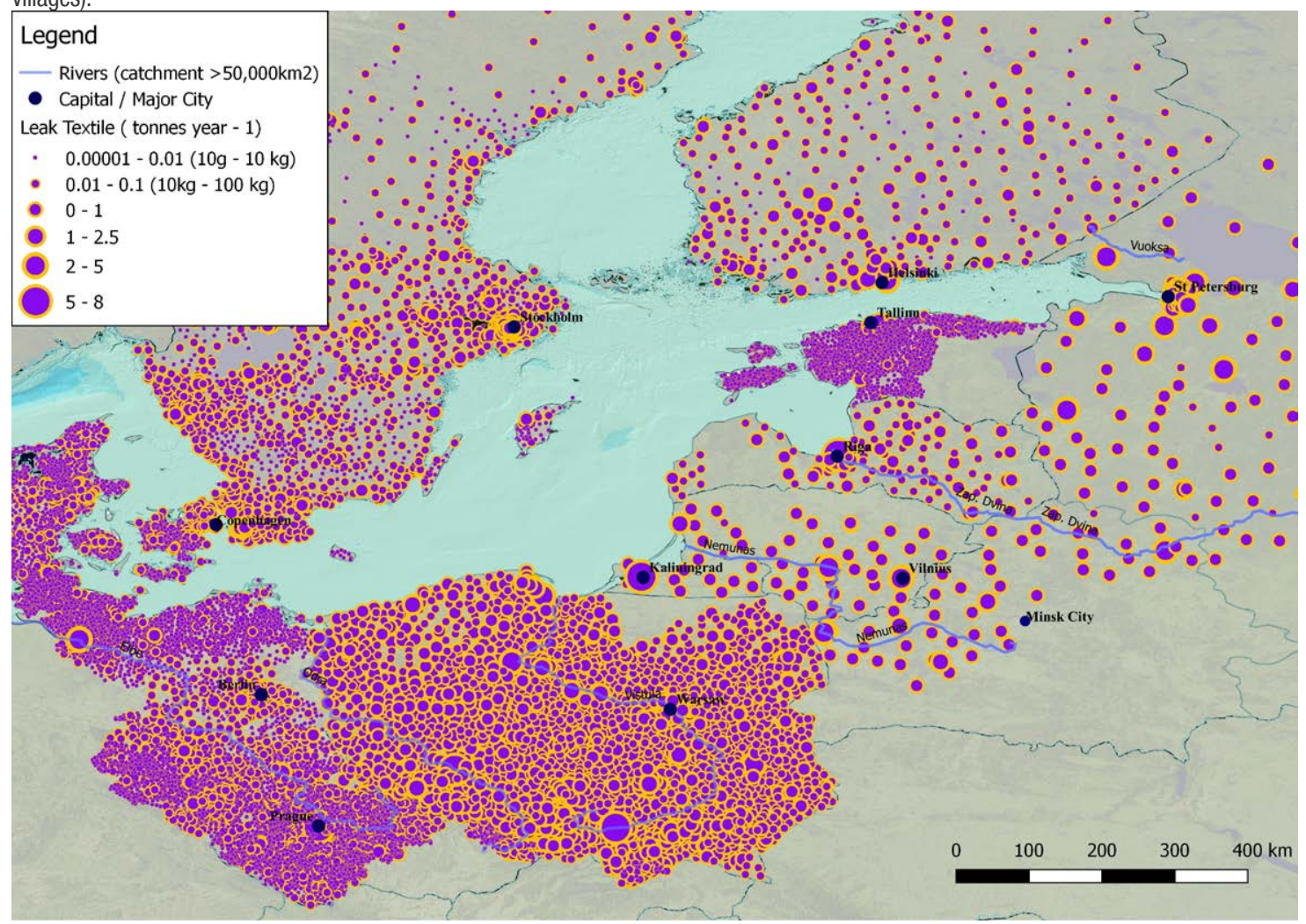

Figure 42: Potential Marine Plastic Footprint of pellets (in mg to $\mathrm{kg} \mathrm{year}^{-1}$ ) in the Baltic Basin countries per population points (cities, towns, villages).

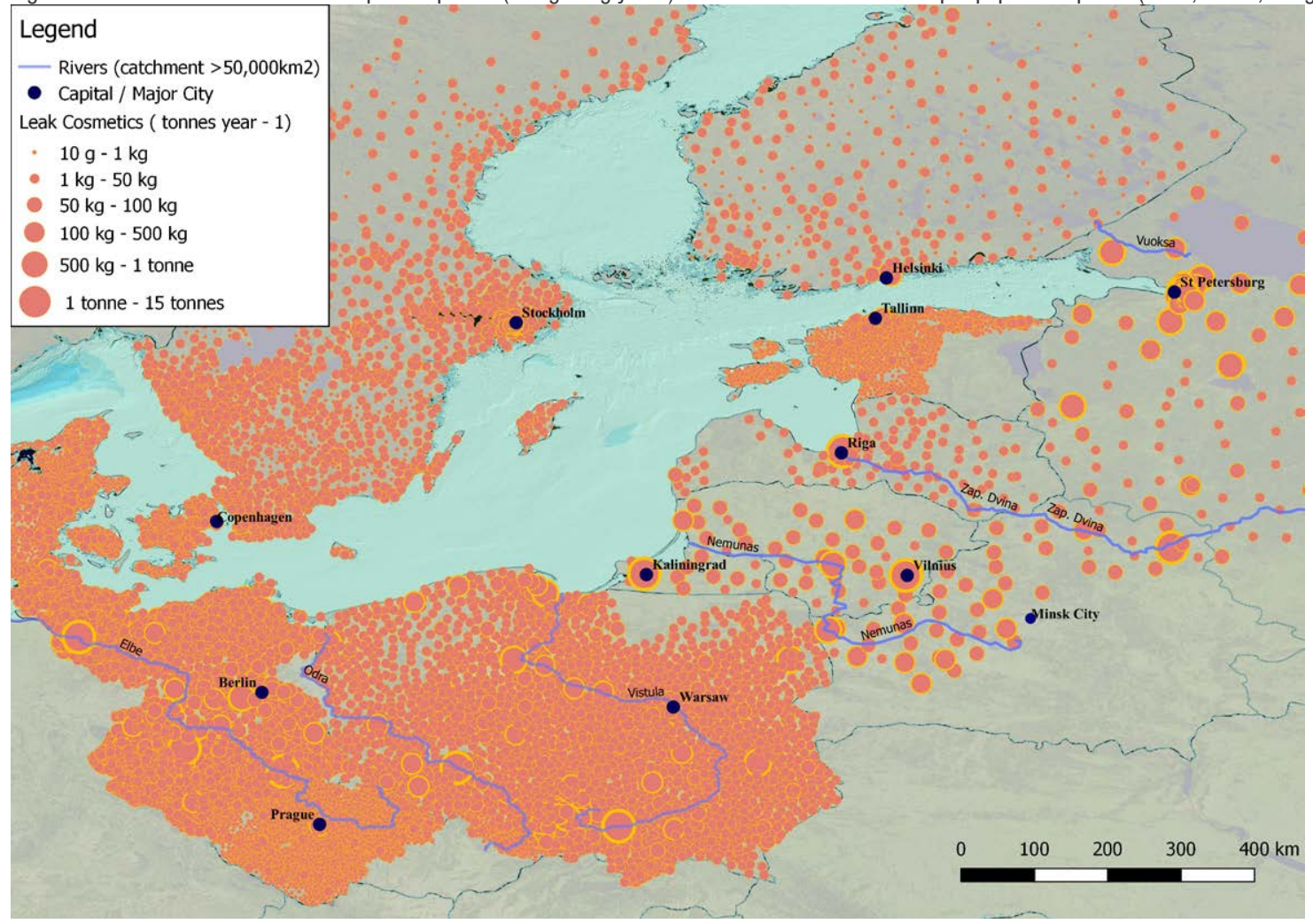


Figure 43: Potential Marine Plastic Footprint of cosmetics in the Baltic Basin countries per population points (cities, towns, villages).

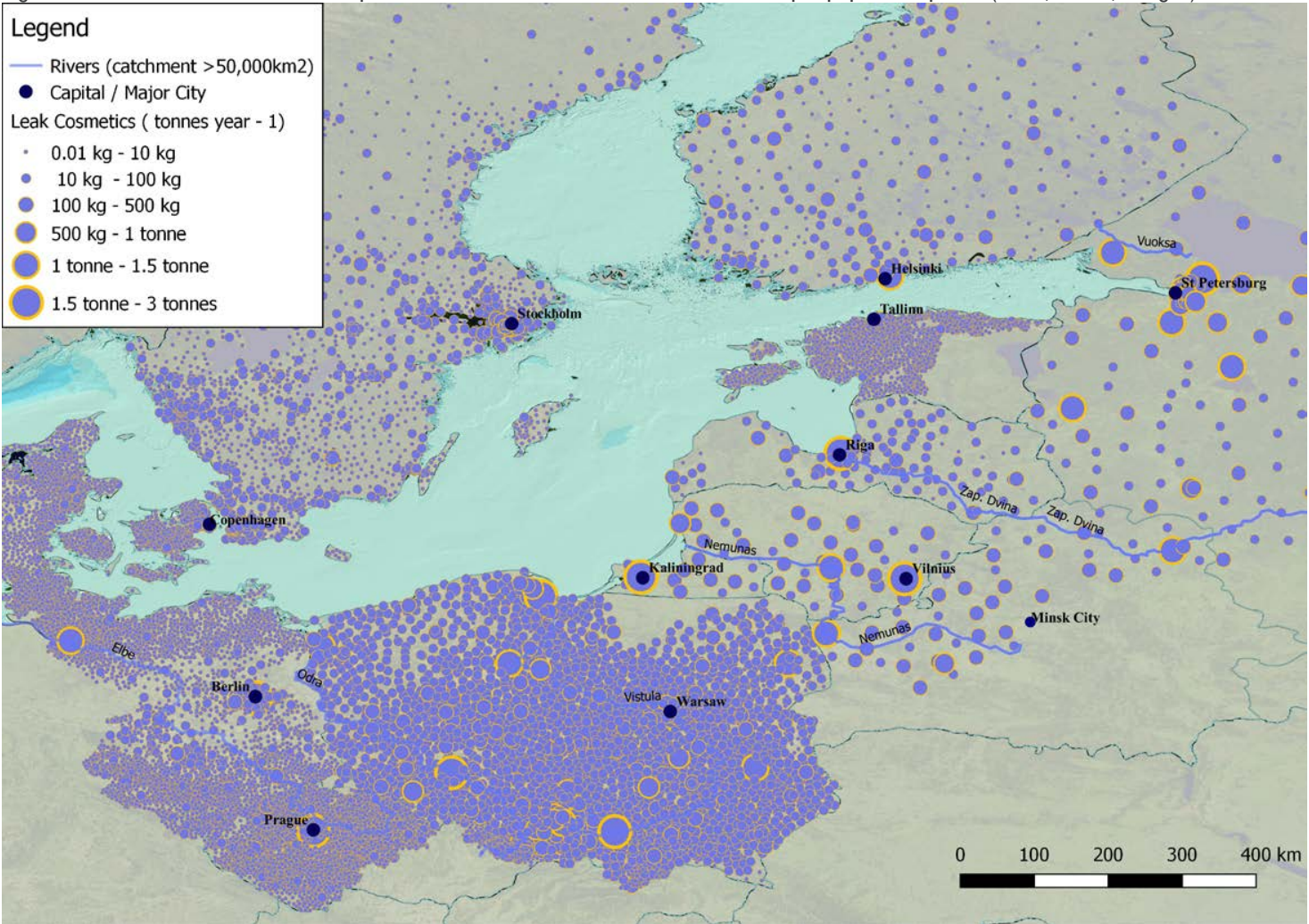

\subsection{Detailed parameters used for the low/central/high scenarios}

To calculate the low/central/high leakage scenarios, a range of values was used for some of the parameters, as reported in the table below:

Table 25: Parameters used in the sensitivity analysis. Several scenarios were tested using low, central, and high values, in order to compare the gap between estimates.

\begin{tabular}{lccc} 
Parameter & Low & Central & High \\
Loss rate, textiles & $49 \mathrm{mg} / \mathrm{kg}$ & $124 \mathrm{mg} / \mathrm{kg}$ & $245 \mathrm{mg} / \mathrm{kg}$ \\
\hline Loss rate, cosmetics & $1 \mathrm{mg} / \mathrm{kg}$ & $6 \mathrm{mg} / \mathrm{kg}$ & $13 \mathrm{mg} / \mathrm{kg}$ \\
\hline Loss rate, pellets & $0.04 \mathrm{mg} / \mathrm{kg}$ & $0.22 \mathrm{mg} / \mathrm{kg}$ & $0.4 \mathrm{mg} / \mathrm{kg}$ \\
\hline Release rate, tyre dust, rural & $2 \%$ & $2 \%$ & $22 \%$ \\
\hline Release rate, tyre dust, urban & $2 \%$ & $12 \%$ & $22 \%$ \\
\hline Release rate max & $10 \%$ & $\mathbf{2 0} \%$ & $40 \%$ \\
\hline
\end{tabular}


Table 26: Raw data of low values for both micro- and macroplastic leakage per country (data in tonnes/year ${ }^{-1}$ ).

\begin{tabular}{|c|c|c|c|c|c|c|}
\hline & $\begin{array}{l}\text { Population } \\
\text { considered }\end{array}$ & leakage & leakage & leakage & leakage & leakage \\
\hline & & Waste & Tyre dust & Textile & Cosmetics & Pellets \\
\hline & & (tonnes) & (tonnes) & (tonnes) & (tonnes) & (tonnes) \\
\hline Denmark & 4146909 & 50 & 43 & 5 & 1 & 0.28 \\
\hline Estonia & 628753 & 165 & 3 & 2 & 0 & 0.22 \\
\hline Finland & 5474233 & 28 & 65 & 10 & 2 & 0.21 \\
\hline Germany & 19214371 & 1069 & 222 & 14 & 2 & 8.40 \\
\hline Latvia & 1749945 & 238 & 9 & 6 & 1 & 0.30 \\
\hline Lithuania & 2394864 & 46 & 37 & 9 & 1 & 0.56 \\
\hline Poland & 37615729 & 310 & 367 & 143 & 23 & 6.74 \\
\hline Sweden & 9779422 & 262 & 115 & 22 & 4 & 1.52 \\
\hline $\begin{array}{c}\text { Russian } \\
\text { Federation }\end{array}$ & 7735374 & 8416 & 77 & 45 & 7 & 2.32 \\
\hline Belarus & 2690891 & 448 & 27 & 10 & 2 & 0.75 \\
\hline $\begin{array}{c}\text { Czech } \\
\text { Republic }\end{array}$ & 7547117 & 21 & 62 & 15 & 2 & 0.28 \\
\hline Slovakia & 205383 & 6 & 2 & 1 & 0 & 0.04 \\
\hline Total & 99182991 & 11060 & 1029 & 281 & 46 & 21.63 \\
\hline
\end{tabular}

Table 27: Raw data of high values for both micro- and macroplastic leakage per country (data in tonnes/year ${ }^{-1}$ ).

\begin{tabular}{|c|c|c|c|c|c|c|}
\hline & $\begin{array}{l}\text { Population } \\
\text { considered }\end{array}$ & leakage & leakage & leakage & leakage & leakage \\
\hline & & Waste & Tyre dust & Textile & Cosmetics & Pellets \\
\hline & & (tonnes) & (tonnes) & (tonnes) & (tonnes) & (tonnes) \\
\hline Denmark & 4146909 & 201 & 469 & 24 & 10 & 28.2 \\
\hline Estonia & 628753 & 661 & 30 & 8 & 3 & 22.1 \\
\hline Finland & 5474233 & 113 & 714 & 50 & 21 & 21.0 \\
\hline Germany & 19214371 & 4277 & 2446 & 72 & 30 & 840.1 \\
\hline Latvia & 1749945 & 953 & 101 & 31 & 13 & 30.3 \\
\hline Lithuania & 2394864 & 184 & 406 & 44 & 19 & 56.3 \\
\hline Poland & 37615729 & 1239 & 4038 & 714 & 301 & 674.3 \\
\hline Sweden & 9779422 & 1049 & 1268 & 110 & 46 & 151.7 \\
\hline $\begin{array}{c}\text { Russian } \\
\text { Federation }\end{array}$ & 7735374 & 33663 & 844 & 223 & 94 & 231.6 \\
\hline Belarus & 2690891 & 1791 & 294 & 48 & 20 & 75.5 \\
\hline $\begin{array}{c}\text { Czech } \\
\text { Republic }\end{array}$ & 7547117 & 84 & 687 & 77 & 32 & 27.8 \\
\hline Slovakia & 205383 & 24 & 19 & 4 & 2 & 3.9 \\
\hline Total & 99182991 & 44240 & 11316 & 1405 & 592 & 2162.7 \\
\hline
\end{tabular}






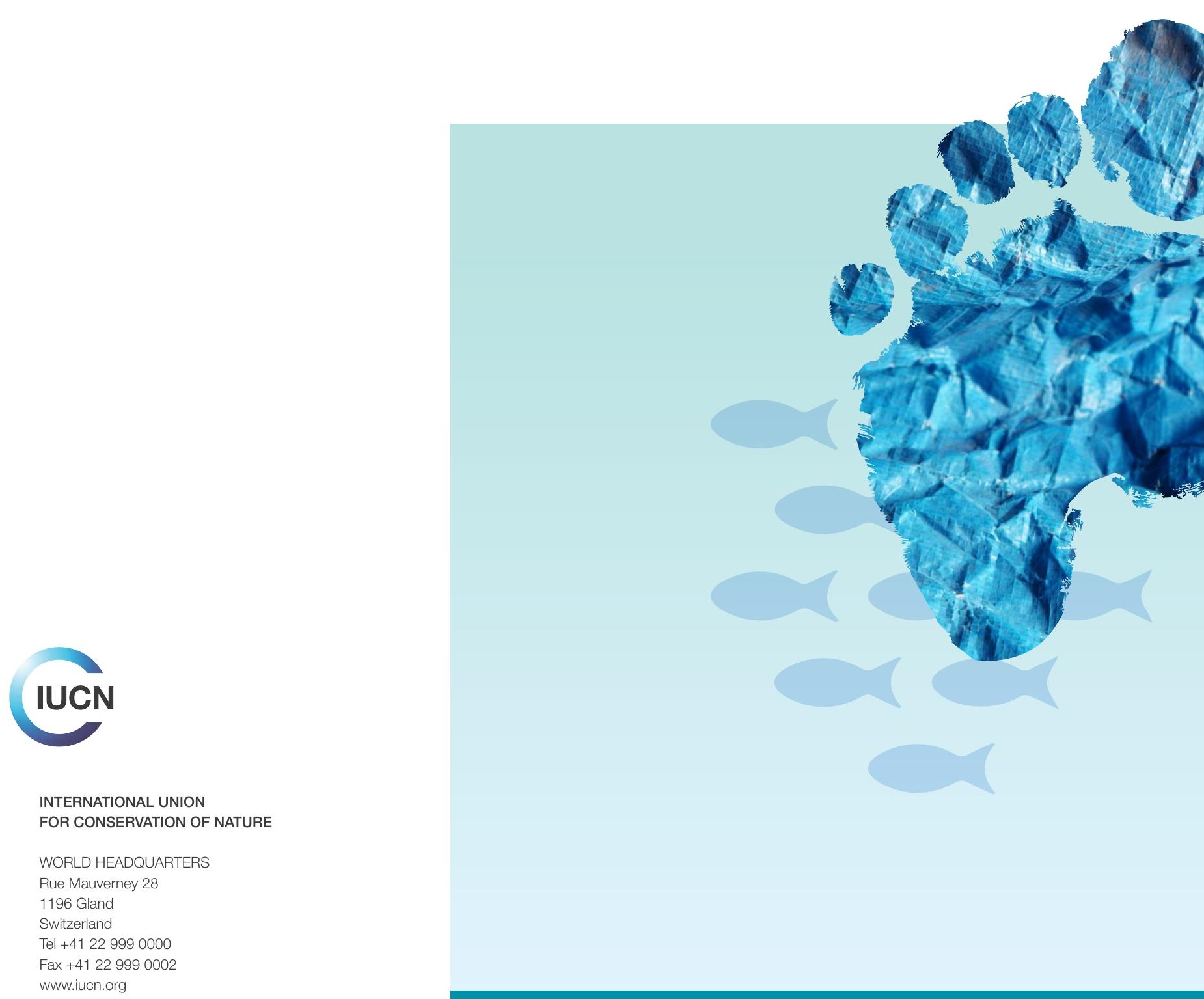

